\author{
UNIVERSIDADE DE SÃO PAULO \\ Faculdade de Filosofia, Ciências e Letras de Ribeirão Preto \\ Departamento de Física e Matemática \\ Programa de Pós-Graduação em Física Aplicada à Medicina e \\ Biologia
}

\title{
Proposta de uma Arquitetura Interoperável para um Sistema de Informação em Saúde
}

\section{AdRiAno DE JESUS HolandA}




\author{
UNIVERSIDADE DE SÃO PAULO \\ Faculdade de Filosofia, Ciências e Letras de Ribeirão Preto \\ Departamento de Física e Matemática \\ Programa de Pós-Graduação em Física Aplicada à Medicina e \\ Biologia
}

\title{
Proposta de uma Arquitetura Interoperável para um Sistema de Informação em Saúde
}

\author{
AdRIANO DE JESUS HolAndA
}

Tese submetida ao Departamento de Física e Matemática da Faculdade de Filosofia, Ciências e Letras de Ribeirão Preto da Universidade de São Paulo como parte dos requisitos para a obtenção do título de Doutor em Física Aplicada à Medicina e Biologia.

Orientador: Prof. DR. EVANDRo EdUARdo SERON RUIZ 
AUTORIZO A REPRODUÇÃO TOTAL OU PARCIAL DESTE DOCUMENTO, POR MEIO CONVENCIONAL OU ELETRÔNICO PARA FINS DE ESTUDO E PESQUISA, DESDE QUE CITADA A FONTE.

Holanda, A J

Proposta de uma Arquitetura Interoperável para um Sistema de Informação em Saúde/ Adriano de Jesus Holanda; orientador Prof. Dr. Evandro Eduardo Seron Ruiz.

- Riberão Preto/SP, 2005.

$87 \mathrm{f}$.

Tese (Doutorado - Programa de Pós-Graduação em Física Aplicada à Medicina e Biologia) - Faculdade de Filosofia, Ciências e Letras de Ribeirão Preto da Universidade de São Paulo.

1. Sistemas de informação em saúde 2. CORBA 3. Sistemas de terminologia 4. Interoperabilidade 5. Middleware 


\section{DEDICATÓRIA}

Aos meus pais Francisco Holanda e Rosa Maria de Jesus Holanda, e aos meus irmãos Rodrigo, Luciana, Fernanda e Eliana, pelo apoio, suporte, dedicação e compreensão durante o período do doutorado e sempre. 


\section{Agradecimentos}

Ao meu orientador, professor Evandro Eduardo Seron Ruiz, pela valiosa orientação, compreensão, tolerância e inestimável amizade. Seus ensinamentos e comportamento ético foram fundamentais para a criação de uma boa relação para o desenvolvimento deste trabalho.

Ao Doutor Luiz Antônio Bailão pela colaboração no desenvolvimento deste trabalho.

Aos amigos Ana Paula Valadares, Daniel Facciolo Pires, Israel Tojal da Silva, Ivan Torres Pisa, Marco Aurélio Valtas Cunha e Rebeca Alves Veríssimo da Silva pelo incentivo, apoio e colaboração.

Aos professores Alexandre Souto Martinez, Maria Aparecida Bená pelo incentivo e amizade.

Aos amigos Daniel Guariz Pinheiro, Rodrigo Brandão pela colaboração.

Ao professor Rafael Andres Rosales Mitrowski pela ajuda na formatação do texto e confecção de figuras no $\mathrm{LT}_{\mathrm{E}} \mathrm{X}$.

Às secretárias Gisele Maranghetti Lourenço, Rita de Cassia Ribeiro e Sonia Aparecida Nali de Paula pela presteza.

Ao Departamento de Física e Matemática pelo suporte ao trabalho.

À CAPES pelo apoio financeiro. 


\section{Sumário}

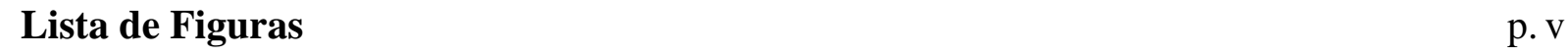

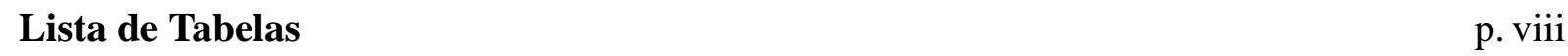

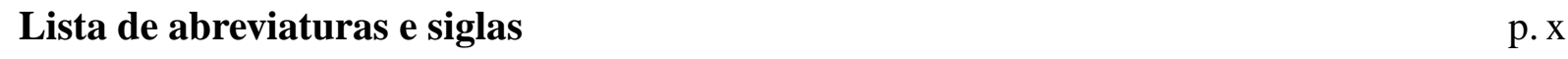

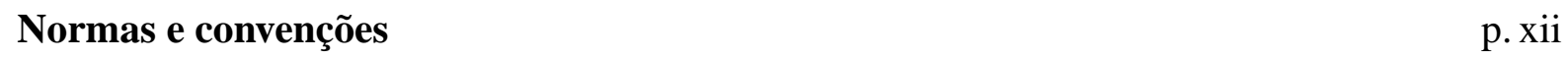

Resumo p.xiii

$\begin{array}{lll}\text { Abstract } & \text { p.xiv }\end{array}$

$\begin{array}{lll}1 & \text { Introdução } & \text { p. } 1\end{array}$

1.1 Interoperabilidade $\ldots \ldots \ldots \ldots \ldots \ldots \ldots$ p. 1

$1.1 .1 \quad$ Interoperabilidade técnica $\ldots \ldots \ldots \ldots$ p. 2

1.1 .2 Interoperabilidade semântica $\ldots \ldots \ldots$ p. 3

1.2 Motivação $\ldots \ldots \ldots \ldots \ldots \ldots \ldots \ldots \ldots$. . . . . . . . . . . . . . . . . . .

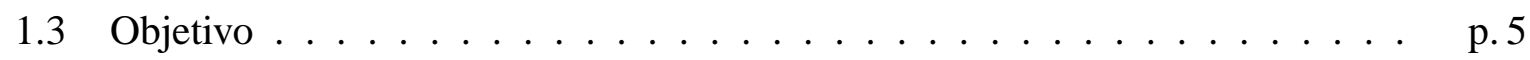

1.4 Organização do trabalho $\ldots \ldots \ldots \ldots \ldots \ldots$ p. 6

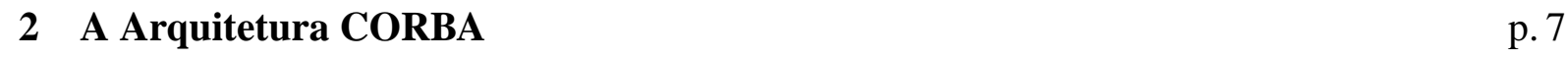

$2.1 \quad$ Arquitetura de gerenciamento de objetos $\ldots \ldots \ldots \ldots \ldots$ p. 7

2.1 .1 Modelo de Referência $\ldots \ldots \ldots \ldots \ldots$ p. 7

2.1.1.1 Object Request Broker. . . . . . . . . . . . . . . . p. 8

2.1 .1 .2 Serviços CORBA $\ldots \ldots \ldots \ldots \ldots \ldots$ 
2.1.1.3 Facilidades CORBA . . . . . . . . . . p 10

2.1.1.4 Serviços de domínio . . . . . . . . . . . . . p. 10

$2.1 .1 .5 \quad$ Aplicação $\ldots \ldots \ldots \ldots \ldots$. . . . . . . . . 10

2.1 .2 Modelo de Objetos $\ldots \ldots \ldots \ldots \ldots \ldots \ldots$. . . . . . . . . . . . .

$2.1 .2 .1 \quad$ Herança $\ldots \ldots \ldots \ldots \ldots \ldots . \ldots \ldots$. . . . . . . . . . .

2.1 .3 Linguagem de definição de interface . . . . . . . . . . . . p. 11

2.1.3.1 Repositórios . . . . . . . . . . . . . p. 13

2.1 .4 Adaptadores de objetos . . . . . . . . . . . . . . p. 13

2.2 Especificação CORBA para o domínio da saúde $\ldots \ldots \ldots$. . . . . . . p. 15

2.2.1 Força Tarefa para o Domínio da Saúde . . . . . . . . . . . . . p. 16

2.2 .2 Sistema de Identificação de Pessoas $\ldots \ldots \ldots$. . . . . . . . p. 17

2.2.2.1 Modelo Conceitual $\ldots \ldots \ldots \ldots$ p. 17

2.2.2.2 Módulos e interfaces PIDS. . . . . . . . . . . . p. 18

2.2 .3 Serviço de Acesso às Observações Clínicas . . . . . . . . . . . . . p. 21

2.2.3.1 Modelo de Observações Clínicas . . . . . . . . . . . p. 22

2.2.3.2 Serviço de Acesso . . . . . . . . . . . . . . p. 24

2.2.3.3 Níveis de conformidade . . . . . . . . . . . . p. 29

2.2 .4 Serviço de Consulta Léxica $\ldots \ldots \ldots$. . . . . . . . . . . 30

2.2.4.1 Tipos Básicos . . . . . . . . . . . . p. 30

2.2 .4 .2 Espaço de Nomes . . . . . . . . . . . . p. 30

2.2 .5 Decisão de Acesso a Recursos . . . . . . . . . . . . . . . p. 32

2.3 Considerações Finais $\ldots \ldots \ldots \ldots \ldots \ldots \ldots$. . . . . . . . . . . . . . . . .

\begin{tabular}{|lll}
\hline 3 & Sistemas de terminologia & p. 33
\end{tabular}

3.1 Introdução . . . . . . . . . . . . . . . . . . p. 33

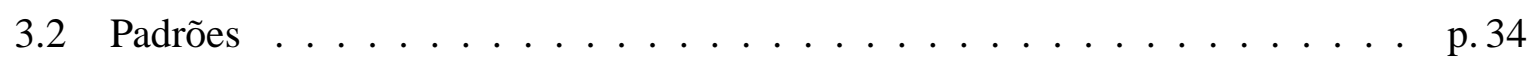

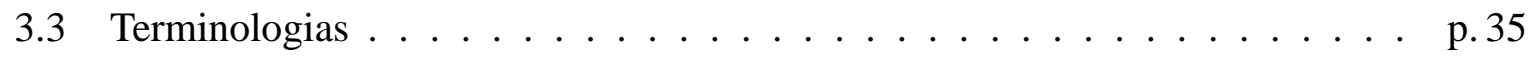


3.3 .1 Codificação $\ldots \ldots \ldots \ldots \ldots \ldots \ldots \ldots$. . . . . . . . . . . . . . . . . . . . .

$3.3 .2 \quad$ Sistemas de terminologia orientados a conceito $\ldots \ldots \ldots$. . . . . 39

3.3.2.1 SNOMED . . . . . . . . . . . . p. 40

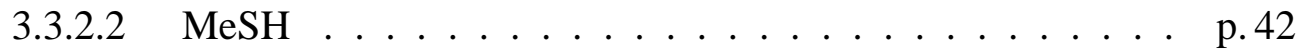

3.3 .2 .3 UMLS . . . . . . . . . . . . . . p. 43

3.3 .2 .4 GALEN $\ldots \ldots \ldots \ldots \ldots \ldots \ldots$. . . . . . . . . . . . . . .

3.3.3 Sistemas de terminologias orientados a classificação estatística . . . . p p.47

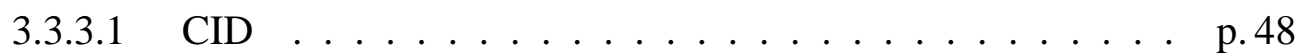

3.4 Considerações finais $\ldots \ldots \ldots \ldots \ldots$. . . . . . . . . . . . . . . . . . . . . . . . . .

4 Arquitetura e implementação $\quad$ p. 50

4.1 Arquitetura $\ldots \ldots \ldots \ldots \ldots \ldots \ldots \ldots \ldots \ldots$. . . . . . . . . . . . . . . . . .

4.2 Implementação $\ldots \ldots \ldots \ldots \ldots \ldots \ldots \ldots \ldots$. . . . . . . . . . . . . . . . . . .

$4.2 .1 \quad$ Middleware . . . . . . . . . . . . . . . . . . p. 54

4.2 .2 Serviços de domínio $\ldots \ldots \ldots \ldots \ldots$. . . . . . . . . . . . . . . . .

4.2.2.1 Serviço de Identificação de Pacientes . . . . . . . . . . . p. 56

4.2.2.2 Serviço de Acesso às Observações Clínicas . . . . . . . . . p. p. 56

4.2.2.3 Serviço de Consulta Léxica . . . . . . . . . . . . p. 59

$4.2 .3 \quad$ Ferramentas comuns - tools $\ldots \ldots \ldots$. . . . . . . . 60

$4.2 .3 .1 \quad$ CORBA $\ldots \ldots \ldots \ldots \ldots \ldots \ldots$ p. . . . . . . . . . .

$4.2 .3 .2 \quad$ Banco de dados $\ldots \ldots \ldots \ldots$. . . . . . . . . . . . 61

4.2 .3 .3 Utilitários $\ldots \ldots \ldots \ldots \ldots$. . . . . . . . . . . . . . .

4.2 .4 Cliente $\ldots \ldots \ldots \ldots \ldots \ldots \ldots \ldots$. . . . . . . . . . . . . . . . .

4.2.4.1 Identificação . . . . . . . . . . . . . . . p. 63

4.2.4.2 Observações clínicas . . . . . . . . . . . . . . p. 67

5 Discussões e conclusões $\quad$ p. 73 


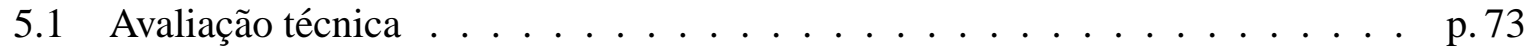

$5.1 .1 \quad$ Benefícios da arquitetura CORBA $\ldots \ldots \ldots \ldots$ p. 74

5.1 .2 Desvantagens da arquitetura CORBA $\ldots \ldots \ldots \ldots$ p. . . . . . . 75

5.2 Avaliação semântica $\ldots \ldots \ldots \ldots \ldots \ldots$ p. . . . . . . . . . . . . .

5.3 Integração com os trabalhos do grupo ImagCom $\ldots \ldots \ldots$. . . . . . . . p.77

5.4 Trabalhos relacionados $\ldots \ldots \ldots \ldots \ldots \ldots \ldots$. . . . . . . . . . . . . .

5.4 .1 OpenEMed $\ldots \ldots \ldots \ldots \ldots \ldots \ldots \ldots \ldots$ p. . . . . . . . . . . . .

5.4 .2 Synapsis $\ldots \ldots \ldots \ldots \ldots \ldots \ldots \ldots \ldots$. . . . . . . . . . . . . . . . .

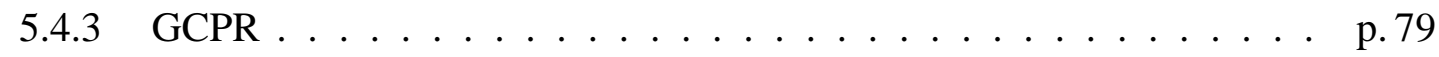

5.5 Futuros trabalhos $\ldots \ldots \ldots \ldots \ldots \ldots \ldots$ p. 8 . . . . . . . . .

\begin{tabular}{ll}
\hline Referências & p. 82
\end{tabular} 


\section{Lista de Figuras}

2.1 Modelo de Referência CORBA. $\ldots \ldots \ldots \ldots \ldots \ldots$

2.2 Comunicação cliente-servidor na arquitetura CORBA. $\ldots \ldots \ldots \ldots$

2.3 Interfaces de invocação da arquitetura CORBA. $\ldots \ldots \ldots \ldots$. . . . . p. 13

2.4 Comunicação cliente servidor na arquitetura CORBA com a intermediação do adaptador de objetos (POA). . . . . . . . . . . . . . . . . . p. 14

2.5 Interação entre o ORB e a implementação dos objetos CORBA através do adaptador . . . . . . . . . . . . . . . . . 15

2.6 Modelo conceitual PIDS $\ldots \ldots \ldots \ldots \ldots \ldots \ldots$

$2.7 \quad$ Diagrama de objetos de um cadastro no PIDS $\ldots \ldots \ldots \ldots$. . . . . . . . . 19

2.8 Diagrama de herança e componentes PIDS . . . . . . . . . . . . p. 20

2.9 Federação PIDS . . . . . . . . . . . . . . . . . . p. 21

2.10 Modelo de informação do COAS . . . . . . . . . . . . . . p. 22

2.11 Diagrama de classes do tipo ObservationValue $\ldots \ldots \ldots \ldots$. . . . . . 24

2.12 Diagrama de classes do tipo Measurement $\ldots \ldots \ldots \ldots$. . . . . . . . 25

2.13 Componentes de acesso às observações clínicas $\ldots \ldots$. . . . . . . . . p. 26

2.14 Atributos de observationDatastruct . . . . . . . . . . . p. 26

2.15 Diagrama de objetos da estrutura de dados de uma entrada de observações iniciais em uma UTI neonatal. . . . . . . . . . . . . . . . . p. 27

2.16 Operações e atributos para ObservationRemote e suas subclasses $\ldots \ldots$. . p. 28

2.17 Diagrama de objetos de uma referência remota de uma entrada de observações iniciais em uma UTI neonatal. . . . . . . . . . . . . . . . . . . . . p.29

2.18 Tipos básicos do LQS $\ldots \ldots \ldots \ldots \ldots \ldots \ldots \ldots \ldots$. . . . . . . . . . . . . . . .

2.19 Espaço de nomes utilizado no LQS . . . . . . . . . . . . . . p. 31 
2.20 Diagrama de objetos do espaço de nomes utilizado pela especificação LQS para representar o CID $10 . \ldots \ldots \ldots \ldots$ p. 32

3.1 Definição de alguns termos terminológicos. . . . . . . . . . . . . p. 33

3.2 Exemplo de análise de expressões de acordo com os níveis lingüísticos. . . . p.34

3.3 Representação do código CID 10 N28.0 nas línguas portuguesa e inglesa. . p.38

3.4 Triângulo da semiótica extendido . . . . . . . . . . . . . . . . . . . . p. 39

3.5 Exemplo de hierarquia em um sistema de conceitos . . . . . . . . . . . . p. 40

3.6 Diagrama de um modelo formal para representação do conceito pneumonia e suas relações. . . . . . . . . . . . . . . . . . . p. 41

3.7 Representação do conceito "Streptococcus" e suas especializações. . . . . . . . p. p3

3.8 Integração do UMLS com outros vocabulários controlados. . . . . . . . . . . p. p. 45

3.9 Códigos e doenças associadas do CID $10 . \quad \ldots \ldots \ldots \ldots$. . . . . . . . . . p. 48

$4.1 \quad$ Arquitetura do sistema. . . . . . . . . . . . . . . . . p. 51

4.2 Componentes da implementação da arquitetura proposta. . . . . . . . . . . . p.52

4.3 Diagrama de pacotes do sistema $\ldots \ldots \ldots \ldots \ldots \ldots$ p. . . . . . . . . . . . .

4.4 Interfaces de gerenciamento implementadas do padrão PIDS. . . . . . . . . . p. 57

4.5 Interfaces de acesso implementadas do padrão COAS. . . . . . . . . . . . . p. p.57

4.6 Interfaces para acesso remoto às observações. $\ldots \ldots \ldots \ldots$. . . . . . . . . p.58

$4.7 \quad$ Tipo de dados utilizados para representar as observações. $\ldots$. . . . . . . . . . p.59

4.8 Diagrama de classes do pacote tools. . . . . . . . . . . . . p. 60

4.9 Diagrama de classes: CORBAManager. $\ldots \ldots \ldots \ldots \ldots$ p. . . . . . . . .

4.10 Diagrama de classes: DBManager. . . . . . . . . . . . . . . p. 61

4.11 Diagrama de classes: utilitários. . . . . . . . . . . . . . . p. 62

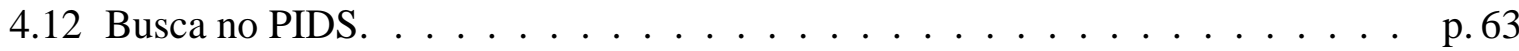

4.13 Diagrama de seqüência para a busca no PIDS. . . . . . . . . . . . . p p.64

4.14 Adição de registro feita pelo cliente PIDS . . . . . . . . . . . . . . . p.64

4.15 Diagrama de seqüência para a busca no PIDS. . . . . . . . . . . . p p.65 
4.16 Atualização de registro no PIDS feita pelo cliente. . . . . . . . . . . . p. 65

4.17 Diagrama de seqüência para a busca no PIDS. . . . . . . . . . . . . p. 66

4.18 Entrada de dados de identificação do paciente. . . . . . . . . . . . . p. 66

4.19 Interface principal do cliente COAS. . . . . . . . . . . . . p. 67

4.20 Entrada das observações iniciais. $\ldots \ldots \ldots \ldots$. . . . . . . . . . . 68

4.21 Entrada de imagens. . . . . . . . . . . . . . . . . . . . . . p. 69

4.22 Entrada de valores de exames. . . . . . . . . . . . . . . . p. 69

4.23 Entrada de texto livre. . . . . . . . . . . . . . . . p. 70

4.24 Diagrama de seqüência para a adição de observações no COAS. $\quad$. . . . . . p p.70

4.25 Visualização das observações requisitadas. . . . . . . . . . . . . . . p.71

4.26 Diagrama de seqüencia para a busca de observações no COAS. $\ldots . . \quad \ldots$ p. 72 


\section{Lista de Tabelas}

3.1 Representação hierárquica no SNOMED RT . . . . . . . . . . . . . . . . p. p. 43

3.2 Representação do diagnóstico "Pneumonia Pneumocócica" utilizando o MeSH. p. 43

3.3 Representações do conceito "Fibrilação Atrial" no meta-tesauro $\ldots .$. . . . p.45

3.4 Explosão combinatória das possíveis combinações da descrição de queimaduras p. 49 


\section{Listagens}

2.1 Definição do tipo Paciente e da interface Buscador utilizando a linguagem IDL-OMG. . . . . . . . . . . . . . . . p. 12

3.1 Exemplo de utilização da linguagem GRAIL $\ldots \ldots \ldots \ldots$. . . . . . . . . p.47

4.1 Fragmento da definição da interface ProfileAccess obtido a partir da especificação do PIDS. . . . . . . . . . . . . . . . . p. 55

4.2 Fragmento da implementação da interface ProfileAccess utilizando a linguagem Java. . . . . . . . . . . . . . . . . . . . . p.55

4.3 Fragmento da definição da interface LexExplorer obtido a partir da especificação do LQS. . . . . . . . . . . . . . . . . . . . . . p.59 


\section{Lista de abreviaturas e siglas}

\begin{tabular}{|c|c|}
\hline ACL & Access Control Lists \\
\hline $\mathrm{AOP}$ & Aspect Oriented Programming \\
\hline $\mathrm{CCM}$ & CORBA Component Model \\
\hline CEN & Comité Européen de Normalisation \\
\hline CID & Catálogo Internacional de Doenças \\
\hline COAS & Clinical Observation Access Service \\
\hline CORBA & Common Object Request Broker \\
\hline CUI & Concept Unique Identifier \\
\hline DICOM & Digital Imaging and Communications in Medicine \\
\hline DII & Dynamic Invocation Interface \\
\hline DNS & Domain Name System (or Server or Service) \\
\hline DSI & Dynamic Skeleton Interface \\
\hline DTC & Domain Technical Committee \\
\hline EUA & Estados Unidos da América \\
\hline GALEN & $\begin{array}{l}\text { General Architecture for Languages Encyclopedia and Nomencla- } \\
\text { tures in Medicine }\end{array}$ \\
\hline GCPR & Government-wide Computer-based Patient Record \\
\hline GRAIL & GALEN Common Reference Model \\
\hline HDTF & Healtcare Domain Task Force \\
\hline HL7 & Health Level 7 \\
\hline IDL & Interface Definition Language \\
\hline IIOP & Internet Inter-ORB Protocol \\
\hline IR & Interface Repository \\
\hline ISO & International Organization for Standardization \\
\hline LQS & Lexicon Query Service \\
\hline LUI & Lexical Unique Identifier \\
\hline $\mathrm{MeSH}$ & Medical Subject Headings \\
\hline NLM & National Library of Medicine \\
\hline OMA & Object Management Architecture \\
\hline
\end{tabular}




$\begin{array}{ll}\text { OMG } & \text { Object Management Group } \\ \text { ORB } & \text { Object Request Broker } \\ \text { PIDS } & \text { Person Identification Service } \\ \text { POA } & \text { Portable Object Adapter } \\ \text { PTC } & \text { Platform Technical Commmittee } \\ \text { QoS } & \text { Quality of Service } \\ \text { RAD } & \text { Resource Access Decision } \\ \text { SNOMED } & \text { Systematized Nomenclature for Medicine } \\ \text { SNOMED-CT } & \text { SNOMED Clinical Terminology } \\ \text { SNOMED-RT } & \text { SNOMED Reference Terminology } \\ \text { SUI } & \text { String Unique Identifier } \\ \text { TCP/IP } & \text { Transmission Control Protocol/Internet Protocol } \\ \text { UMLS } & \text { Unified Medical Language System } \\ \text { URL } & \text { Universal or Uniform Resource Locator }\end{array}$




\section{Normas e convenções}

Este documento foi preparado com o formatador de textos LTTEX. O sistema de citações de referências bibliográficas utiliza a classe ieeetr do $\mathrm{BIBT}_{\mathrm{E}} \mathrm{X}$, que segue as recomendações do IEEE (Institute of Electrical and Electronics Engineers) para publicação em periódicos da instituição.

A formatação da capa, folha de rosto, folha de aprovação, resumo e abstract segue as "diretrizes para apresentação de dissertações e teses da USP", disponivel em $<$ http://www.teses.usp.br $>$.

A formatação de sumário, lista de figuras e tabelas, lista de abreviaturas e siglas, espaçamento entre linhas, numeração de páginas e cabeçalhos de páginas segue a norma ABNT NBR 14724 para "Apresentação de trabalhos acadêmicos".

A formatação de títulos e capítulos de seções segue a norma ABNT NBR 6024 para "Numeração progressiva das seções de um documento".

Todas as formatações que seguem a norma ABNT foram geradas automaticamente utilizando as macros da classe abntex disponíneis em $<$ http://abntex.codigolivre.org.br/>.

Todos os diagramas apresentados neste trabalho foram confeccionados utilizando a Linguagem de Modelagem Unificada (UML - Unified Modeling Language).

Este trabalho utiliza as seguintes convenções tipográficas:

- Códigos fontes, elementos provenientes de códigos fontes colocados no texto e códigos provenientes de sistemas de terminologia aparecem em Computer Modern Typewriter.

- Palavras provenientes de língua estrageira aparecem em itálico. 


\section{Resumo}

HOLANDA, A J. Proposta de uma Arquitetura Interoperável para um Sistema de Informação em Saúde. Tese (Doutorado)-Faculdade de Filosofia, Ciências e Letras de Ribeirão Preto, Universidade de São Paulo, Ribeirão Preto, 2005.

A interoperabilidade entre sistemas de informação em saúde está se tornando fundamental para o compartilhamento da informação num ambiente de saúde, onde normalmente as diversas especialidades que atuam no atendimento ao paciente armazenam seus dados, em sistemas computacionais distintos e em regiões geograficamente distribuídas. Devido à diversidade existente entre estes sistemas, a integração as vezes torna-se difícil.

Os problemas de interoperabilidade podem ser técnicos, onde os componentes de computação dos sistemas não permitem a cooperação devido às diferenças nos protocolos de comunicação ou semânticos, ocasionados devido à diversidade de representação da informação transmitida. Este trabalho propõe uma arquitetura para facilitar ambos os aspectos de interoperabilidade, sendo que a interoperabilidade técnica é proporcionada pela utilização de um middleware e a semântica, pela utilização de sistemas de terminologia adotados internacionalmente.

Para a implementação de referência foi utilizada como middleware a arquitetura CORBA e suas especificações para o domínio da saúde, sendo que uma das especificações CORBA para o domínio da saúde foi adotada para padronizar a comunicação com os sistemas de terminologia. Para validar a implementação, foi construído um aplicativo cliente baseado na análise de requisitos de uma UTI neonatal. O cliente foi utilizado também para acessar os componentes implementados e verificar dificuldades e ajustes que podem ser feitos na implementação.

Palavras-chave: Sistemas de informação em saúde, CORBA, Sistemas de terminologia, Interoperabilidade, Middleware. 


\section{Abstract}

HOLANDA, A J. Study of an Interoperable Architecture for a Health Information System. Thesis (Doctoral)-Faculdade de Filosofia, Ciências e Letras de Ribeirão Preto, Universidade de São Paulo, Ribeirão Preto, 2005.

The interoperability among health information systems are becoming fundamental to share the information in a health environment, where commonly the diverse medical specialties that act in the patient care store the data, in distinct computational systems and in geographically distributed regions.Because of the existing diversity among these information systems, the integration can be a difficult task.

Interoperability problems can either be technical, when the communication components do not cooperate due to the diversity of the information representation. This work proposes an architecture to improve both interoperability aspects. The technical and partial semantic interoperability is achieved by the use if a middleware whereas the semantic interoperability by the use of internationally approved terminological systems.

For the reference implementation was used the CORBA middleware architecture. One of the CORBA specifications in health care was adopted to standardize the communication with the terminological systems. To validate the implementation it was developed a client application based on the requirement analysis of neonatal ICU. The client application was also used to access the software components and to verify possible problems.

Keywords: Health information systems, CORBA, Terminological systems, Interoperability, Middleware. 


\section{$1 \quad$ Introdução}

Este Capítulo descreve a motivação para a pesquisa em padronização de sistemas de informação em saúde . A Seção 1.1 descreve a importância da interoperabilidade entre os agentes de saúde. A Seção 1.2 descreve as motivações deste trabalho. A Seção 1.3 descreve os objetivos deste trabalho, enquanto que a Seção 1.4 fornece uma visão geral da organização da tese.

\subsection{Interoperabilidade}

Até o momento, nenhum sistema computadorizado de informação em saúde é capaz de dar suporte a todo o espectro de conhecimento médico. Conseqüentemente, hospitais e instituições de saúde adquirem sistemas de diferentes fornecedores para satisfazer as suas necessidades específicas. Como a troca de informações entre diferentes sistemas geralmente não é trivial, esta prática acaba criando "ilhas de informação" dentro das próprias instituições. Considerando, por exemplo, que um sistema computadorizado de registros clínicos deve trabalhar com um sistema especialista de diagnóstico para melhorar o atendimento ao paciente, para atingir integração ótima entre os dois sistemas, a transferência dos registros de pacientes para o sistema especialista deve ser automatizada. Na tentativa de atingir tal objetivo, as diferenças entre os vocabulários controlados dos dois sistemas foi citada por Wong et al. [1] como o maior obstáculo para o intercâmbio de informações, mesmo se ambos os sistemas tivessem sido implementados pelos mesmos desenvolvedores.

Um sistema computacional de arquitetura aberta em que houvesse a possibilidade de se acoplar componentes de software que pudessem colaborar na troca de informação com outros sistemas é o passo inicial para ampliar o nível de acesso às informações do paciente. Porém, como atualmente a informação médica trocada é fortemente baseada em linguagem natural, há a necessidade de conformação dos termos usados a algum vocabulário controlado para a representação dos conceitos. Com a adoção destes procedimentos, há início da facilitação da troca de informações entre sistemas heterogêneos criando assim condições para alcançar a interoperabilidade. 
A interoperabilidade entre componentes de um sistema distribuído heterogêneo é definida como a habilidade destes componentes trocarem informações e serviços [2]. Ela permite aos componentes cooperarem, apesar das diferenças nas linguagens, interfaces e plataforma de execução [3].

A interoperabilidade entre os sistemas de informação em saúde, que incluem aplicativos heterogêneos, é um aspecto chave nos ajustes do compartilhamento distribuído das informações relativas à saúde. Nos hospitais, muitos e diferentes sistemas de computação necessitam estar conectados, exigindo assim padrões comuns de interoperabilidade para conseguir o intercâmbio de informações [4].

As dificuldades para se alcançar a interoperabilidade são muitas. Por um lado, há o aspecto da interoperabilidade técnica, ou seja, a transmissão de dados e integração de serviços. Por outro lado, há o aspecto da interoperabilidade semântica, ou seja, os clientes e servidores devem ter um entendimento comum do significado dos dados e serviços requisitados [5]. Ambos aspectos da interoperabilidade estão fortemente relacionados, como veremos a seguir.

\subsubsection{Interoperabilidade técnica}

Para garantir a interoperabilidade técnica entre sistemas heterogêneos pode-se utilizar um middleware, que é um software entre a aplicação e a camada de rede cujo objetivo é garantir a comunicação. Nesta camada intermediária podem ser empregadas infraestruturas de middleware como CORBA $\mathrm{I}^{1}$ (Common Object Request Broker Architecture), database gateways e monitores de transação [6].

Alguns padrões de middleware, além de especificar a infraestrutura, avançam a linha usual do seu domínio de aplicação, especificando as interfaces, ou seja, o modo como as mensagens devem ser transmitidas, fornecendo suporte sintático e semântico às transações. Para a área de saúde, padrões como HL 72 (Health Level 7), HDTF-CORBA ${ }^{3}$ (Healthcare Domain Task Force) e CEN/TC251 ${ }^{4}$ (Comité Européen de Normalisation) foram propostos e estão em constante desenvolvimento com o objetivo de possibilitar a construção de arquiteturas interoperáveis num ambiente de saúde, substituindo as soluções proprietárias e isoladas [7].

\footnotetext{
${ }^{1}$ http://www.corba.org

${ }^{2}$ http://www.hl7.org

${ }^{3}$ http://healthcare.omg.org

${ }^{4}$ http://www.centc251.org
} 


\subsubsection{Interoperabilidade semântica}

Os sistemas de terminologias permitem que sistemas computacionais possam trocar informações com um pouco mais de "entendimento" do significado (semântica) do conteúdo.

A sintaxe e a semântica da troca de informações médicas utilizando uma linguagem específica para este fim podem ser padronizadas utilizando um sistema de terminologia. Os sistemas de terminologia ajudam a lidar com a enorme variabilidade das expressões e termos médicos, reduzindo a ambigüidade e relacionando os termos sinônimos. Com a utilização destes sistemas, os termos médicos podem ser representados por códigos que são independentes da linguagem natural. Porém, os sistemas de terminologia existentes possuem diversas desvantagens, sendo a maioria delas relacionadas a falta de expressividade, especialmente os vocabulários uniaxiais como o Catálogo Internacional de Doenças (CID) . Vocabulários como SNOMED (Systematized Nomenclature of Medicine) e MeSH (Medical Subject Headings) oferecem acesso multiaxial e permitem que o usuário utilize os códigos de várias categorias para representar conceitos complexos. Mas devido à falta de representação explícita da semântica, os sistemas de codificação são inadequados para usos mais ambiciosos, como por exemplo, para o armazenamento de informações em um prontuário eletrônico. Para este fim, deve ser desenvolvido um sistema baseado em um modelo formal de conceitos médicos como o GALEN5 (General Architecture for Languages Encyclopedia and Nomenclatures in Medicine) [8], para que seja possível gerenciar a semântica utilizando métodos computacionais [9].

\subsection{Motivação}

A principal motivação para o desenvolvimento deste trabalho deve-se ao fato da interoperabilidade entre sistemas de informação para a área de saúde, principalmente os que contêm dados clínicos, sempre ter sido um fator crítico para o compartilhamento de informações armazenadas em diferentes localidades. Além dos problemas técnicos, provenientes das diferenças tecnológicas do ambiente da aplicação, há o aspecto da dificuldade de se adotar um vocabulário comum para que as aplicações consigam manipular os dados sem necessidade de processamento adicional da informação ou da construção de adaptadores para os diferentes esquemas de armazenamento de dados em bases distribuídas.

Há muitos obstáculos para a aplicação ampla e integrada da tecnologia na área de saúde, dentre eles destacamos a falta de interoperabilidade entre os sistemas de saúde e falta de adoção ampla de padrões para dados clínicos, as políticas desatualizadas de reembolso, a preocupação

\footnotetext{
${ }^{5}$ http://www.opengalen.org
} 
com privacidade e segurança e a falta de investimento em inovação e tecnologia. Atualmente, a situação da tecnologia de informação em clínicas, consultórios e pequenos hospitais pode ser resumida através da formulação: educação + visão = automação. Em outras palavras, pequenos agentes de saúde combinam o conhecimento das opções de tecnologia com os benefícios de sua aplicação na área criando sistemas de saúde locais, para automatizar o fluxo de informação da sua unidade [10].

Com a evolução da Web, é possível implantar, com baixo custo, um servidor simples de aplicação para acesso a um repositório clínico. O baixo custo possibilita o desenvolvimento crescente de repositórios médicos que oferecem capacidade de gerenciamento de parte de dados de pacientes, porém, o acesso às informações só é possível utilizando máquinas de busca, o que acarreta problemas de segurança. Além disso, não há arquitetura no projeto destas soluções ad hoc para acesso aos dados médicos, tornando suas capacidades de escalabilidade e extensibilidade desconhecidas [11].

Segundo Peth [10], a equação do futuro será: padrões + infraestrutura = integração, ou seja, somente com o uso extensivo de padrões conseguiremos obter plena integração entre sistemas. Ao longo do tempo, padrões vão evoluir, permitindo que os sistemas locais possam ser integrados formando um vasto sistema nacional de informação, trazendo benefícios para todos os participantes da rede.

Os middlewares exercem um papel importante nesta infraestrutura, tanto que para o planejamento da Internet2 2 , há um grupo de trabalho que atua sobre especificações de middleware para esta rede. O middleware deverá fornecer serviços de identificação, autenticação, catálogos e segurança. Na Internet de hoje, as aplicações tentam oferecer estes serviços elas mesmas, o que leva a padrões ad hoc que competem entre si e são incompatíveis. Promovendo a padronização e interoperabilidade, o middleware fará as aplicação da rede avançada mais fáceis de utilizar [12].

Outra razão para a padronização dos dados do paciente é a integração de aplicações desenvolvidas por diferentes fabricantes com os sistemas já existentes, formando uma arquitetura distribuída de sistemas de informação clínica [13]. Como boa parte da informação da área de saúde é baseada em observações qualitativas, não possuindo um modelo formal ou matemático para representar esta informação, o armazenamento, processamento e recuperação desta informação torna-se complexo e baseado em expressões heurísticas.

Assim como é difícil construir um sistema que atenda as necessidades de todas as espe-

\footnotetext{
${ }^{6} \mathrm{~A}$ Internet2 é uma colaboração entre universidades, governo e indústria para oferecer melhoria de qualidade da internet utilizando novas tecnologias. Mais informações podem ser encontradas no sítio http://www.internet2.edu/about/.
} 
cialidades da área de saúde, também é inviável pensar em um sistema de terminologia que possa ser utilizado para representar toda a informação armazenada. Por isso, há a necessidade de utilização de um middleware tentando formar um sistema global, amplo, abrangendo um espectro maior de tipos e quantidade de dados. Além disso, esse middleware deve oferecer suporte à extensibilidade e deve interagir com as diversas representações terminológicas da informação.

Egyhazy e Mukherji [14] listaram 5 problemas principais para o projeto de uma arquitetura interoperável. Estes princípios estão descritos a seguir:

1. Política de segurança e acesso dos dados;

2. Procedimentos para certificação e autenticação do usuário;

3. Formatos de gravação e esquema de dados;

4. Interfaces para acesso e comunicação entre os sistemas;

5. Ambientes de software e de hardware.

Os sistemas necessitam dos ítens $1 \mathrm{e} 2$ para proporcionar privacidade à informação armazenada e possuem diversidade nos ítens 3, 4 e 5 para se adequar ao seu ambiente de execução, tecnologia empregada e escolhas relacionadas a custos. Porém, esta diversidade ocasiona dificuldades no momento em que há necessidade de integração dos sistemas. O estudo, projeto e especificação de arquiteturas abertas e interoperáveis constituem um passo inicial e importante para o compartilhamento da informação, cada vez mais necessário, não somente para a geração de estatísticas, mas como ferramenta indispensável para uma tomada de decisão mais confiável graças aos elementos adicionais que antes não estavam acessíveis devido a problemas tecnológicos e de incompatibilidade de modelos de dados.

\subsection{Objetivo}

O objetivo deste trabalho é propor soluções para os problemas 3,4 e 5 descritos anteriormente, ou seja, especificar uma arquitetura aberta e realizar uma implementação de referência de componentes necessários para o gerenciamento da informação da área de saúde de modo que seja propiciada plena interoperabilidade técnica e semântica na troca de dados para outros sistemas computadorizados da área de saúde, independente do formato dos registros e tipos de dados, aplicativos e sistema operacional, modelos de dados e interfaces. 
Para a validação desta arquitetura proposta deveremos implementar um cliente para um domínio da área de saúde para a realização de testes de comunicação com os componentes desta arquitetura.

\subsection{Organização do trabalho}

Esta tese está estruturada da seguinte maneira:

- O Capítulo 2 descreve, de modo genérico, a arquitetura CORBA e de maneira mais específica, a mesma arquitetura aplicada ao domínio da saúde;

- O Capítulo 3 descreve a importância da utilização de sistemas de terminologias em sistemas computadorizados de saúde;

- O Capítulo 4 detalha a arquitetura proposta e fornece uma implementação de referência com um estudo de caso para o domínio de uma UTI neonatal;

- O Capítulo 5 apresenta as discussões e conclusões provenientes deste trabalho e elabora opções para pesquisas futuras. 


\section{A Arquitetura CORBA}

No Capítulo 1 foi discutida a motivação para a construção de um sistema altamente baseado em padrões e as vantagens que ele pode oferecer quando comparado a um sistema construído com soluções add hoc. Neste Capítulo será dada uma visão geral sobre a especificação CORBA, que é o padrão utilizado na construção dos componentes do sistema apresentado nesta tese. Três especificações CORBA para o domínio da saúde serão apresentadas com detalhes e exemplificadas para facilitar o entendimento.

\subsection{Arquitetura de gerenciamento de objetos}

A arquitetura CORBA (Commom Object Request Broker) foi especificada pelo OMG (Object Management Group ) com o objetivo de resolver o problema de aplicações distribuídas para sistemas heterogêneos. Ela é baseada na OMA (Object Management Architecture ) que descreve como os objetos devem interagir de maneira independente da plataforma [15]. A OMA padroniza as interfaces dos componentes de software facilitando o modelo de desenvolvimento de software plug-and-play baseado na tecnologia de objetos [16]. A OMA é dividida em Modelo de Referência e Modelo de Objetos.

\subsubsection{Modelo de Referência}

O Modelo de Referência, esquematizado na Figura 2.1, padroniza as interfaces da infraestrutura e serviços que as aplicações podem usar, sendo dividido em cinco componentes principais [17]:

- Object Request Broker (ORB);

- Serviços (Nomes, Trader, Eventos, Segurança,...);

- Facilidades Comuns; 
- Interfaces de domínio (objetos de domínio);

- Interfaces de aplicação (aplicação).

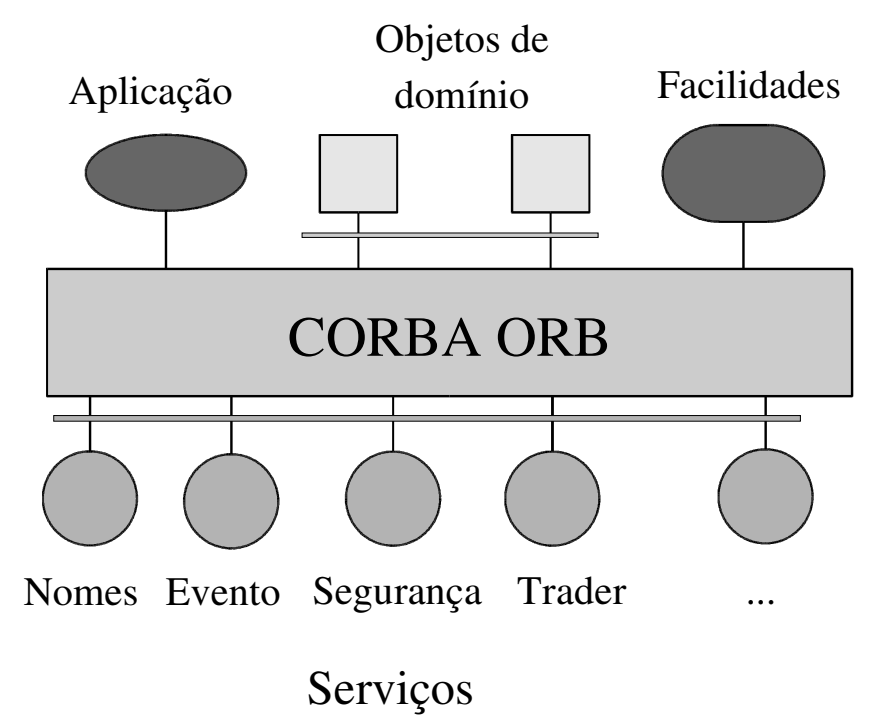

Figura 2.1: Modelo de Referência CORBA.

\subsubsection{Object Request Broker}

O Object Request Broker (ORB ) é o middleware que implementa o barramento (bus) CORBA e age como um "negociador" entre os objetos cliente e servidor, conforme mostrado na Figura 2.2. O ORB gerencia a requisição do cliente e oculta os detalhes de localização e implementação do cliente [16].

\subsubsection{Serviços CORBA}

O serviços CORBA (CORBAservices) são coleções de serviços horizontais com a especificação padronizada pelo OMG. Alguns serviços são descritos a seguir [18, 19]:

- Serviço de nomes (Naming Service): permite que os objetos do barramento CORBA localizem outros objetos pelo nome. Ele também permite que seja formada uma federação de contextos de nomes, ou seja, vários serviços de nomes podem ser agrupados fornecendo um ponto único de acesso a estes;

- Serviço de eventos (Event Service): permite que os objetos conectados ao ORB possam registrar o interesse em eventos específicos gerados por outros objetos, assim quando o evento for gerado, os objetos registrados serão notificados sobre sua ocorrência; 


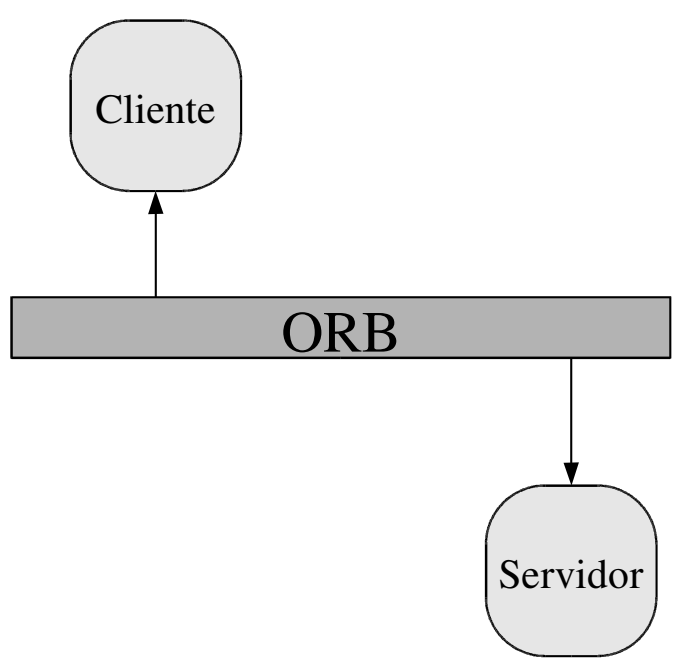

Figura 2.2: Comunicação cliente-servidor na arquitetura CORBA.

- Serviço de Transação: permite a recuperação de objetos que se tornaram inconsistentes devido a falhas durante a alteração de seu estado;

- Serviço de controle de concorrência (Concurrency Control Service): fornece um gerenciador de bloqueio (lock) que pode fornece suporte à transação e threads;

- Serviço de ciclo de vida (Life Cicle Service): define operações para criar, copiar, mover e destruir objetos no barramento CORBA;

- Serviço de Segurança (Security Service): fornece um framework completo para a segurança dos objetos distribuídos. Ele suporta autenticação, listas de controle de acesso, confidencialidade e não-repudiação, e também gerencia a delegação de credenciais entre os objetos;

- Serviço de negócios de objetos (Trading Object Service): facilita a oferta e a descoberta de instâncias de serviços;

- Serviço de Consulta (Query Service): fornece operações de consulta para os objetos;

- Serviço de coleção (Collection Service): fornece interfaces para criar e manipular genericamente coleções comuns, que são conjuntos de objetos agrupados em uma estrutura de dados;

- Serviço de relacionamento (Relationship Service): permite que entidades e relacionamentos sejam representados explicitamente aos interessados. Entidades são representadas como objetos CORBA. 


\subsubsection{Facilidades CORBA}

As Facilidades CORBA fornecem serviços de nível intermediário para as aplicações como internacionalização (Internationalization) e tempo (Time); e de agentes móveis (Mobile Agent) [20. 21].

\subsubsection{Serviços de domínio}

O OMG tem um grande número de grupos de interesse e forças tarefas que focalizam domínios particulares, tais como, telecomunicações, Internet, finanças e área da saúde. A padronização de serviços de domínio foi separada das Facilidades CORBA em 1996 [17]. A partir destas especificações são gerados os objetos de domínio que interagem com a infraestrutura CORBA para realizar tarefas específicas de áreas como financeira, telecomunicações, médica, dentre outras.

\subsubsection{Aplicação}

Os objetos das aplicações, tais como interface gráfica, desenvolvidos para interagir com a arquitetura CORBA, não são padronizados.

Pelo fato da arquitetura CORBA não ditar regras sobre a implementação, um ORB bem projetado não requer que componentes e tecnologias já em uso sejam abandonadas. A especificação CORBA é flexível suficiente para permitir os ORBs incorporarem e integrarem protocolos e aplicações legadas ao invés de trocá-las [22].

\subsubsection{Modelo de Objetos}

O Modelo de Objetos do OMG define uma semântica comum de objetos para especificar as características dos objetos de uma maneira padronizada e independente da implementação. $\mathrm{O}$ Modelo de Objetos define um conjunto de requisitos que deve ser suportado por todos sistemas em conformidade com os padrões do OMG [23].

No Modelo de Objetos OMA, um objeto é uma entidade encapsulada, com uma identidade distinta imutável, cujos serviços podem ser acessados através de interfaces bem definidas. A localização e a implementação destes objetos ficam ocultas dos clientes que fazem requisições de serviços [22]. Um objeto contem a implementação das operações definidas pelas interfaces.

Uma operação descreve ações que podem ser aplicadas aos argumentos. Cada operação 
tem uma assinatura. A assinatura consiste do nome da operação, lista de argumentos, e a lista de valores retornados, se existirem. Formalmente a operação $O$ tem a assinatura

$$
O:\left(p_{1}: t_{1}, p_{2}: t_{2}, \ldots, p_{n}: t_{n}\right) \rightarrow\left(r_{1}: s_{1}, r_{2}: s_{2}, \ldots, r_{m}: s_{m}\right)
$$

onde $O$ é o nome da operação. A assinatura especifica $n \geq 1$ parâmetros com nome $p_{i}$ e tipos $t_{i}$, e $m \geq 0$ valores retornados com nomes $r_{i}$ e tipos $s_{i}$ [24].

\subsubsection{Herança}

O Modelo de Objetos distingue subtipo e herança da seguinte maneira:

Subtipagem é o relacionamento entre os tipos baseado em suas interfaces. Ela define as regras nas quais os objetos de um tipo são determinados serem aceitos em contextos em que outro tipo é esperado. Herança é um mecanismo para reuso. Ele permite que um tipo seja definido em termos de outro tipo [24].

Dentre as três características importantes decorrentes do paradigma orientado a objeto, o encapsulamento, a herança e o polimorfismo, a OMA não fornece suporte ao polimorfismo e define um suporte a encapsulamento e herança de um modo restrito. Herança (incluindo herança múltipla) é restrita somente a herança de interface e não define suporte à sobrecarga ou especialização de operações. Como o objetivo do OMG é estabelecer especificações para computação distribuída baseada em objetos para as tecnologias existentes, o grupo não se preocupa como estas interfaces serão implementadas, por este motivo, herança de implementação não foi considerada. O ORB não tem conhecimento se o conjunto de serviços acessados através de uma hierarquia de interfaces está relacionado a uma hierarquia de implementação. Por outro lado, nada em CORBA impede o desenvolvedor de utilizar herança de implementação em um conjunto de objetos [23].

\subsubsection{Linguagem de definição de interface}

Antes de um cliente executar uma requisição sobre um objeto, ele deve saber os tipos suportados pelas operações daquele objeto. A interface do objeto especifica as operações e tipos suportados por este e as requisições que podem ser feitas para o objeto. As interfaces para os objetos são definidas na Linguagem de Definição de Interface (IDL - Interface Definition Language ). Interfaces são similares a classe em $\mathrm{C}++$ e interfaces em Java [22]. A Listagem 2.1 mostra um exemplo de definição de atributos e interface usando a OMG IDL. 
Listagem 2.1: Definição do tipo Paciente e da interface Buscador utilizando a linguagem IDL-OMG.

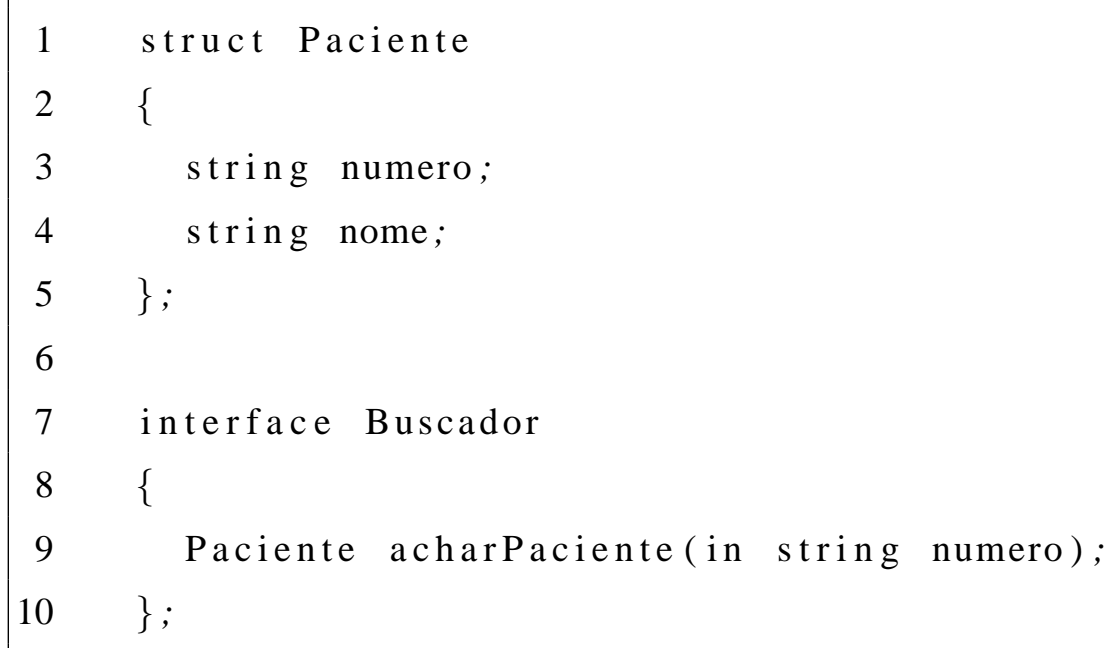

A estrutura Paciente (linha 1) define dois atributos do tipo cadeia de caracteres (string linhas 3 e 4) e a interface Buscador (linha 7) define uma operação que retorna o tipo Paciente (linha 9) recebendo como argumento o número do paciente.

Um compilador de IDL automaticamente transforma as definições da IDL em códigos de linguagens de programação como $\mathrm{C}++$ ou Java. Além de propiciar transparência de linguagem, os compiladores de IDL eliminam fontes de erros comuns na programação dos componentes de rede e possibilita a otimização da compilação [25].

Após a compilação da IDL são gerados procedimentos ou linhas de código computacional chamados stubs nos clientes e skeletons no servidor que funcionam como uma "cola" entre estes e o ORB, conforme mostrado na Figura 2.3. Os stubs fornecem invocação estática fortemente tipificada que empacotam os dados da aplicação em uma representação comum de pacotes. Os skeletons desempacotam esta representação novamente para a aplicação no servidor [25].

Por outro lado, os clientes podem invocar operações no servidor sem ter conhecimento, em tempo de compilação, da interface do objeto através da invocação dinâmica de interface (DII Dynamic Invocation Interface ) [22]. Com isto, não há a necessidade da utilização dos stubs, que necessitam do conhecimento da interface em tempo de compilação, e as requisições são geradas em tempo de execução.

De modo análogo, no lado do servidor, temos a invocação dinâmica de skeleton (DSI Dynamic Skeleton Interface) que permite que os objetos nos servidores possam ser programados sem a geração de skeletons estáticos em tempo de compilação. 


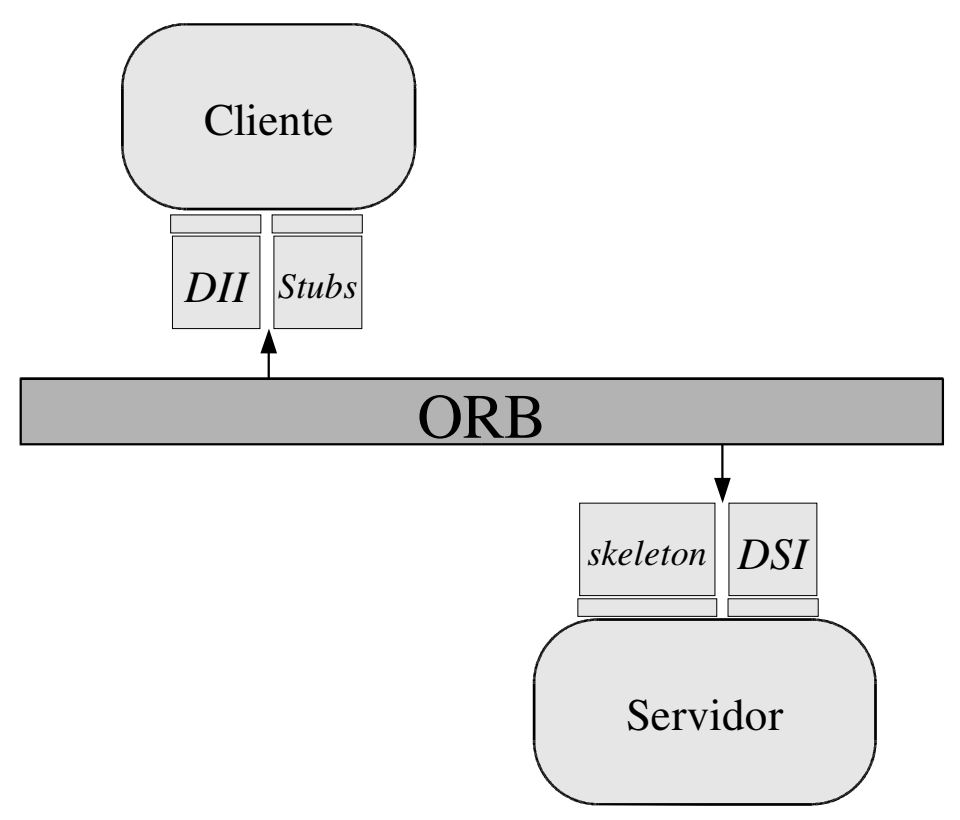

Figura 2.3: Interfaces de invocação da arquitetura CORBA.

\subsubsection{Repositórios}

Toda aplicação baseada na arquitetura CORBA requer acesso ao tipo definido na IDL. Isto é necessário porque a aplicação deve saber os tipos dos valores a serem passados como argumentos para a requisição. Porém, nem sempre é possível ter conhecimento em tempo de compilação dos tipos a serem transportados. Para os casos em que há a necessidade de acesso aos tipos durante a execução, CORBA fornece o repositório de interfaces (IR - Repositório de Interfaces). O IR é em si mesmo um objeto CORBA cujas operações podem ser invocadas como qualquer outro objeto CORBA. Usando a interface do IR, as aplicações podem atravessar uma hierarquia inteira de informações sobre a IDL, interagindo com os módulos definidos e obtendo informações sobre interfaces [22].

Já o repositório de implementação (Implementation Repository) fornece um repositório de informações que podem ser obtidas pelos objetos CORBA, em tempo de execução, sobre as classes que o servidor suporta, os objetos que foram instanciados e seus identificadores. Ele também serve como um local padrão para armazenar informação adicional com a implementação dos ORBs, tais como dados administrativos e de segurança [18].

\subsubsection{Adaptadores de objetos}

$\mathrm{Na}$ arquitetura CORBA, os adaptadores de objetos (POA - Portable Object Adapter ) são necessários para intermediar o mundo dos objetos CORBA e o mundo das linguagens de 
programação utilizadas para a implementação das interfaces. A especificação dos adaptadores é padronizada pelo OMG e sua implementação fornece os seguintes serviços [26]:

- Criação de objetos CORBA e suas referências;

- Demultiplexação das requisição feitas em cada objeto CORBA;

- Envio das requisições ao objeto que provê a implementação do objeto CORBA;

- Ativação e desativação de objetos CORBA.

Com a utilização do adaptador de objetos, a arquitetura cliente-servidor das requisições adquire o formato mostrado na Figura 2.4, onde o ORB utiliza o adaptador para interagir com as implementações dos objetos CORBA e os skeletons estáticos e dinâmicos.

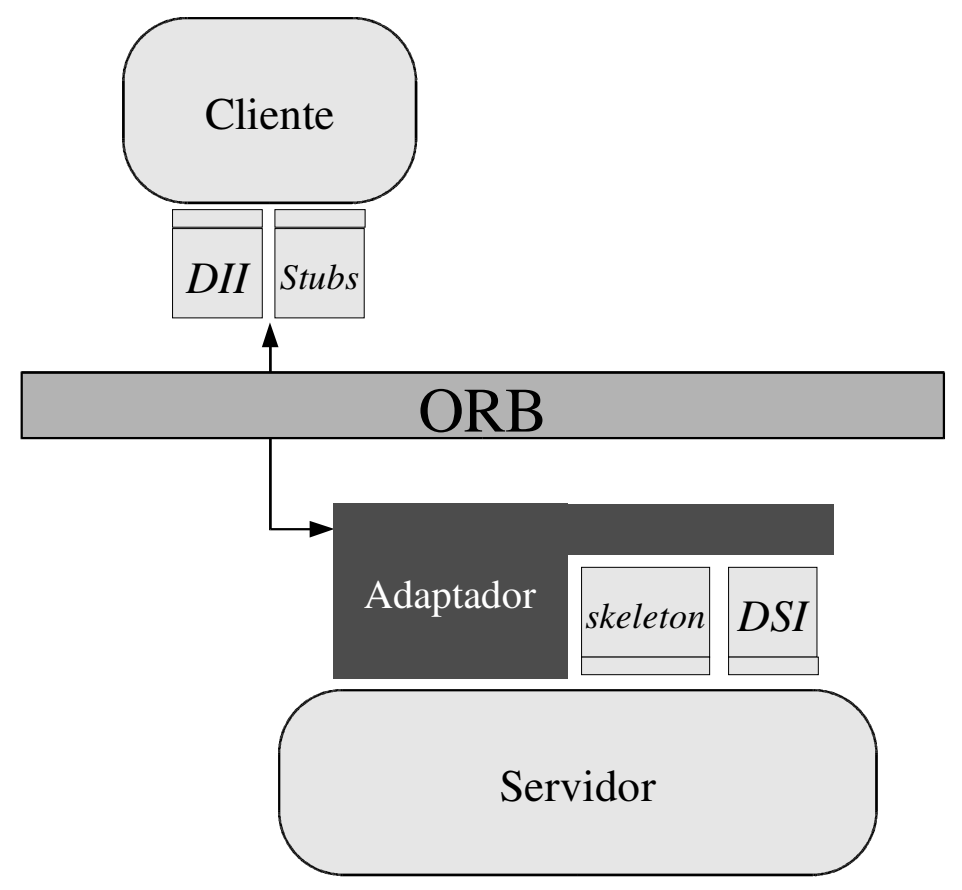

Figura 2.4: Comunicação cliente servidor na arquitetura CORBA com a intermediação do adaptador de objetos (POA).

A Figura 2.5 mostra uma requisição feita para o ORB, sendo que parte desta requisição contém a identificação do objeto. Esta identificação será usada pelo adaptador para instanciar, se já não houver instanciado, e executar a invocação do método no objeto, retornando o resultado, se houver, para o adaptador e depois para o ORB, que retorna para o cliente. Esta comunicação pode ser realizada de maneira síncrona ou assíncrona. 
Como a aplicação pode ter vários adaptadores POAs instanciados, o identificador do objeto é importante para que o ORB possa enviar a requisição para o adaptador que contem o objeto, e este executar a operação requisitada [26].

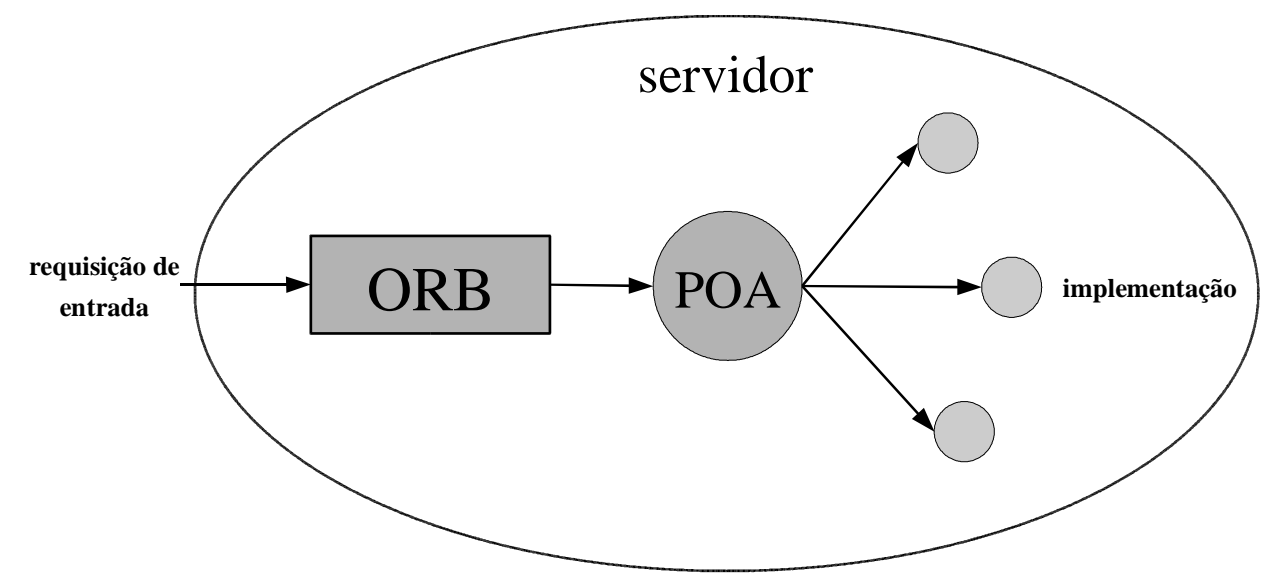

Figura 2.5: Interação entre o ORB e a implementação dos objetos CORBA através do adaptador (POA). FOnTE: Vinoski [26].

Para o transporte na rede e entre ORBs, o protocolo GIOP (General Inter-ORB Protocol) especifica todos os aspectos de interoperabilidade. O GIOP especifica um pequeno conjunto de padrões de mensagens que os ORBs podem enviar entre si, de modo que os clientes vejam a requisição e a resposta orientadas a objeto. O GIOP sobre a camada de transporte TCP/IP (Transmission Control Protocol/Internet Protocol) forma o IIOP (Internet Inter-ORB Protocol ), implementação obrigatória para que o ORB seja considerado compatível com o padrão CORBA [26].

\subsection{Especificação CORBA para o domínio da saúde}

No começo de 1996, o OMG se reorganizou para oferecer aos usuários dos componentes CORBA o poder de influenciar nas direção das especificações técnicas. Parte desta reorganização envolveu a divisão do Comitê Técnico em duas partes [22]:

- Comitê Técnico de Domínio (DTC - Domain Technical Committee ): esta parte focaliza tecnologias que são orientadas verticalmente, ou seja, específica do domínio. As Forças Tarefas (Task Forces) do comitê de domínio incluem as áreas Financeira, Manufatura, Saúde, Negócios e Telecomunicações; 
- Comitê Técnico de Plataforma (PTC - Platform Technical Commmittee): esta parte focaliza em tecnologias que são orientadas horizontalmente, ou seja, independente de domínio. As Forças Tarefas do comitê de plataforma lidam com a especificação do ORB, dos Serviços e das Facilidades CORBA.

As Forças Tarefas de Domínio escrevem documentos de requisitos para novas especificações, além de avaliar e recomendar especificações candidatas. Baseado na recomendação das Forças Tarefas, o Comitê de Domínio conduz uma votação formal da especificação, assegurando que toda especificação de um domínio tenha a aprovação de todos os domínios e não somente daquele da qual ela foi originada. Em um passo final, o documento precisa da aprovação da Comissão de Diretores do OMG para tornar-se uma especificação oficial [20].

\subsubsection{Força Tarefa para o Domínio da Saúde}

A Força Tarefa para o Domínio da Saúde (HDTF - Healthcare Domain Task Force) foi criada com o objetivo de padronizar interfaces de objetos que compõe um sistema desenvolvido para a área da saúde.

A HDTF adotou quatro propostas de especificações baseadas na arquitetura CORBA:

- Serviço de Identificação de Pessoas (PIDS - Person Identification Service): define um conjunto de interfaces para um conjunto de serviços intercambiáveis que fornecem uma verificação da identidade pessoal baseada nos dados de uma determinada pessoa. Esta especificação não está restrita à área da saúde, podendo ser utilizada em qualquer domínio que necessite o armazenamento e a busca de dados que ajudam na identificação de uma pessoa;

- Serviço de Acesso às Observações Clínicas (COAS - Clinical Observation Access Service): padroniza o acesso às observações clínicas armazenadas em diferentes formatos, incluindo dados numéricos extraído de instrumentos ou observações, imagens e texto livre;

- Serviço de Consulta Léxica (LQS - Lexicon Query Service): padroniza um conjunto de interfaces somente-leitura capazes de acessar sistemas de terminologia médica que podem variar de um conjunto de códigos a complexos sistemas de classificação hierárquicos;

- Recurso de Acesso às Decisões (RAD - Resource Access Decision): fornece decisões de acesso granular aos dados que necessitam de controle de segurança e administração, de acordo com as políticas que definem as decisões. 
Um detalhe importante dos componentes especificados pela HDTF-OMG é a separação da identificação do paciente e os seus dados médicos, possibilitando a pesquisa nos dados sem relacionar com uma pessoa específica, proporcionando a privacidade de uma pesquisa. Se caso for necessária a identificação da pessoa, isto é possível pelo relacionamento entre entre o sistema de identificação e o sistema de armazenamento de dados médicos (COAS) [27].

As especificações HDTF-OMG foram construídas sobre as vantagens da arquitetura CORBA. Elas especificam serviços para a área de saúde com as mesmas propriedades que a especificação CORBA: escalabilidade, independência de plataforma, independência de linguagem de programação e estabilidade; sendo que o serviço de segurança CORBA (CORBAsecurity) pode ser acoplado tornando este serviço transparente ao desenvolvedor de aplicação [28]

\subsubsection{Sistema de Identificação de Pessoas}

A especificação do Sistema de Identificação de Pessoas (PIDS - Person Identification Service) define interfaces para o gerenciamento dos registros de pessoas, principalmente em um ambiente de saúde. Ela foi projetada para:

- Suportar a atribuição de registros dentro de um domínio particular e a correlação de registros entre múltiplos domínios;

- Suportar a busca com e sem retorno de mensagens;

- Suportar federação de serviços PIDS independente da topologia do projeto;

- Permitir implementações que protejam a confidencialidade das pessoas sob os mais variados mecanismos de segurança e políticas de confidencialidade;

- Habilitar interoperabilidade plug-and-play de elementos de um conjunto de perfil e permitir a personalização destes elementos;

- Definir níveis de compatibilidade apropriados para os diversos graus de complexidade da aplicação, variando de domínios específicos de registros até federações [29].

\subsubsection{Modelo Conceitual}

O modelo conceitual do PIDS é mostrado no diagrama de classes da Figura 2.6 e evidencia os principais tipos de dados que um implementação PIDS deve ter. 
O tipo de dados IDDomain representa o domínio em que a identificação da pessoa será armazenada. A partir de IDDomain diversos domínios PIDS podem ser correlacionados formando uma federação.

O tipo Trait Type especifica os atributos de identificação suportados pelo domínio, e quais as propriedades desses atributos, se são obrigatórios (Mandatory), se uma procura pode ser realizada sobre o atributo (Searchable), e se estes atributos têm características somente-leitura (ReadOnly). O tipo Trait indica os valores recebidos pelos atributos e Profile indica o conjunto de atributos de uma determinada pessoa representada de maneira única por QualifiedID.

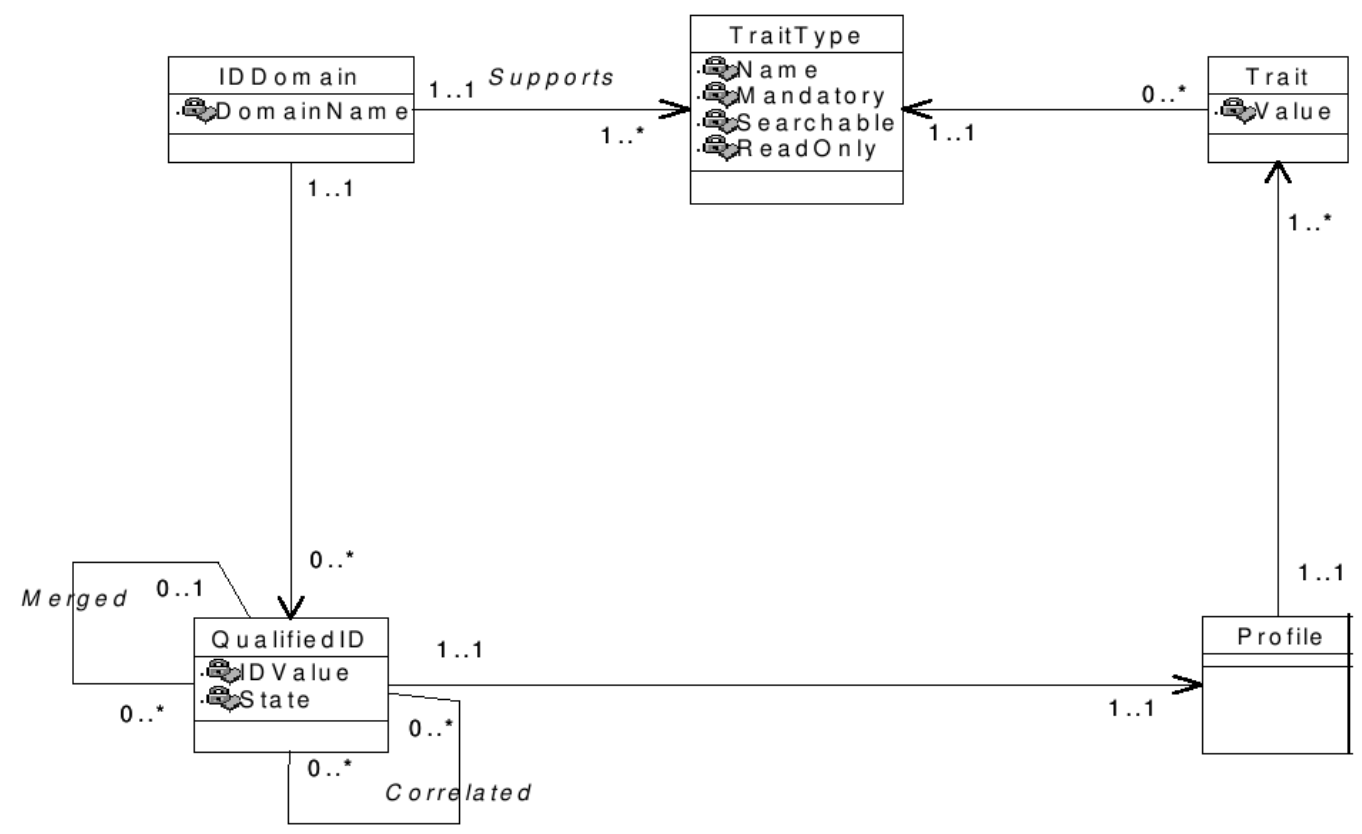

Figura 2.6: Modelo conceitual PIDS. FonTE: especificação PIDS [29].

A Figura 2.7 mostra o diagrama de objetos de uma pessoa cadastrada no PIDS, com a atribuição de nome e data de nascimento. A pessoa recebeu uma identificação local (“6666”) que está ligada ao domínio (DNS) “imagcom.ffclrp.usp.br”. O perfil (Profile) desta pessoa contém os atributo nome e data de nascimento, que são representados pelos códigos "HL7/PatientName" e "HL7/DateTimeofBirth", respectivamente, especificados no PIDS e extraídos do padrão HL7. Estes atributos recebem valores que são armazenados no banco de dados.

\subsubsection{Módulos e interfaces PIDS.}

A Figura 2.8 mostra as interfaces definidas no módulo PersonIdService. As principais interfaces funcionais herdam os atributos e operações de IdentificationComponent e são referenciadas por elas. 


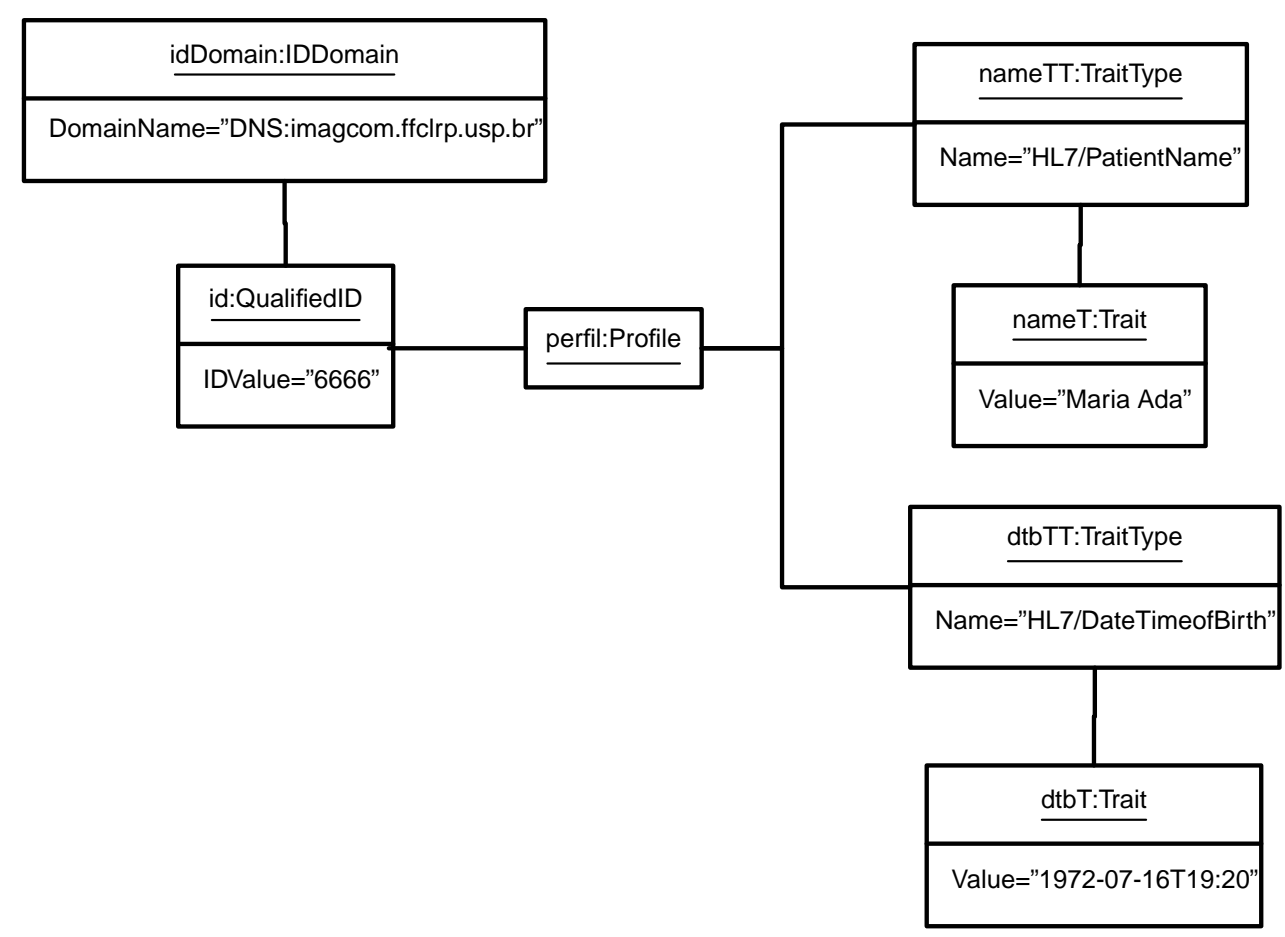

Figura 2.7: Diagrama de objetos demonstrando os valores atribuídos a uma pessoa cadastrada no PIDS.

A interface IdentifyPerson é utilizada para buscar candidatos do sistema PIDS que possuam o perfil fornecido pelo usuário. O usuário pode selecionar os atributos de busca, o estado de interesse dos registros e o valor de confiança.

A interface IdMgr provê funcionalidades para o gerenciamento de registros. Sua implementação deve fornecer a possibilidade de:

- armazenar novos registros;

- buscar registros;

- criar registros temporários;

- tornar permanentes alguns registros;

- unir registros;

- separar registros;

- tornar registros obsoletos (deprecated) [29].

A interface ProfileAccess fornece acesso ao perfil tendo como base para a busca o número do registro ou um conjunto de números, havendo a possibilidade de seleção dos atributos a serem requisitados. 


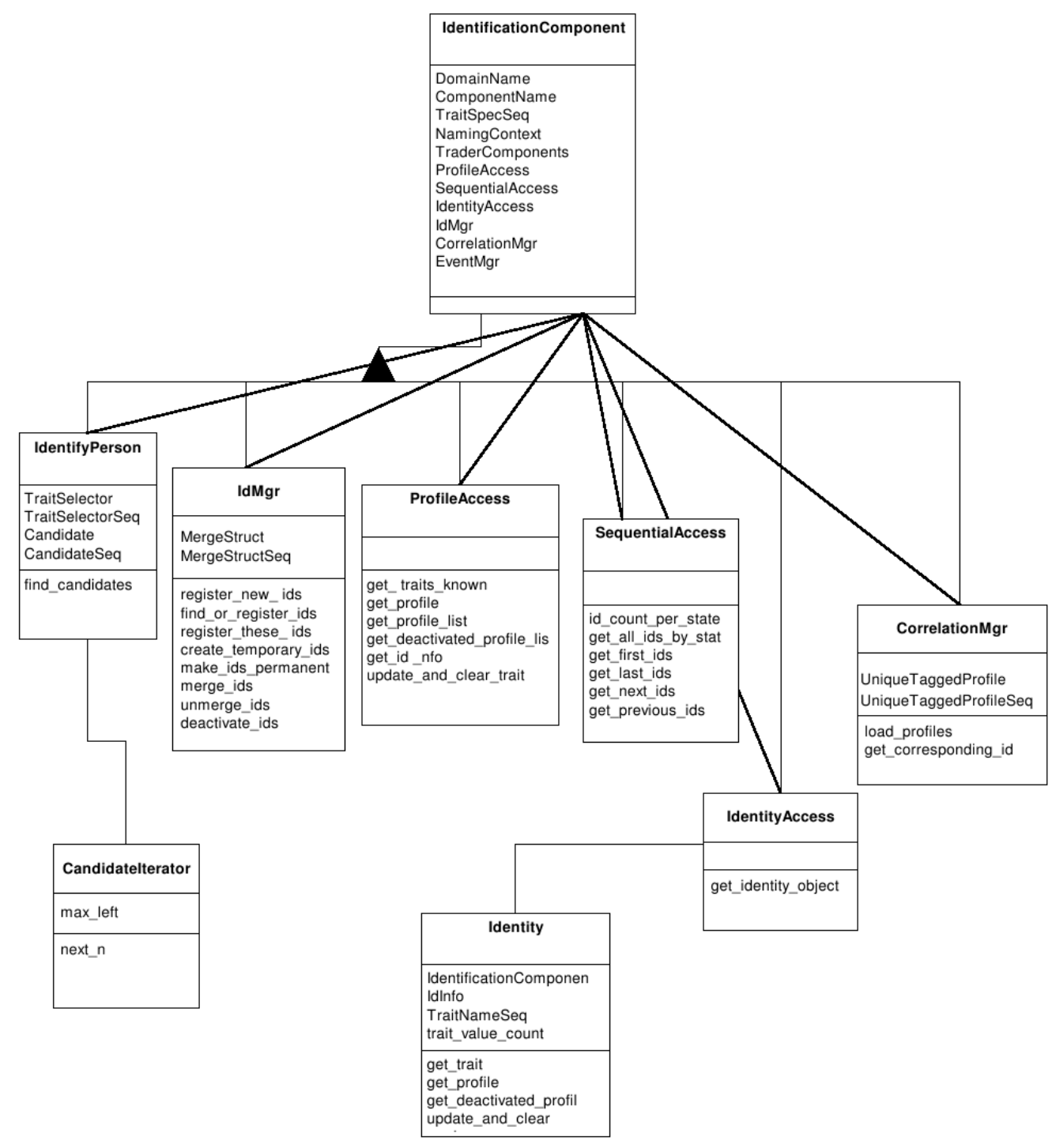

Figura 2.8: Diagrama de herança e componentes PIDS. FONTE: especificação PIDS [29].

A interface SequentialAccess fornece acesso seqüencial aos registros, podendo haver a requisição da informação sobre os perfis associados, o estado do registro e o número de registros a serem requisitados.

A interface IdentityAccess fornece acesso à interface Identity, cuja implementação possibilita encapsular informações de uma pessoa identificada pelo registro de um objeto. Através do número de registro é possível buscar objetos Identity, podendo obter informações sobre o perfil e atualizar as informação da pessoa associada ao registro.

A interface CorrelationManager é utilizada para correlacionar registros de diferentes domínios formando um federação. A Figura 2.9 mostra a correlação de três domínios feita pelo componente CorrelationManager no PIDS Mestre. A consulta retorna dados de pessoas 
que possam existir nos três sistemas.

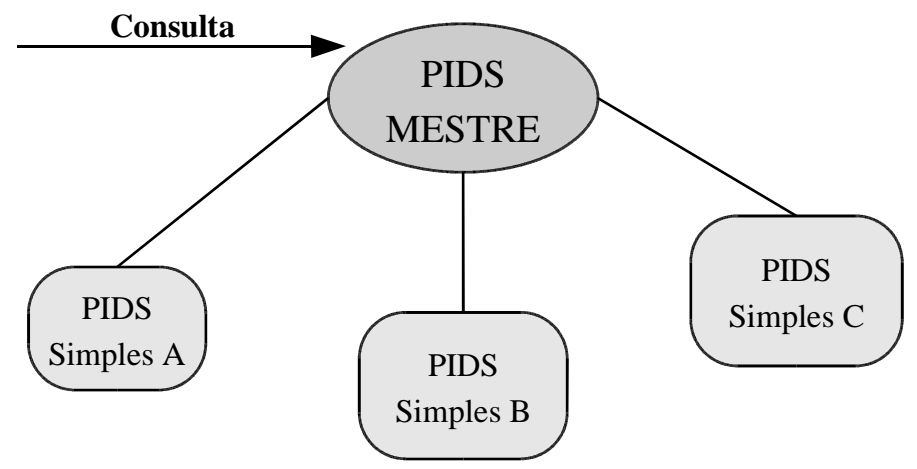

Figura 2.9: Federação PIDS formada pelos domínios de identificadores A, B e C, onde a consulta ao PIDS Mestre extrai informações comuns dos domínios.

O PIDS permite a utilização do serviço de nomes (Naming) para a localização e instanciação dos objetos pelo nome e não pela referência (IOR). O Trader também pode ser utilizado, principalmente para fornecer uma federação de objetos PIDS pertencentes a domínios distintos.

A utilização do padrão CORBA para identificação do paciente (PIDS) permite que outros sistemas de domínios diferentes integrem seus registros com os armazenados pelo sistema implementado. A separação da identificação da pessoa e dos dados médicos é muito importante para questões de confidencialidade.

O servidor PIDS pode ser utilizado para pesquisas em populações baseadas em dados demográficos. O servidor pode fornecer identificadores que permitem a obtenção dos dados clínicos do candidatos selecionados na busca utilizando o COAS, que será descrito na Seção 2.2.3. Por exemplo, uma pesquisa de pessoas que residem em uma determinada região pode ser feita, correlacionando o resultado da busca com alguma observação clínica armazenada no COAS.

\subsubsection{Serviço de Acesso às Observações Clínicas}

A especificação do Serviço de Acesso às Observações Clínicas (COAS - Clinical Observations Access Service) padroniza a interface e a estrutura de dados para o gerenciamento dos dados clínicos de um ambiente de saúde.

As observações clínicas podem ser qualitativas ou quantitativas, tais como: sinais vitais, exames laboratoriais, impressões de um exame clínico, correlações de impressões qualitativas 
e imagens [30].

\subsubsection{Modelo de Observações Clínicas}

O diagrama de classes do Modelo de Observações Clínicas, mostrado na Figura 2.10, demonstra as abstrações chaves que envolvem a estrutura de armazenamento das observações.

O paciente (tipo ObservedSubject) que está sendo consultado possui diversas entradas (tipo HealthRecordEntry) que contém 0 ou 1 observação (tipo Atomicobservation: Observation 1 ) ou conjunto de observações clínicas (tipo Compositeobservation: Observation). Cada observação pode possuir 1 ou mais valores (tipo ObservationValue). As observações podem referenciar outras observações através de ObservationReference, e tanto as observações como seus valores podem possuir qualificadores (ObservationQualifier).

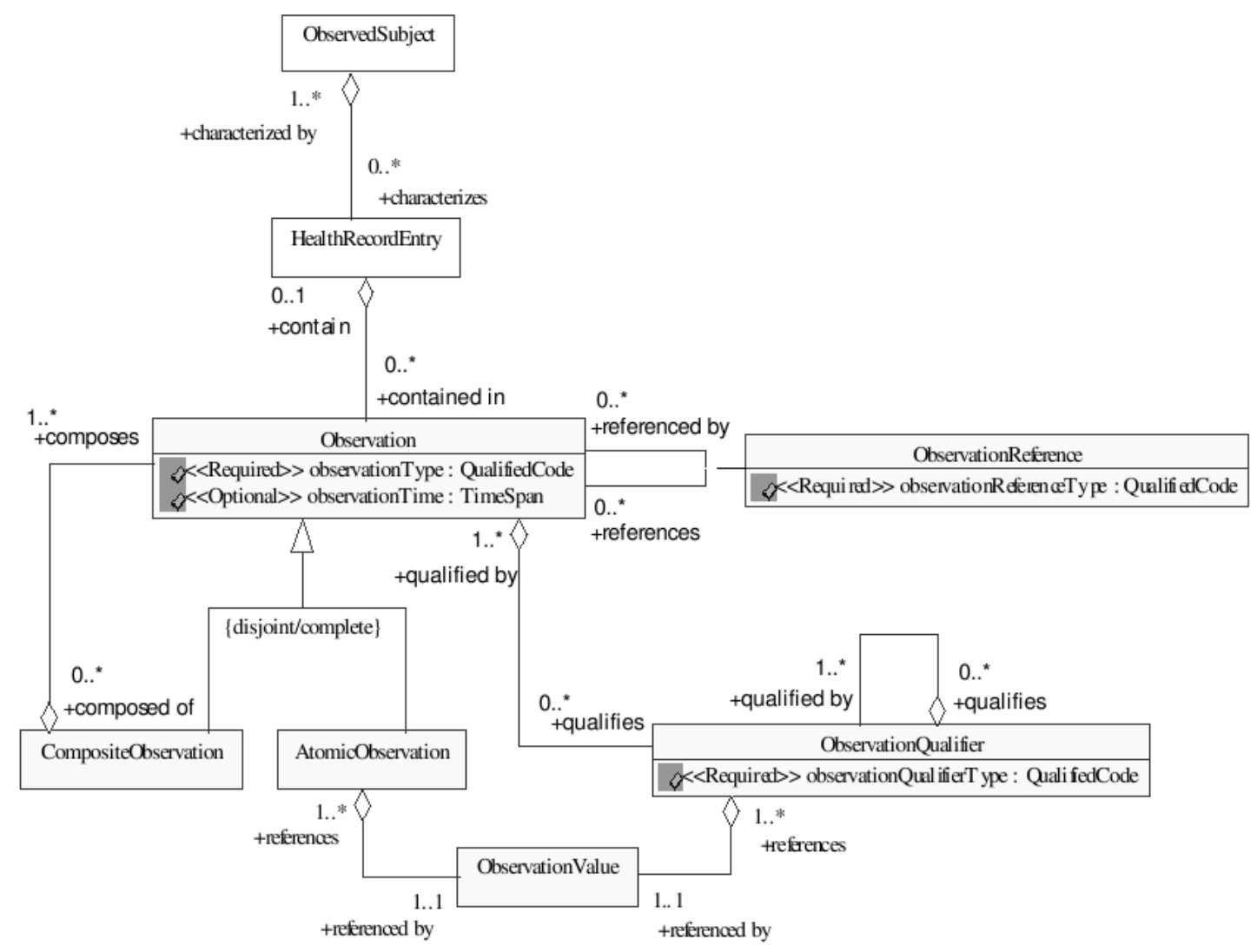

Figura 2.10: Modelo de informação do COAS. FONTE: especificação COAS [30].

O COAS define uma estrutura de dados muito genérica para a recuperação dos dados clínicos. Esta estrutura simples, porém poderosa, foi projetada para lidar com os tipos de diferentes necessidades e de diferentes especialidades dentro da área da saúde. Como consequiência,

\footnotetext{
${ }^{1}$ Representação de herança de acordo com a sintaxe da IDL, onde observation é a classe pai.
} 
o COAS não faz nenhuma suposição sobre o modelo de estrutura da informação necessário dentro de uma especialidade. Como o modelo da estrutura da informação define conceitos de um domínio específico, é necessário utilizar o serviço de consulta léxica (LQS - Seção 2.2.4) para acessar a estrutura da informação de determinada área [27].

Os valores que uma observação clínica pode conter são mostrados na Figura 2.11 e descritos a seguir:

- Elementos codificados (CodedElement): valores provenientes principalmente de sistemas de terminologias para representação da informação clínica de forma padronizada;

- Elementos fracamente codificados (LooselyCodedElement): valores que não são provenientes de sistemas de terminologias, mas também não são "texto livre". Normalmente são provenientes de sistemas de codificações locais;

- Curva (Curve): valores de observações que podem ser plotados graficamente;

- Multimídia (Multimedia): aplicação, áudio, imagem, mensagem, texto e vídeo podem ser associados ao objeto multimídia;

- Localizador de instância tecnológica (Technology InstanceLocator): é usado para referenciar informações que podem executar alguma operação. É uma generalização do conceito de URL (Universal or Uniform Resource Locator );

- Calendário (DateTime): armazena informações sobre data e hora;

- Medida (Measurement): valores de medidas são associados a este tipo.

- Texto (PlainText): texto livre são associados a este tipo;

- Sem informação (NoInformation): quando não há informação associada à observação este tipo é utilizado.

O tipo de dados de medidas (Measurement) é estendido por quatro classes, mostradas na Figura 2.12, que representam as seguintes especializações:

- Escala de valores (Range): armazena faixa de valores onde o atributo lower representa o limite inferior e upper o superior;

- Numérico (Numeric): representa um valor numérico no atributo value; 


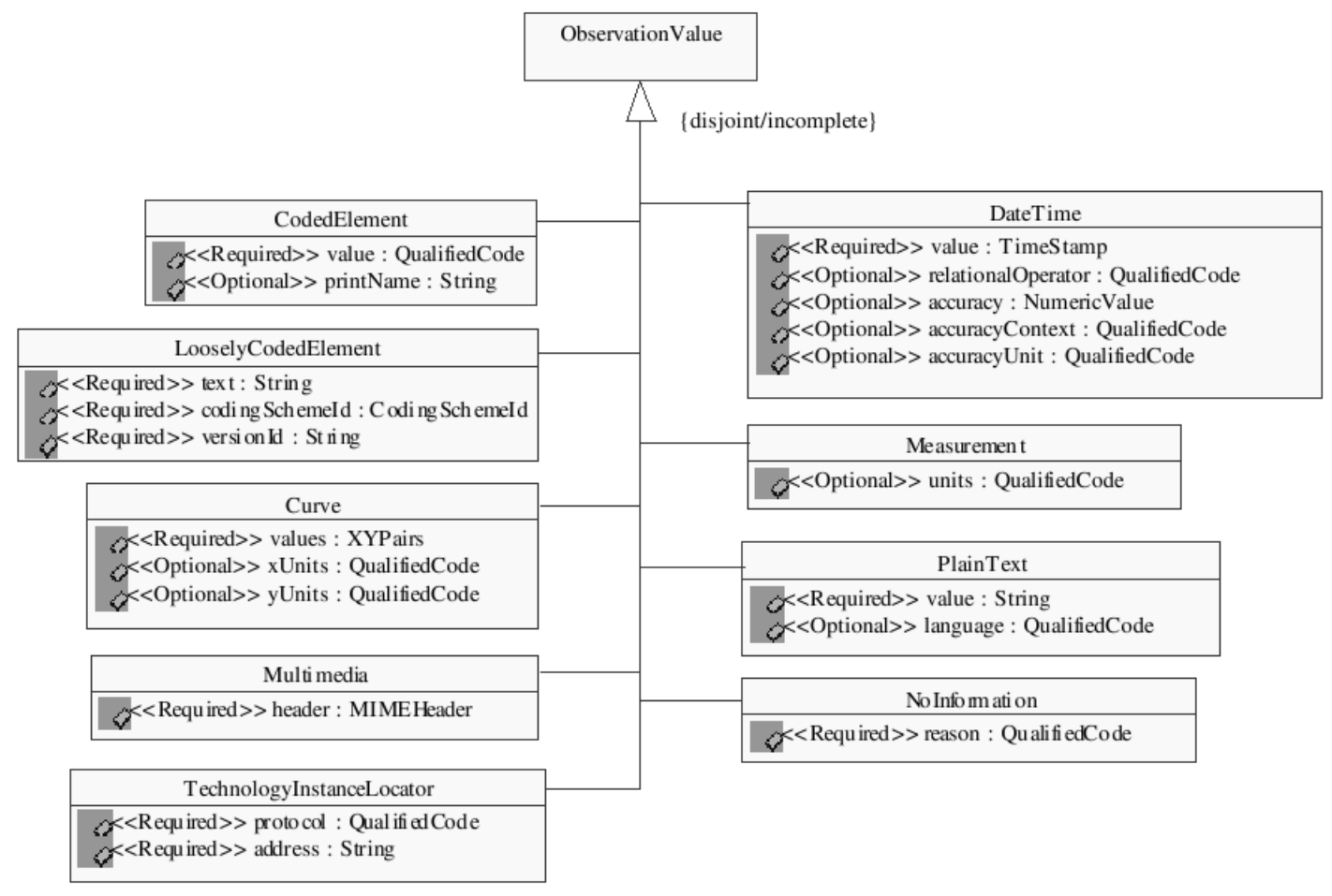

Figura 2.11: Diagrama de classes do tipo ObservationValue mostrando os possíveis tipos (valores) que uma observação clínica pode armazenar. FONTE: especificação COAS [30].

- Proporção (Ratio): representa uma proporção onde o atributo numerator é o numerador e denominator o denominador;

- Séries de tempo (TimeSeries): representa séries de tempo de exames em seus três atributos, período amostrado (samplePeriod), seqüência de valores numéricos e tamanho da amostra.

Uma das vantagens do COAS é o fato de poder armazenar informações ricas em contexto. Não só os valores são associados a unidades, faixas de valores válidos e outras informações que permitem a interpretação correta dos valores, como também cada observação poder ser suprida com qualificadores que expressam relações com outros valores [28].

\subsubsection{Serviço de Acesso}

O acesso às observações clínicas é fornecido por interfaces mostradas na Figura 2.13, que permitem a navegação entre elas de acordo com o tipo de transmissão (síncrona ou assíncrona) que deseja ser efetuado. A interface AccessComponent é o ponto de entrada para as outras interfaces. 


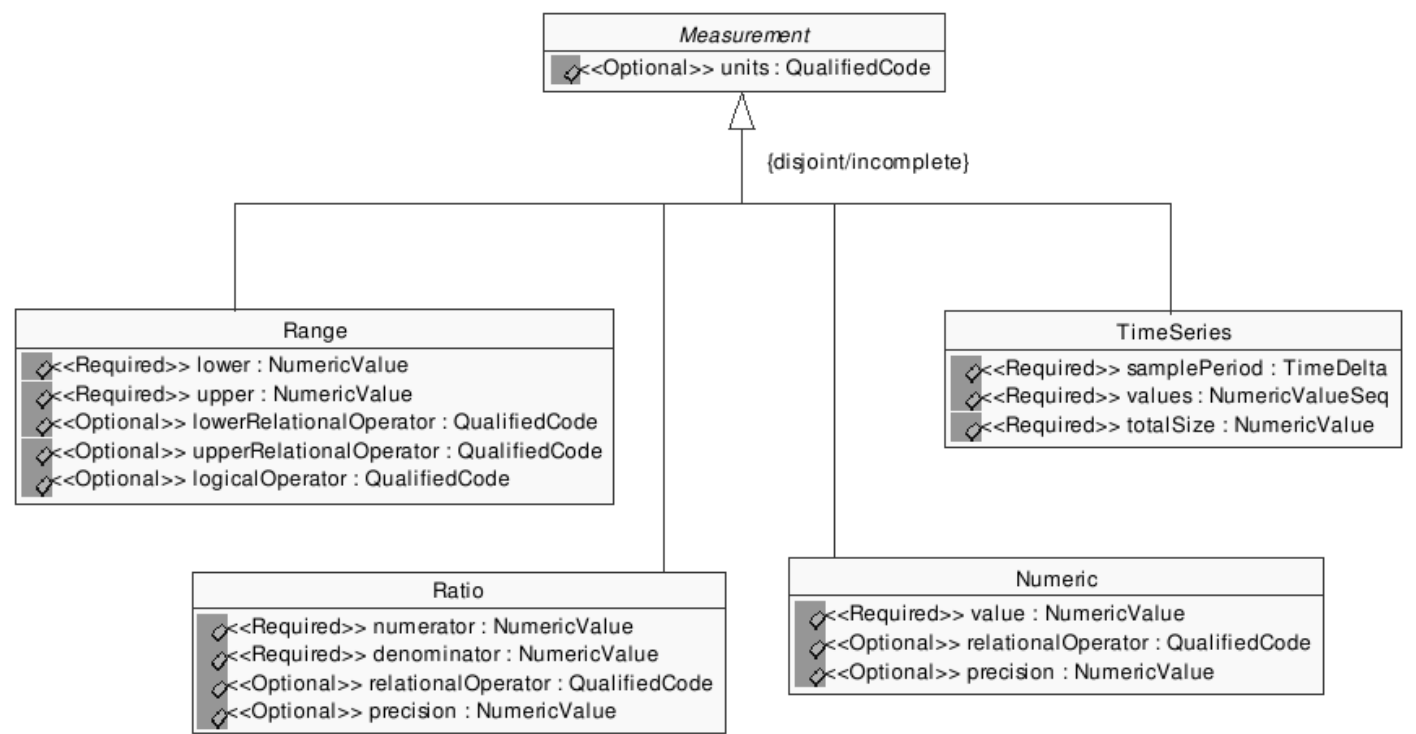

Figura 2.12: Diagrama de classes do tipo Measurement mostrando suas possíveis especializações. FONTE: especificação COAS [30].

As observações podem ser acessadas por valor e por referência. Por valor, elas são obtidas pela transmissão da estrutura ObservationDataStruct, mostrada no diagrama de classes da Figura 2.14, do servidor para o cliente, contendo tanto as observações atômicas quanto as compostas, juntamente com os qualificadores, se existirem. Se a estrutura estiver encapsulando uma observação composta deve conter um número de atributos maior do que zero no atributo composite e nenhum ítem no atributo value. Inversamente, uma observação atômica local não terá conteúdo em composite e um único ítem no atributo value [30].

As informações de observações iniciais, entradas por um profissional de uma UTI neonatal, por exemplo, poderiam ser estruturadas conforme mostra o diagrama de objetos da Figura 2.15 .

O objeto de nome obsDataStruct do tipo ObservationDataStruct contém o atributo code que recebeu o valor "CODIGO_OBSERVACOES_INICIAIS". Em uma aplicação, code seria o código proveniente de algum sistema de terminologia que representasse as observações iniciais. Simplificando o exemplo, a Figura 2.15 supõe que o profissional realize duas observações, a primeira, o exame APGAR, que indica os sinais vitais de um bebê nos instantes 1 e 5 minutos após o nascimento, e a segunda, a medida do peso do bebê após o nascimento.

O atributo composite de obsDataStruct seria não nulo e o atributo value teria valor nulo indicando que a observação é composta. Os dois atributos de composite seriam apgarobs e weightobs recebendo os valores do exame APGAR e do peso de nascimento, respectivamente.

O atributo code do objeto apgarobs receberia o valor "CODIGO_APGAR" proveniente de 


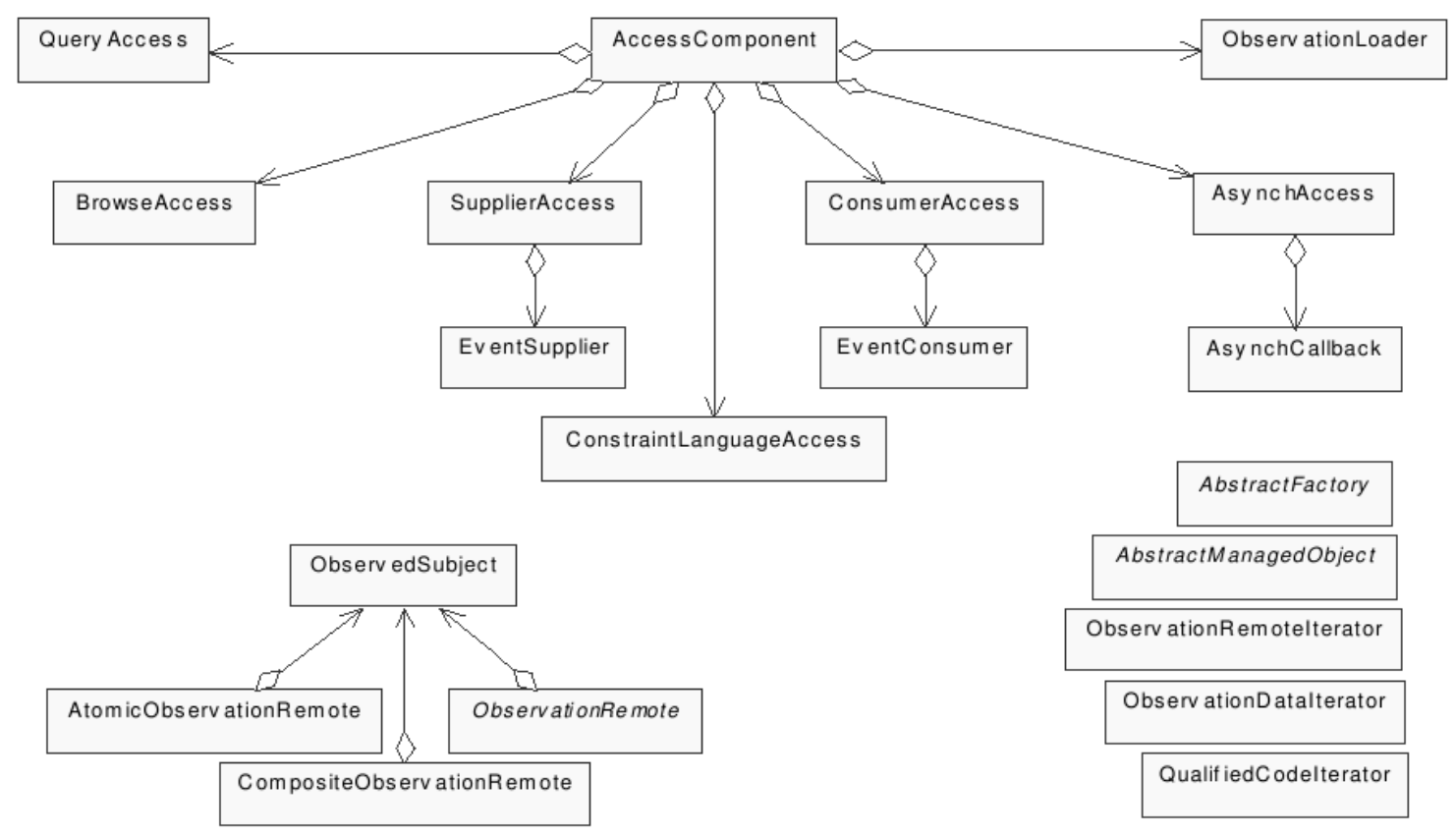

Figura 2.13: Componentes de acesso às observações clínicas. FONTE: especificação COAS [30].

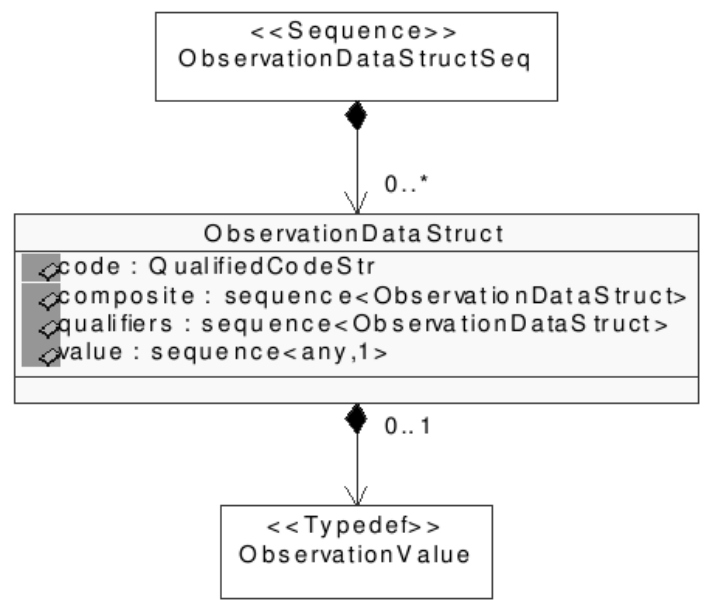

Figura 2.14: Atributos de ObservationDataStruct. FONTE: especificação COAS [30].

um sistema de terminologia e indicando que o conteúdo daquele objeto representa o resultado de um exame APGAR. O atributo value seria não nulo e composite nulo indicando que a observação é atômica. O tipo Any de value pode receber qualquer tipo de objeto, no caso recebeu o tipo Range contendo o resultado do exame, com lower representando o exame em 1 minuto e upper em 5 minutos.

A observação weightobs contém um código para indicar que a observação está relacionada 


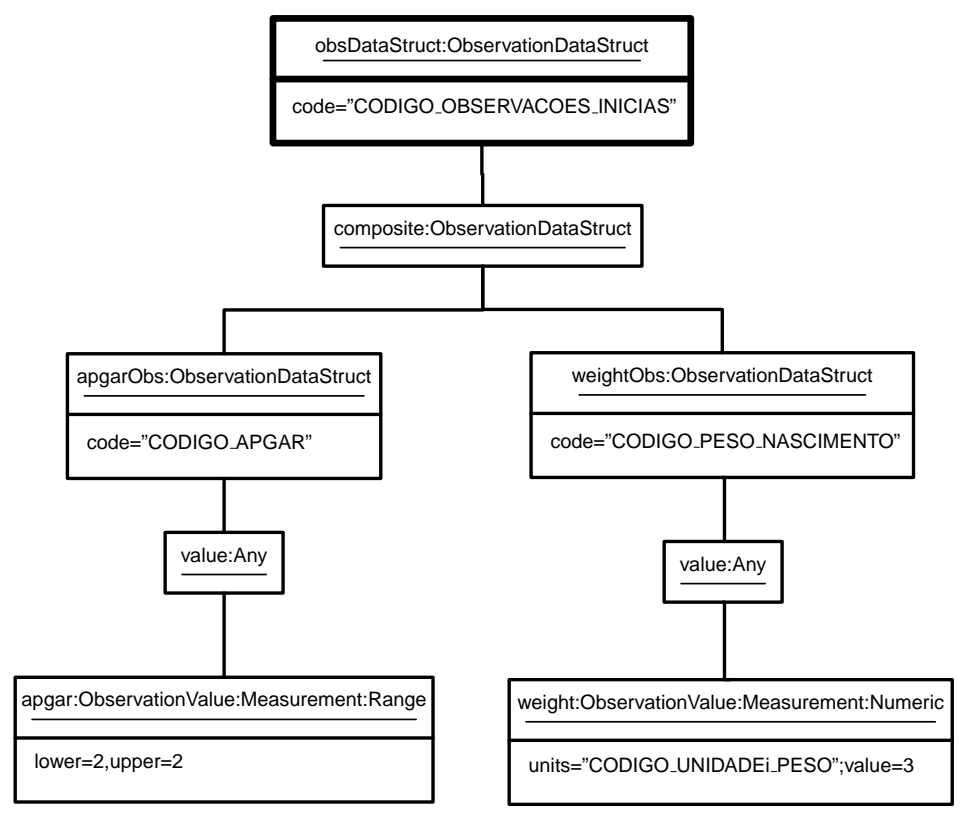

Figura 2.15: Diagrama de objetos da estrutura de dados de uma entrada de observações iniciais em uma UTI neonatal.

ao conceito peso de nascimento, e que este possui um valor numérico (Numeric) encapsulado no tipo Any e recebe um valor inteiro igual a 3. Para indicar a unidade deste valor, um código (units) proveniente de um sitema de terminologia fica associado ao peso $(\mathrm{kg}, \mathrm{lb}, \ldots)$.

As observações clínicas também podem ser acessadas por uma referência a ObservationRemote, conforme mostrado na Figura 2.16. Uma observação remota também pode ser composta ou atômica. As informações sobre a observação podem ser acessadas invocando as operações de ObservationRemote e suas subclasses. AtomicobservationRemote armazena uma referência para uma única observação, enquanto que CompositeobservationRemote referencia um conjunto de observações.

QueryAccess é o componente de AccessComponent que fornece acesso síncrono ao valor das observações ObservationDataStruct. O cliente executa a consulta e bloqueia a comunicação até receber o resultado ou uma exceção. O cliente fornece parâmetros para a consulta de acordo com as operações fornecidas pela interface, e recebe uma estrutura de dados contendo todas as observações requisitadas.

Os mesmos dados enviados pela estrutura mostrada na Figura 2.15 poderiam ser acessados a partir de uma referência a observationRemote, conforme mostrado no diagrama de objetos da Figura 2.17. O cliente recebe uma referência para obsRemote e se tiver interesse nas observações contidas, requisita-as utilizando os métodos get_observation ${ }^{*}()^{2}$. Ao receber referências para observações atômicas (AtomicobservationRemote) como apgarobs e

\footnotetext{
${ }^{2} \mathrm{O}$ asterisco indica que qualquer método que comece com get_observation pode ser usado.
} 


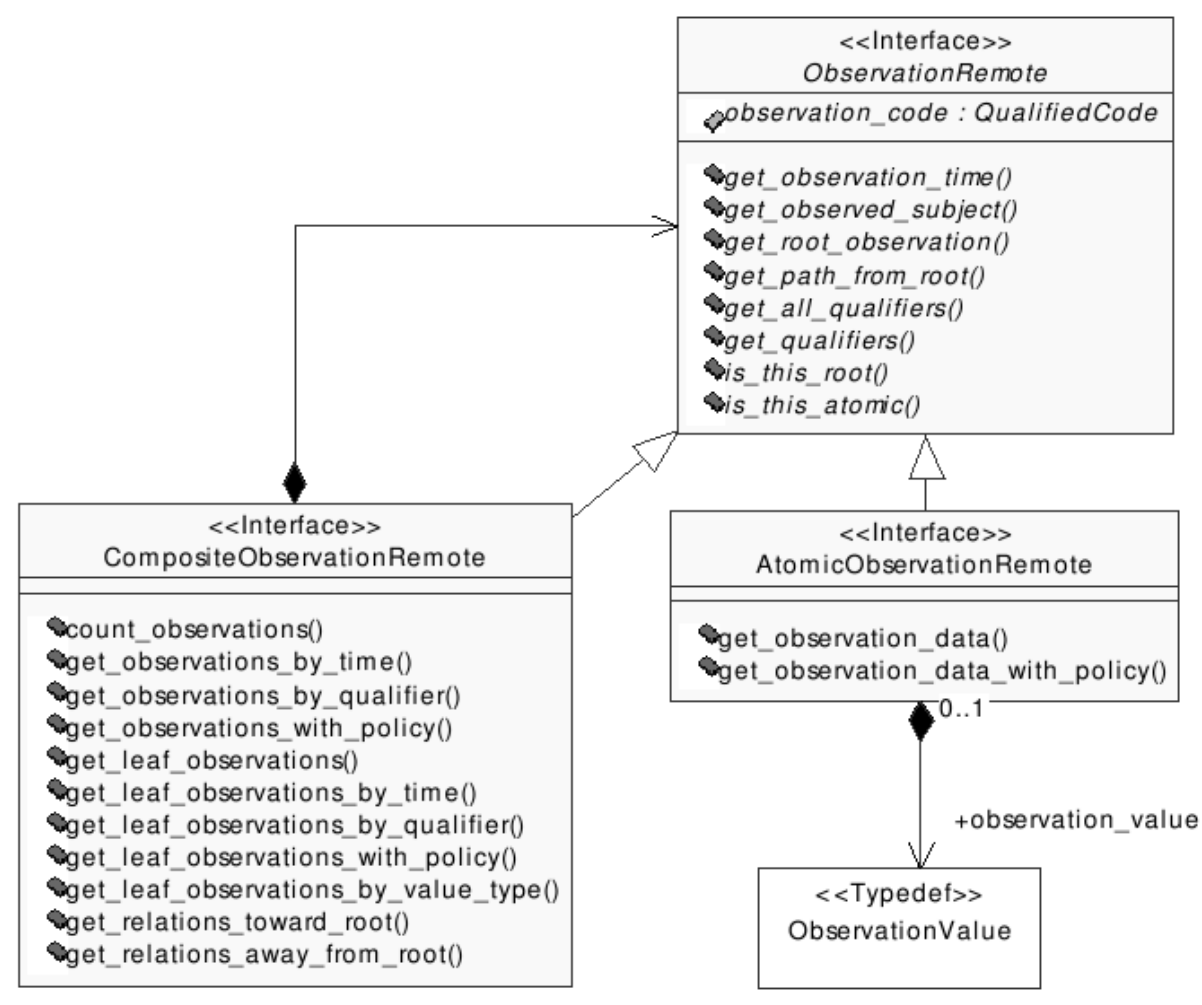

Figura 2.16: Operações e atributos para ObservationRemote e suas subclasses. FONTE: especificação COAS [30].

weightobs, requisita os dados das observações através do método get_observation_data () que retorna os dados destas observações, no caso, a escala de valores do exame APGAR e o peso após o nascimento do bebê, respectivamente.

BrowseAccess fornece acesso síncrono, porém ao invés de retornar uma estrutura de dados contendo as observações, retorna referências a objetos ObservationRemote. Este acesso interativo é importante quando o cliente mostra o resultado após cada comando, porém, é necessário controlar o ciclo de vida dos objetos gerados no servidor.

A vantagem de acessar uma referência remota no servidor é que somente os dados de interesse do cliente são requisitados, reduzindo o tráfego de pacotes na rede.

A interface AsynchAccess permite o cliente requisitar informações, e estas serem entregues de modo assíncrono. Isto permite que a conexão com o servidor seja liberada após o envio da consulta. As operações retornam um valor do tipo ServerCallId, que identifica a requisição do ponto de vista do servidor.

O serviço DsObservationAccess suporta consultas por observações que vão ocorrer no 


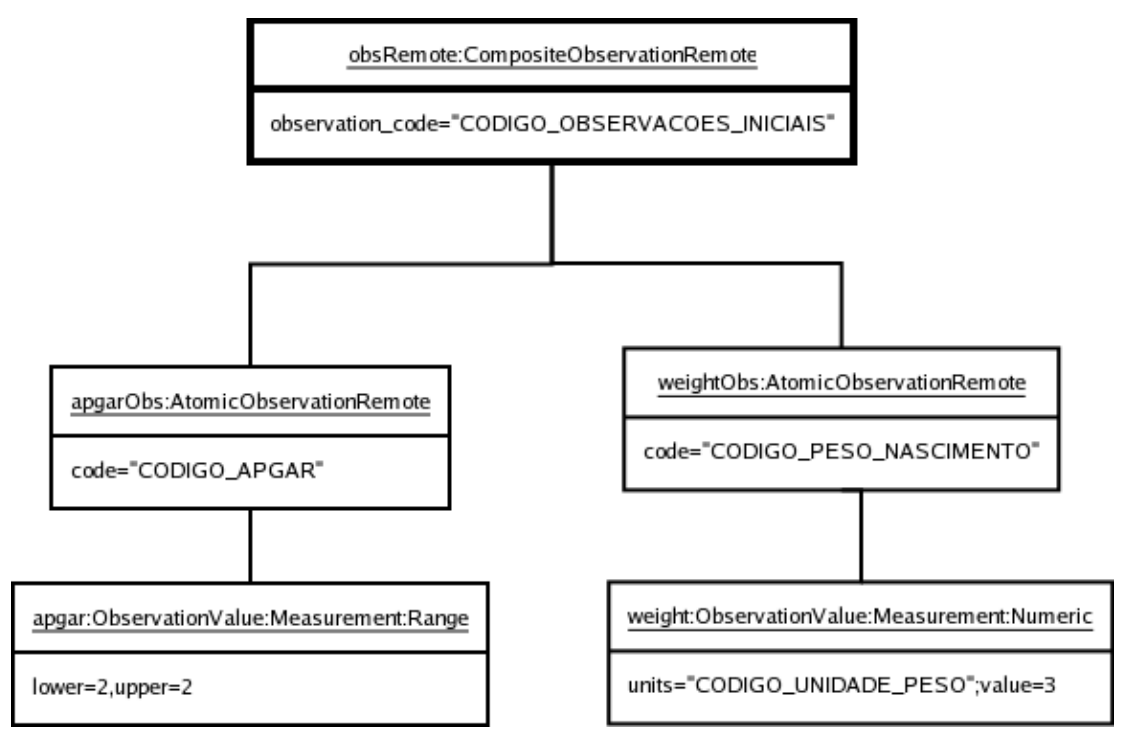

Figura 2.17: Diagrama de objetos de uma referência remota de uma entrada de observações iniciais em uma UTI neonatal.

futuro. O cliente se registra no servidor informando quais parâmetros e valores das observações tem interesse. Este registro é feito em EventSupplier. ConsumerAccess e SupplierAccess são os componentes que gerenciam este registro e fornece as observações que satisfazem um condição, respectivamente. Estas interfaces herdam de AbstractFactory o controle do número máximo de conexões e as conexões correntes.

\subsubsection{Níveis de conformidade}

A especificação COAS estabelece 3 níveis de conformidade [31]:

1. Interface: conformidade com uma ou mais interfaces descritas na especificação;

2. Estrutura de dados: conformidade com o mecanismo de comunicação das estruturas contendo valores de observações;

3. Códigos qualificados (Qualified Code): conformidade com a convenção de termos provenientes de um sistema de terminologia padronizado.

Para estar em conformidade com a especificação COAS, a implementação deve estar nos níveis 1 e 2, sendo o nível 3 opcional. Porém, para alcançar uma nível maior de interoperabilidade semântica proposto por esta tese, a implementação COAS também deve abranger o nível 3. 


\subsubsection{Serviço de Consulta Léxica}

O Serviço de Consulta Léxica (LQS - Lexicon Query Service Specification) especifica operações com atributos somente leitura para acessar o conteúdo de sistemas de terminologias médicos. Um sistema de terminologia pode ser desde uma simples lista de códigos e frases até um esquema multi-hierárquico de classificação e categorização [32]. Os sistemas de terminologias serão abordados com mais profundidade no Capítulo 3 .

Os seguintes cenários descrevem como os sistemas de terminologias podem ser utilizados:

- Aquisição de informação: auxilia no processo de entrada de dados codificados;

- Exibição da informação: ajuda na tradução dos elementos de dados codificados em formatos de exibição;

- Mediação: transformar mensagens de forma de representação para outra;

- Indexação e inferência: auxilia na localização de conjuntos de dados pertencentes a determinados grupos e inferência sobre associações que possam existir entre os conceitos;

- Navegação: determina a estrutura e o significado de um sistema de terminologia;

- Manipulação de conceitos compostos: ajuda na entrada, validação e conversão de conceitos compostos.

\subsubsection{Tipos Básicos}

As classes mostradas na Figura 2.18 representam as extensões dos tipos de dados que são usados no modelo LQS.

O tipo Blob representa uma stream de bytes. IntlString é um objeto que encapsula uma cadeia de caracteres (string) com o tipo especificado por CharacterSet. Trinary representa os valores booleanos falso (FALSE), verdadeiro (TRUE) e o valor desconhecido (UNKNOWN) quando não houver representação booleana. Weight representa a medida relativa da proximidade do resultado de uma busca, de acordo com o valor esperado, podendo receber valores entre 0 e 1 . Cardinality representa a mínima e máxima ocorrências de um elemento em uma associação.

\subsubsection{Espaço de Nomes}

Naming Authority, como mostrado no diagrama da Figura 2.19, oferece um espaço de 


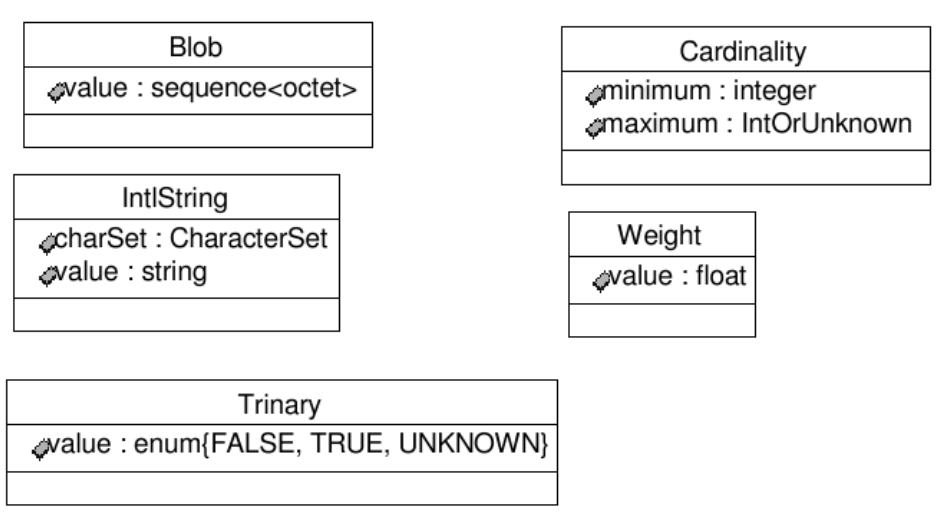

Figura 2.18: Tipos básicos do LQS. FONTE: especificação LQS [32]

nomes para identificação global única de nomes. RegistrationAuthority identifica a raiz no espaço de nomes. NamingEntity identifica a sintaxe e o formato especificado pelo sistema de terminologia. LocalName é o nome do conceito pertencente ao sistema de terminologia.

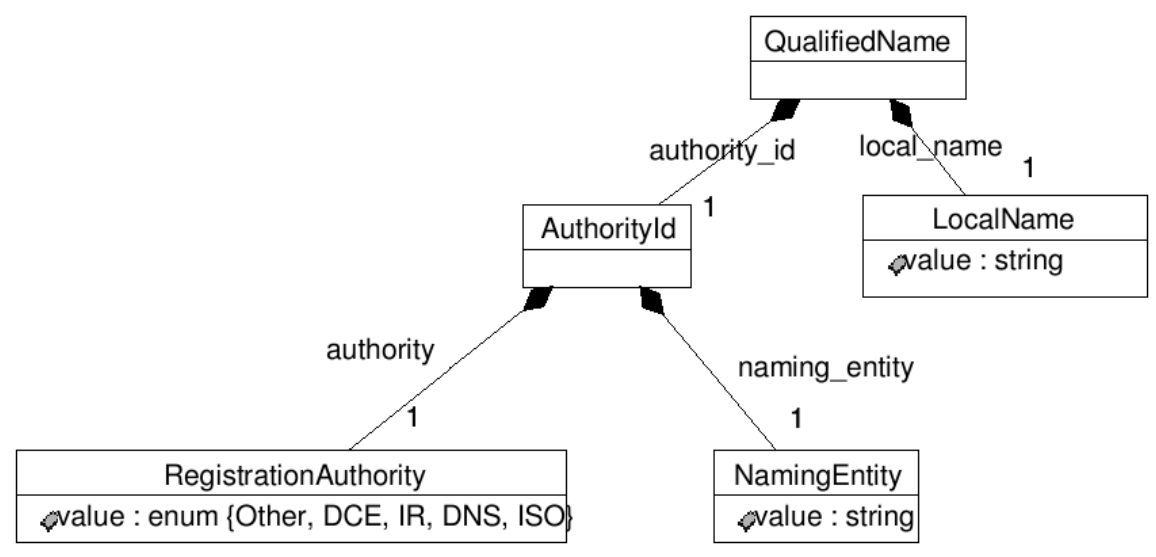

Figura 2.19: Espaço de nomes utilizado no LQS. FONTE: especificação LQS [32].

A Figura 2.20 mostra o diagrama de objetos para a representação do CID versão 10 no LQS. Para a transmissão do nome qualificado do atributo cidQN, a estrutura de dados mostrada na Figura é convertida sob a forma "DNS:hl7.omg.org/I10".

No diagrama de objetos, a variável cidRA do tipo RegistrationAuthority tem como atributo value que recebe o valor 0 , indicando que o nome da entidade representada provem de um DNS. O nome da entidade (NamingEntity) é recebe o valor "hl7.omg.org", indicando que valor do nome provem de parte do padrão HL7 incorporado nas especificações do OMGCORBA. O nome local (LocalName) recebe o valor "I10", que é o código que representa o CID versão 10 no padrão HL7. 


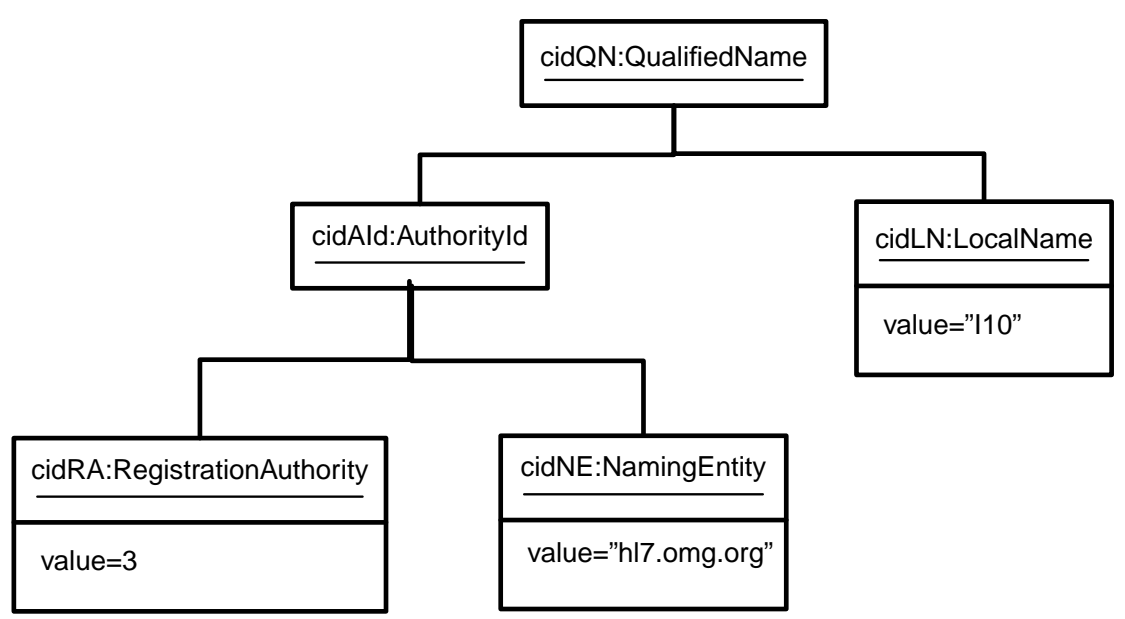

Figura 2.20: Diagrama de objetos do espaço de nomes utilizado pela especificação LQS para representar o CID 10.

\subsubsection{Decisão de Acesso a Recursos}

A especificação da Decisão de Acesso a Recursos (RAD - Resource Access Decision) padroniza interfaces para o gerenciamento escalável de permissões. Estas interfaces permitem a controle do acesso granularizado à informação baseado em relacionamentos dinâmicos entre as entidades, como entre médico e paciente. As partes dos dados do paciente a serem mostradas são baseadas na função, credenciais e local de quem está acessando-as. Este mecanismo é projetado para ser independente de uma implementação específica e interoperável entre instituições de saúde. Este mecanismo fornece um modo mais adaptável de autorização do que as Listas de Controle de Acesso (ACL - Access Control Lists) [11].

\subsection{Considerações Finais}

A utilização da arquitetura CORBA pode ajudar na melhoria do compartilhamento de recursos distribuídos difíceis de serem integrados diretamente devido às diferenças técnicas e semânticas. A especificação CORBA para domínios verticais tenta colaborar na integração, não só das interfaces de comunicação, como também na semântica dos elementos essenciais destes domínios. Porém, devido à diversidade de aplicações destas especificações, a preocupação principal está focada na padronização da estrutura e das interfaces. A padronização de como manter a semântica daquilo que está sendo armazenada fica por conta da integração dos serviços CORBA com sistemas de terminologia já existentes, discutidos no Capítulo 3 . 


\section{$3 \quad$ Sistemas de terminologia}

No Capítulo 2 foram abordados os fundamentos teóricos do middleware CORBA, que pode ser utilizado na integração de sistemas para garantir a interoperabilidade técnica.

Neste capítulo serão abordados os fundamentos teóricos de sistemas de terminologias, com enfoque na interoperabilidade semântica. A Seção 3.1 apresenta uma breve introdução sobre interoperabilidade semântica. A Seção 3.2 descreve o processo de formação de padrões e sua importância. A Seção 3.3 descreve a importância da utilização de sistemas de terminologias, os conceitos fundamentais destes sistemas e exemplifica alguns sistemas de terminologia para a área de saúde.

\subsection{Introdução}

Na Figura 3.1 é apresentada a definição de alguns termos com o objetivo de esclarecer a diferença entre terminologia, vocabulário e nomenclatura.

Objeto: Qualquer parte do mundo perceptível ou concebível.

Nome: Designação de um objeto por uma expressão lingüística.

Conceito: Uma unidade de pensamento constituída através de uma abstração baseada nas propriedades comuns de um conjunto de objetos.

Termo: Designação de um conceito definido em uma linguagem especial por uma expressão lingüística.

Terminologia: Conjunto de termos representando o sistema de conceitos de uma área particular.

Nomenclatura: Sistema de termos elaborado de acordo com regras preestabelecidas.

Dicionário: Coleção estruturada de unidades léxicas, com informação lingüística sobre elas.

Vocabulário: Dicionário contendo a terminologia de uma área.

Figura 3.1: Definição de alguns componentes terminológicos. FONTE: NORMA ISO 1087.

O uso de texto livre para o armazenamento da informação clínica torna difícil a realização de análises pelos sistemas de informação e torna fraco o controle sobre os elementos da informação, 
para que estes possam ser classificados e agregados de forma automatizada [33]. A análise de expressões como "o paciente do 41B tem altos níveis de açúcar", como mostrada na Figura 3.2 , deve ser feita no nível sintático, onde há a verificação da validade da seqüência de palavras tendo o auxílio de um vocabulário e regras (gramática) para a sua construção. A análise no nível semântico procura identificar o significado da expressão, sendo dividida em semântica referencial, com a determinação da referência do objeto principal, e semântica conceitual com determinação do significado da frase que é atribuída ao referente. Considera-se também que o significado associado a semântica conceitual deve levar em consideração o contexto [34].

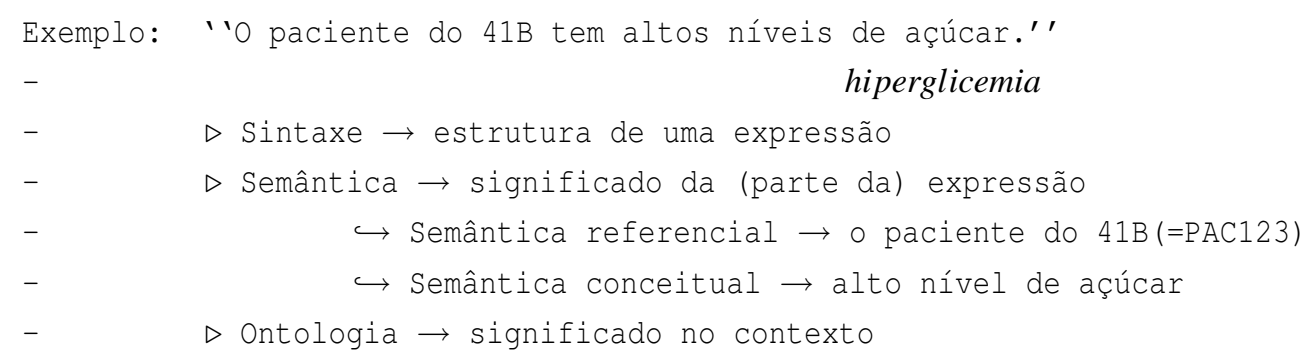

Figura 3.2: Exemplo de análise de expressões de acordo com os níveis lingüísticos.

Portanto, para melhorar a interoperabilidade semântica torna-se necessário o uso de padrões para a representação dos registros clínicos, procurando com isto reduzir a redundância e ambigüidade dos termos associados à informação. Na expressão da Figura 3.2, o termo "altos níveis de açúcar" poderia ser substituído por "hiperglicemia”, dificultando sua recuperação devido à variabilidade de termos representando o mesmo conceito. Além disso, há a conformação dos termos a uma representação, o que possibilita que os desenvolvedores de aplicativos possam trocar informações sem processamento adicional da informação.

\subsection{Padrões}

Padrões são geralmente necessários quando a diversidade excessiva cria ineficiência e falta de efetividade. Um padrão pode ser produzido de quatro modos:

1. Ad hoc: Um grupo de organizações e pessoas interessadas concordam sobre a especificação de um padrão. Estas especificações são informais e são aceitas mutuamente entre os grupos participantes. Um exemplo deste modo de padronização é o padrão DICOM ${ }^{1}($ Digital Imaging and Communications in Medicine ) para imagens médicas [35].

2. De facto: Um único fabricante controla grande parte do mercado tornando o seu produto um padrão de mercado. Um exemplo é o sistema operacional Windows da Microsoft.

\footnotetext{
${ }^{1}$ http://medical.nema.org
} 
3. Exigência governamental: Uma agência governamental cria um padrão e legisla seu uso.

4. Consenso: Um grupo de voluntários representando as partes interessadas trabalham em um processo aberto para criar um padrão. A maioria dos padrões da área de saúde são criados por este método. Um exemplo é o padrão HL7 para a troca de dados clínicos [36].

Os padrões para a área clínica normalmente são criados por consenso com a participação das universidades, indústrias e órgãos governamentais. As indústrias, particularmente, têm interesse no desenvolvimento de padrões com escopo bem definido e reduzido e que tragam retorno nos investimentos em desenvolvimento de sistemas computadorizados para a área de saúde [37].

Na prática clínica, a utilização de padrões para o armazenamento dos termos torna-se importante no caso em que há a necessidade de integração da informação armazenada com outras fontes de dados para aumentar o nível de correlação entre as informações e fornecer suporte para o estudo e pesquisa do significado das relações existentes entre os dados. O uso de terminologias também pode melhorar a eficiência das buscas realizadas por sistemas de recuperação da informação.

Nas próximas seções serão descritos alguns conceitos básicos de terminologias, sua classificação e alguns sistemas padronizados para utilização em sistemas de informação em saúde.

\subsection{Terminologias}

As regras gramaticais e a semântica da troca de informações médicas, utilizando uma linguagem, podem ser padronizadas utilizando um sistema de terminologia. Os sistemas de informação da área de saúde necessitam de um serviço de terminologia para:

1. representar o conhecimento do domínio fornecendo uma ontologia básica;

2. associar os conceitos a outras bases de conhecimento tais como: literatura biomédica, procedimentos médicos e base de dados de fatos;

3. padronizar os nomes para conceitos, atributos e valores na representação do conhecimento médico, na modelagem e no armazenamento dos dados do paciente;

4. garantir a integração das aplicações desenvolvidas pelos diferentes grupos.

Cimino [38] listou propriedades desejáveis a um vocabulário controlado para a área da saúde: 
- Conteúdo: é necessário porque os usuários sempre demandam adição de termos para que o vocabulário tenha ampla cobertura e porque o campo da medicina está sempre se expandindo. É esperado que os vocabulários tenham mais conteúdo, mas a simples adição de termos pode levar a uma explosão combinatória e dificultar o resgate da informação. Uma solução seria enumerar todos os átomos de uma terminologia e combiná-las conforme necessário, permitindo extensibilidade composicional.

- Reconhecimento da redundância: a redundância nos vocabulários existe, principalmente devido à sinonímia, onde duas palavras são mapeadas para o mesmo conceito e, as vezes, esta redundância é necessária para que o profissional tenha conhecimento dos diversos termos de sua área. Porém, os sistemas devem reconhecer esta redundância e formular mecanismos para agrupá-las.

- Orientação a conceito: significa que termos devem corresponder a pelo menos um conceito e não mais que um conceito e que os conceitos não devem corresponder a mais que um termo. Tendo o conceito como unidade de processamento simbólico reduz-se a ambigüidade e redundância dos termos que dificultam a recuperação da informação.

- Poli-hierarquia: é quase uma unanimidade que um vocabulário deve ser hierárquico. Esta característica é útil para a localização e agrupamento de conceitos similares. Por exemplo, se o conceito "célula" estiver ligado ao conceito "unidade anatômica", haverá o entendimento de um significado diferente se este conceito aparecesse abaixo do conceito "fonte de energia". Porém, não há consenso se o vocabulário deve ser poli-hierárquico, ou seja, com um conceito podendo estar ligado a um ou mais conceitos. Mas é razoável, por exemplo, que ambos os conceitos "doença hepática" e "doença renal" devam estar ligados ao conceito "síndrome hepatorrenal”, formando uma poli-hierarquia.

- Múltiplas granularidades: cada usuário do sistema de terminologia o utiliza com um propósito específico em mente. Por isso, o vocabulário deve procurar atender a este espectro de necessidades. Por exemplo, os conceitos associados a diabetes, indo em direção a uma granularidade mais fina, podem ser "Diabetes Mellitus", "Diabetes Mellitus Tipo 2", "Diabetes Mellitus Tipo 2 Insulino Dependente". O conceito mais específico é importante para o endocrinologista, mas pode não ser para outro profissional interessado, por exemplo, em uma estatística mais geral.

- Visões múltiplas consistentes: se um vocabulário pretende atender a diferentes funções, há a necessidade de oferecer diferentes visões para determinadas funções. Por exemplo, se uma aplicação aplicação mostrar o termo ligado a um conceito mais genérico 
como "Diabetes Mellitus", deve haver a possibilidade de se expandir este termo para representação de um conceito mais específico como "Diabetes Mellitus Insulino Dependente" atendendo às diversas funções e mantendo a consistência da representação.

- Definições formais: muitos pesquisadores e desenvolvedores têm manifestado o desejo por sistemas de terminologias com definições formais para expressar os relacionamentos entre os conceitos.

- Rejeitar "Não Classificado em Outra Parte": Como nenhum vocabulário pode garantir completude de domínio, há a tentativa de se incluir um termo que represente toda a informação que não pode ser representada pelos termos existentes. Este termo normalmente aparece nos vocabulários com a frase "Não Classificado em Outra Parte". O problema com estes termos é que eles nunca podem ter uma definição formal diferente de exclusão, porque sua definição pode somente ser baseada no conhecimento dos conceitos restantes do vocabulário. Isto não só é inadequado, mas também como o vocabulário evolui, o significado de "Não Classificado em Outra Parte" mudará de modo súbito. Este "movimento semântico" causará problemas, como interpretação inapropriada de dados históricos.

Partindo do pressuposto de que a proposta de um sistema de terminologia é dar suporte a sistemas de computação clínicos e que devem fornecer conversão para os esquemas de codificação epidemiológicos já existentes, como por exemplo o CID 9/10 e CID 9-CM, e ainda ter tradução na língua de aplicação do sistema, Rector [39] citou algumas dificuldades para a confecção de um sistema de terminologia, dentre elas:

- A escala e multiplicidade de tarefas e usuários a servir é vasta, pois o escopo do conhecimento médico de todas as especialidades é ordens de magnitude maior que a terminologia necessária para relatar a mortalidade ou morbidade ou registrar um diagnóstico simples de uma única especialidade;

- Conflitos entre as necessidades dos usuários e os requisitos rigorosos do software devem ser conciliados;

- As convenções das ontologias clínicas freqüentemente não estão em conformidade com a lógica geral e paradigmas lingüísticos por usarem construções lingüísticas próprias;

- É difícil definir formalismos para representação de conceitos clínicos e utilizá-los como representação do conhecimento clínico; 
- É difícil atingir um nível de consenso clínico a respeito da terminologia proposta;

- A terminologia deve ser coerente com os modelos de mensagens e padrões de registros clínicos;

- As mudanças devem ser gerenciáveis sem corromper os dados já armazenados.

\subsubsection{Codificação}

Os sistemas de codificação ajudam a lidar com a enorme variabilidade das expressões e termos médicos, reduzindo a ambigüidade e relacionando os termos sinônimos.

A codificação da informação médica é uma função básica da maioria dos sistemas clínicos. Padrões para esta codificação podem servir a dois propósitos. Primeiro, eles podem ajudar desenvolvedores de sistemas a economizar tempo ao inventar seu próprio vocabulário. Segundo, usar padrões aceitos pela comunidade da área de trabalho pode facilitar a troca de dados entre sistemas [36].

Alguns requisitos são necessários para que os sistemas de terminologias possam ser usados para habilitar a interoperabilidade. Um deles é a independência da linguagem natural para que sistemas de ampla utilização possam ser utilizados por pessoas de diferentes países, havendo a necessidade de fazer o mapeamento da representação do conceito para a linguagem de utilização.

Para atingir este objetivo normalmente são sistemas utilizados códigos contendo letras e números sem significado especial em qualquer língua. Como exemplo, temos a Figura 3.3 mostrando a representação de um código da Classificação Internacional de Doenças versão 10 (CID 10) em 2 línguas.

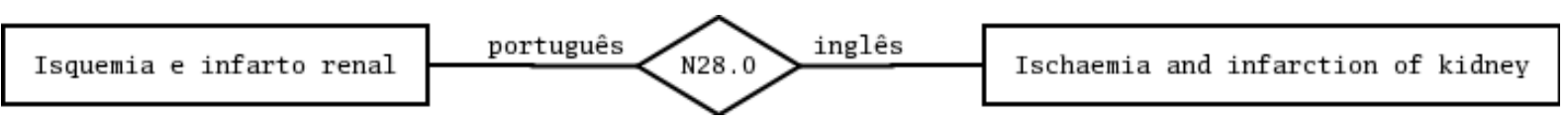

Figura 3.3: Representação do código CID 10 N28.0 nas línguas portuguesa e inglesa.

Os sistemas de terminologia podem ser orientados a conceito ou a classificação estatística. No primeiro a unidade básica é o conceito e são utilizados para armazenar a informação de acordo com a observação realizada. O segundo tem por objetivo gerar estatísticas a partir da extração de elementos essenciais da informação.

A codificação de um sistema pode ser feita independentemente se o sistema é orientado a conceito ou à classificação estatística [40]. 


\subsubsection{Sistemas de terminologia orientados a conceito}

Os sistemas orientados a conceitos são organizados de acordo com o conjunto de características dadas pela definição de um conceito que, por sua vez, é designado por um termo que denota um objeto, ver Figura 3.4. Eles são inerentemente poli-hierárquicos, ou seja, dispõem de mecanismos para a composição de conceitos complexos baseados em conceitos primitivos [40].

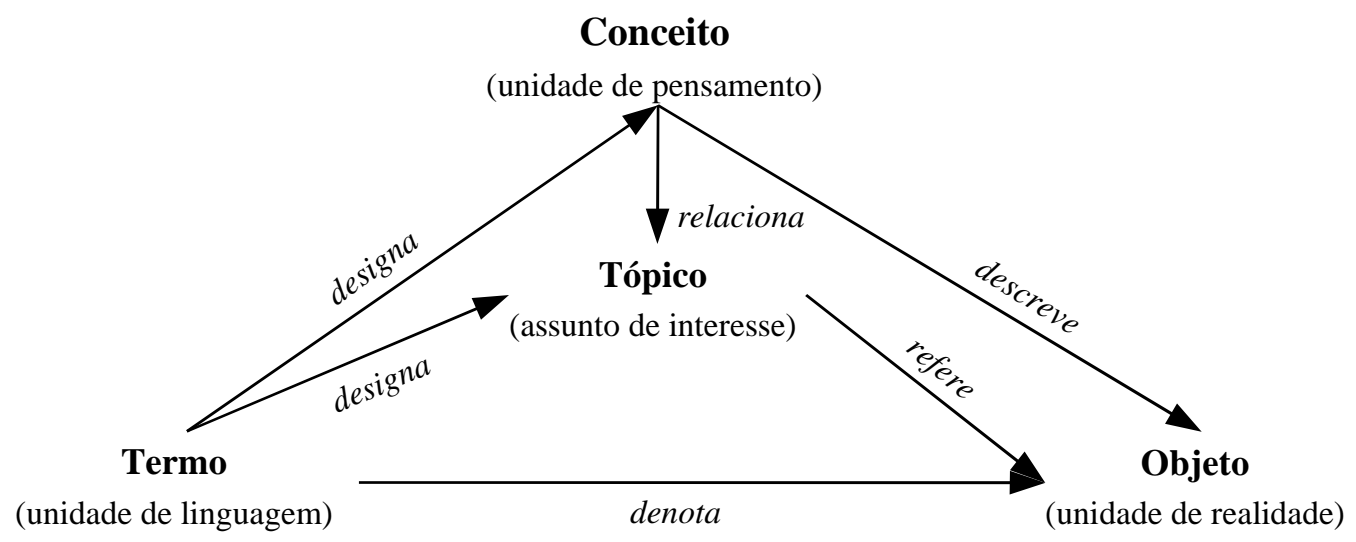

Figura 3.4: Triângulo da semiótica extendido. FONTE: Ingenerf [40].

Os sistemas de terminologia orientados a conceitos não dão suporte a um guia de entrada de dados, eles fornecem auxílio sobre o "que pode ser dito" e não sobre "como deve ser dito" [40].

Os vocabulários atuais estão lidando com a noção de conceito ao invés de termos. Orientação a conceito significa que os termos têm pelo menos um significado e não mais que um significado, e este pode ser representado por diversos termos. Isto permite que o conceito seja representado por somente um termo, tendo os sinônimos e as variações léxicas associados a ele. Com isto a ambigüidade e redundância dos termos armazenados são reduzidas. Estes conceitos devem ser representados por identificadores não semânticos e qualquer conotação semântica como hierarquia não deve estar implícita nestes identificadores e sim como atributo do conceito. Com o vocabulário orientado a conceito é possível então criar hierarquias entre os conceitos, vide exemplo na Figura 3.5. Para que o vocabulário possa ser utilizado com múltiplos propósitos deve-se dispor de múltiplas granularidades. Por exemplo o conceito "Diabetes" pode ser representado por conceitos mais específicos como "Diabetes Mellitus", sendo que o profissional que acessa a informação deve saber qual o nível de granularidade é necessário para transmitir a informação [38].

Para aperfeiçoar os sistemas de conceitos pode ser utilizada uma linguagem formal para o relacionamento entre os conceitos, pois sistemas como MeSH (detalhes na Seção 3.3.2.2) 


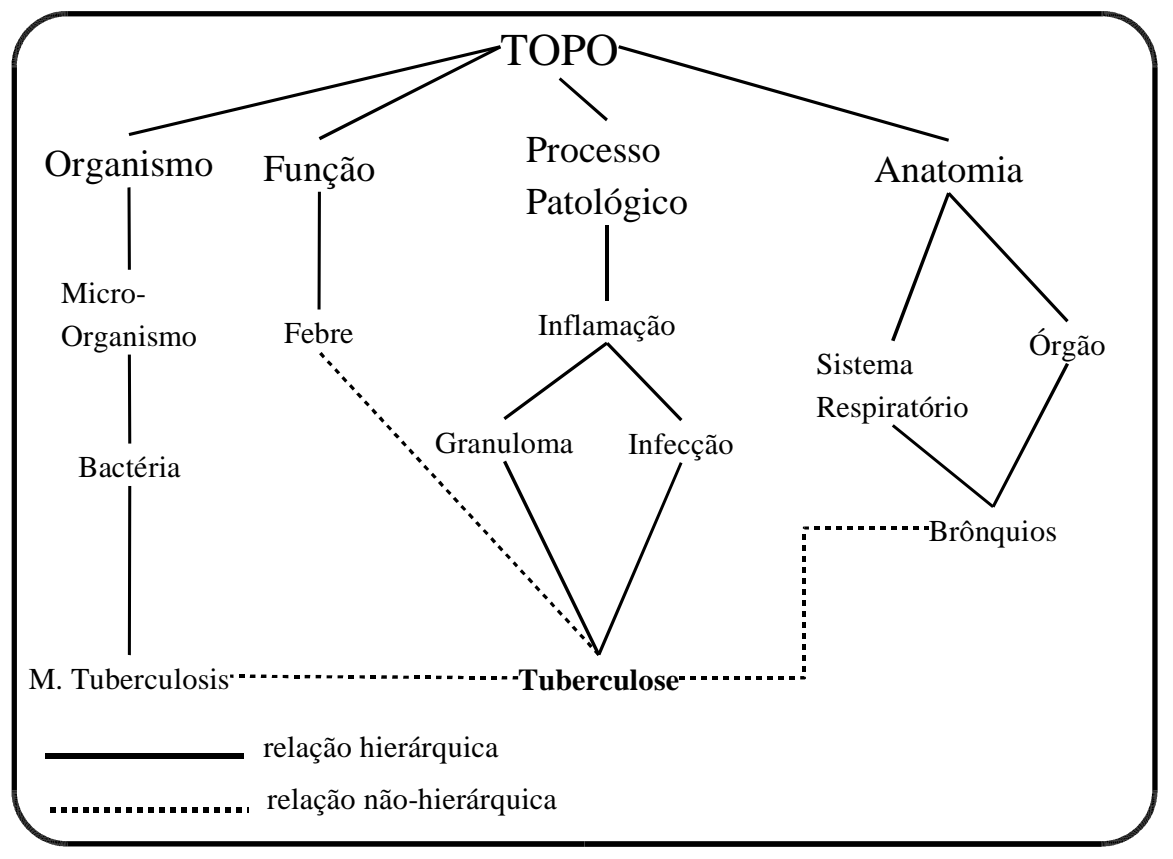

Figura 3.5: Exemplo de hierarquia em um sistema de conceitos. FONTE: Ingenerf [40].

não evitam que composição entre conceitos conflitantes sejam formadas, provocando inconsistências nos conceitos compostos formados. A esta linguagem formal estaria associada uma série de restrições que evitariam a geração de inconsistências, evitando que, por exemplo, o conceito "Diabetes" seja a associado diretamente ao conceito "Osso" de alguma forma.

A utilização de definições formais, ou seja, expressões de relacionamentos entre os conceitos é um forma de fixar os conectores dos conceitos e propiciar computação simbólica [38]. Por exemplo, o conceito "Pneumonia pneumocócica" pode ter uma relação de hierarquia "is a" com o conceito "Pneumonia" e uma ligação "causada por" (“caused by") com o conceito “Streptococcus pneumoniae", veja Figura 3.6 .

Porém, uma grande desvantagem da utilização de um arcabouço formal para a geração de fatos é o aumento da complexidade computacional a medida que há um aumento do número de condições a serem analisadas na junção dos conceitos primitivos através de suas relações. A seguir são descritos alguns sistemas de terminologia orientados a conceito mais utilizados.

\subsubsection{SNOMED}

O SNOMED (Systematized Nomenclature of Human and Veterynary Medicine) é um sistema com mais de 150.000 entradas em 12 diferentes eixos: anatomia (topografia), morfologia (estrutura patológica), funções normais e anormais, sintomas e sinais de doença, química, drogas, enzimas e outras proteínas do corpo, organismos vivos, agentes físicos, relações espaciais, 


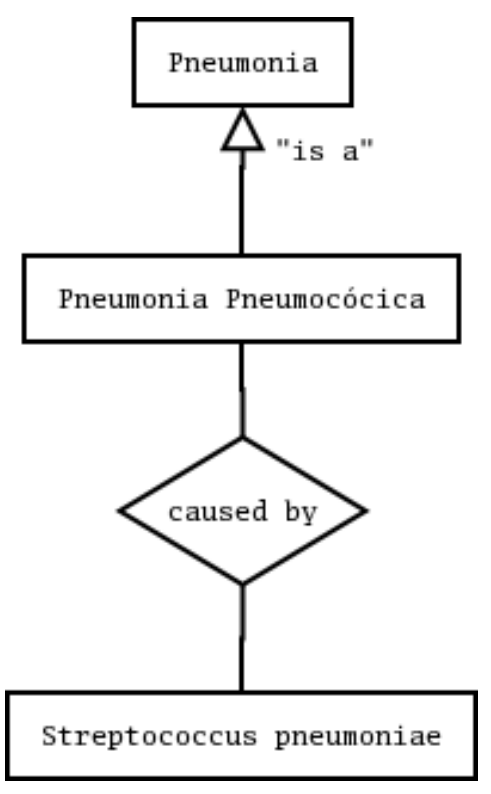

Figura 3.6: Diagrama de um modelo formal para representação do conceito pneumonia e suas relações.

ocupações, contextos sociais, diagnósticos e procedimentos. Dentro do eixo diagnóstico, muitos conceitos têm referência cruzada para outros conceitos permitindo posterior formalização [41].

Usando o sistema SNOMED, um diagnóstico normalmente é representado por códigos dos eixos topográfico, morfológico, organismos vivos e funcional. Se um diagnóstico for bem definido, ele recebe um código próprio. Como exemplo, temos a representação de "Pneumonia pneumocócica" que recebeu o código D-13510, porém, este diagnóstico pode ser representado pela junção dos códigos T-28000 (pulmão), M-40000 (inflamação) e L-25116 (Streptococcus pneumoniae).

O SNOMED passou por diversas alterações com a inclusão de multi-hierarquia e um modelo formal baseado na lógica descritiva na versão chamada de SNOMED-RT (Reference Terminology); e junção com o vocabulário Clinical Terms Version 3 em 1999, na versão chamada de SNOMED-CT (Clinical Terminology) [42].

A junção dos conceitos para formar uma expressão composta pode ser feita obedecendo-se a lógica descritiva com a sintaxe definida na linguagem, estabelecendo uma semântica formal e uma relação bem definida entre os conceitos do SNOMED [43]. Por exemplo, o conceito "Esofagite pós-operatória" seria expresso da seguinte forma [41]:

O código D5-30150 representa o conceito "Esofagite pós-operatória", porém se quiséssemos representá-lo a partir da junção de conceitos primitivos utilizando a semântica formal para es- 
tabelecer a relação entre eles, poderíamos utilizar o conceito mais genérico

- D5-30100 Esofagite

e qualificadores que especializem este conceito, indicando a topologia, morfologia e etiologia do conceito, que seriam

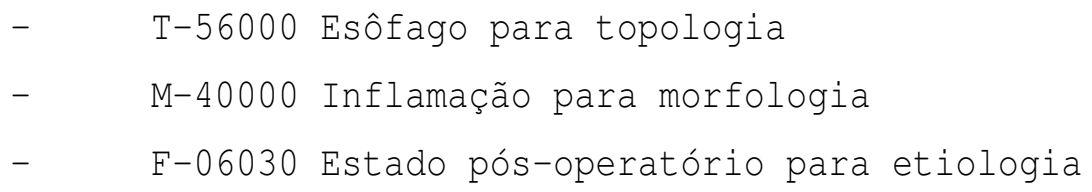

resultando na junção realizada pelo operador \& com a qualificação dos conceitos sendo indicada pelas funções assoc-*, como mostrado a seguir:

D5-30150:

D5-30100\&

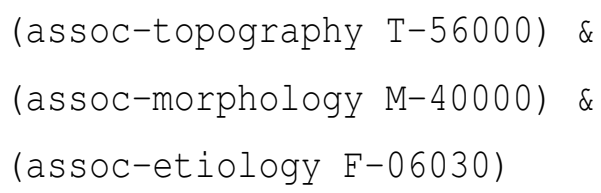

Estas descrições formais podem ser usadas por algoritmos de inferência para determinar a equivalência das diferentes descrições de conceitos, bem como os relacionamentos hierárquicos das descrições. Em outras palavras, elas dão suporte à determinação algorítmica de sinonímia e hierarquia [41].

SNOMED também provê um representação única e consistente de múltiplas hierarquias através de tabelas relacionais (Tabela 3.1) que possuem as seguintes características [41]:

- Representação independente;

- Múltiplas hierarquias por termo;

- Múltiplos tipos de hierarquia (“Is-a”, "Part-Of”,...);

- Muitos níveis de granularidade;

- Suportadas e determinadas pela lógica descritiva.

\subsubsection{MeSH}

O MeSH (Medical Subject Heading) é um sistema de terminologia criado pela Biblioteca Nacional de Medicina dos EUA com o objetivo de fornecer um sistema multi-axial, hierárquico, 


\begin{tabular}{ccc}
\hline Termo pai & Termo filho & relacionamento \\
\hline DD-00000 & DD-20000 & Is-A \\
DD-20000 & DD-22100 & Is-A \\
DD-22100 & DD-22111 & Is-A \\
DD-00000 & D2-80000 & Is-A \\
D2-80000 & D2-80300 & Is-A \\
D2-80300 & DD-22111 & Is-A \\
\hline
\end{tabular}

Tabela 3.1: Representação hierárquica no SNOMED RT. FONTE: Spackman [41].

com 26 categorias compostas de termos principais (main headings), qualificadores e conceitos complementares.

A Figura 3.7 mostra a representação da hierarquia de um conceito e suas especializações no MeSH.

\begin{tabular}{|l|}
\hline Streptococcus [B03.510.400.800.872] \\
Streptococcus agalactiae [B03.510.400.800.872.100] \\
Streptococcus bovis [B03.510.400.800.872.150] \\
Streptococcus equi [B03.510.400.800.872.225] \\
Streptococcus pneumoniae [B03.510.400.800.872.550] \\
Streptococcus pyogenes [B03.510.400.800.872.575] \\
Streptococcus suis [B03.510.400.800.872.750] \\
Viridans Streptococci [B03.510.400.800.872.875]
\end{tabular}

Figura 3.7: Representação do conceito "Streptococcus" e suas especializações.

O diagnóstico "Pneumonia Pneumocócica" pode ser representado pela junção dos códigos mostrados na Tabela 3.2 .

\begin{tabular}{|l|l|l|}
\hline código & conceito & categoria \\
\hline $\mathrm{A} 04.411$ & pulmão & Anatomia \\
\hline $\mathrm{C} 23.550 .470$ & inflamação & Doenças \\
\hline $\mathrm{B} 03.510 .400 .800 .872 .550$ & Streptococcus pneumoniae & Organismos \\
\hline
\end{tabular}

Tabela 3.2: Representação do diagnóstico "Pneumonia Pneumocócica" utilizando o MeSH.

MeSH também é o vocabulário controlado usado para indexar a literatura biomédica armazenada na base de dados bibliográfica do PubMed [44].

\subsubsection{UMLS}

A 'solução universal' em terminologia, ou seja, um sistema que possa ser aplicado a todas as necessidades, é impossível e inadequada [9], pois cada sistema de terminologia é desenvol- 
vido com um propósito específico. Porém, esta limitação pode ser parcialmente resolvida com a utilização do UMLS $2^{2}$ (Unified Medical Language System) que integra a maioria dos vocabulários médicos existentes.

O projeto UMLS é um esforço de pesquisa e desenvolvimento da Biblioteca Nacional de Medicina (NLM - National Library of Medicine) dos EUA que tem por objetivo dar suporte ao desenvolvimento de sistemas amigáveis ao usuário que possam extrair e integrar informações relevantes provenientes de diferentes fontes de dados digitais. Para atingir este objetivo foram desenvolvidas fontes de conhecimento de múltiplas funções projetadas por desenvolvedores de sistemas, tais como: o meta-tesauro (Metathesaurus), a rede semântica (Semantic Network), o mapa das fontes de informação, o léxico SPECIALIST e programas léxicos associados [45].

O componente mais importante do UMLS é o meta-tesauro, que é um repositório de conceitos biomédicos inter-relacionados. No UMLS, o conhecimento é organizado por conceito. Termos sinônimos são agrupados para formar um conceito e conceitos são conectados a outros conceitos através de vários tipos de relacionamentos, resultando em um grafo denso. Relacionamentos entre conceitos são também herdados da estrutura das fontes de vocabulários ou geradas pelos editores do meta-tesauro. Os relacionamentos podem ser hierárquicos ('is a kind of', 'is a', 'part of') ou associativos ('location of', 'caused by') [44]. Na versão 2003AB (julho de 2003), o meta-tesauro possuia 2,5 milhões de nomes para representar 900.551 conceitos e mais de 12 milhões de relações entre estes conceitos.

Na Tabela 3.3 vemos a representação do conceito "Fibrilação Atrial" (Atrial Fibrilation) como conceito único (CUI - Concept Unique Identifier), com seus possíveis sinônimos (LUI Lexical Unique Identifier), variações léxicas (SUI - String Unique Identifier) e o mapeamento deste para os vocabulários como MeSH identificado pelo código MSH.

Além de relacionar os conceitos entre si, o meta-tesauro também relaciona os conceitos com os seus correspondentes nos vocabulários biomédicos controlados, dentre eles, o CID 10, MeSH, SNOMED, Gene Ontology, veja Figura 3.8, possibilitando uma integração do conhecimento gerado pelos diversos domínios.

Cada conceito do meta-tesauro é caracterizado por meio de 135 tipos semânticos de alto nível que representam classes genéricas no topo da hierarquia e fazem parte da Rede Semântica.

O UMLS também armazena todas as variações léxicas provenientes dos vocabulários médicos para um dado termo, incluindo as inflecções, variantes devido a maiúsculas, minúsculas e hífen, e variantes relacionadas à presença de modificadores terminológicos que não afetam o signi-

\footnotetext{
${ }^{2}$ http://www.nlm.nih.gov/research/umls/
} 


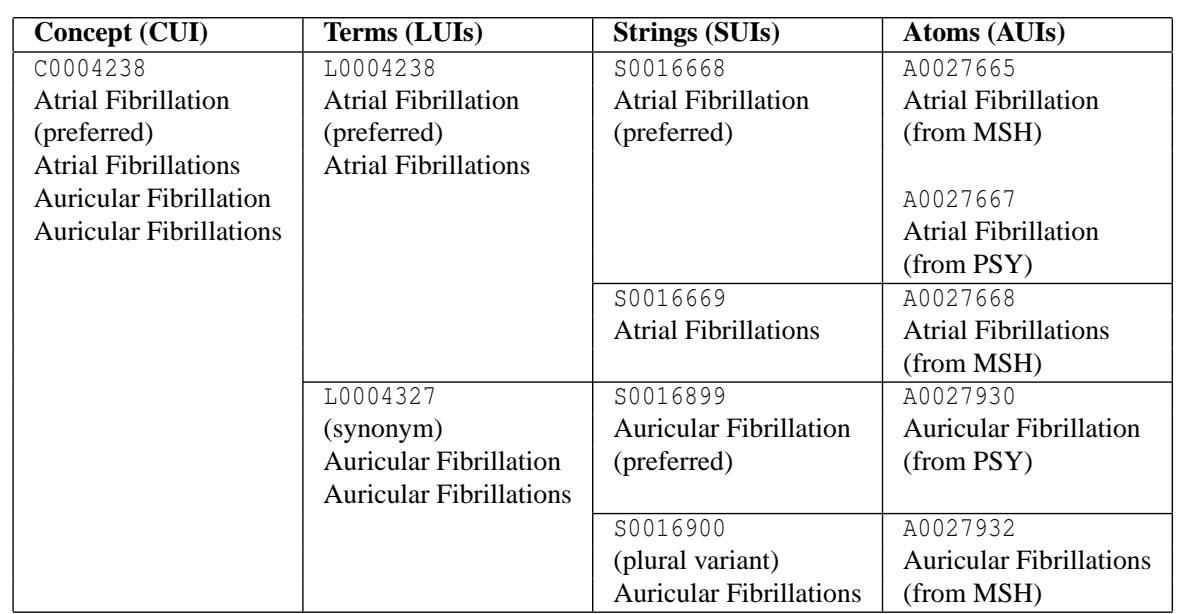

Tabela 3.3: Representações do conceito "Fibrilação Atrial" (Atrial Fibrilation) no meta-tesauro.

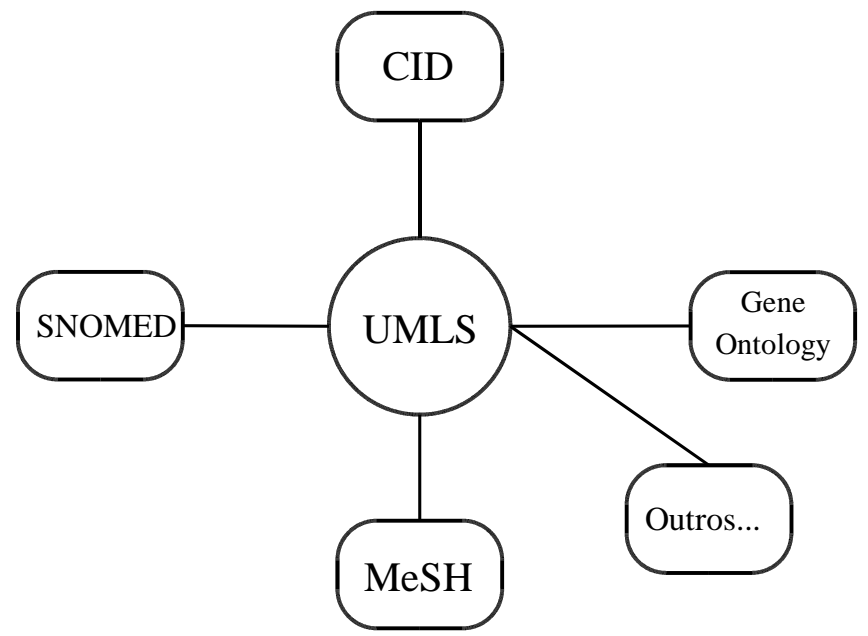

Figura 3.8: Integração do UMLS com outros vocabulários controlados.

ficado [46]. O programa $l v g$, baseado no léxico (lexicon) SPECIALIST e regras heurísticas, permite que os usuários gerem variações léxicas baseadas nas inflecções, por exemplo o plural de um substantivo, bem como realize tarefas úteis para o mapeamento dos termos e recuperação da informação como a remoção de palavras não importantes semanticamente (chamadas stop words) ou retirada de hífen [44].

Utilizando estas fontes, pode-se buscar um conceito de acordo com a sua categoria e navegar independentemente das fontes de vocabulário, possibilitando, por exemplo, associar o código MeSH com a base de dados de citações na literatura do PubMed. É possível também mapear de um sistema de codificação para outro, por exemplo de CID 10 para MeSH, utilizando a tabela 
de sinônimos. Porém, não há um mapeamento um-para-um entre os vocabulários. Em 2001, dos 4.000 conceitos principais do MeSH na categoria 'Doença', apenas 1.200 apresentavam correspondência no CID 10.

Um outro problema com esquemas de codificação multi-axiais é a necessidade de agrupar diversos códigos quando não há um código único para o conceito de interesse. Códigos agrupados são chamados expressões associadas dentro do UMLS e são armazenados numa tabela separada. Em 2001 havia menos de 10.000 expressões associadas baseada no tesauro do MeSH. Mais de $80 \%$ de todos os códigos do CID 10 não tem um identificador único de conceito chamado CUI (Unique Identifier for Concept) comum com o tesauro do MeSH. Estes códigos são representados como uma combinação de códigos MeSH, por exemplo, o código CID 10 N28.0 para 'Isquemia e infarto renal' precisa ser representado pela expressão MeSH 'Infarto AND Rim/Suprimento de Sangue', não sendo possível criar uma expressão sinônima, tornando o mapeamento de CID 10 para MeSH difícil de ser automatizado.

\subsubsection{GALEN}

O projeto GALEN (General Architecture for Languages Encyclopedia and Nomenclatures in Medicine) é conduzido por um consórcio europeu formado por diversas instituições com o objetivo de desenvolver um 'Servidor de Terminologia' para gerenciar sistemas de conceitos compartilhados independentes de linguagem natural para aplicações clínicas [47].

Para lidar com a complexidade da terminologia clínica, GALEN está construindo um modelo semanticamente plausível de terminologia clínica chamado Modelo de Referência Comum GALEN Common Reference Model. Este modelo compreende:

• Conceitos clínicos elementares como "fratura", "osso", “esquerdo" e "úmero";

- Relacionamentos tais como "fraturas podem ocorrer em ossos", que controlam como os conceitos podem ser combinados;

- Conceitos complexos tais como "fratura do úmero esquerdo" compostos de conceitos primitivos [48].

Esta abordagem composicional permite descrições detalhadas dos conceitos, preservando a estrutura existente nos componentes individuais [48].

As regras formais para manipular os conceitos e relacionamentos são especificadas em uma linguagem denominada GRAIL (GALEN Representation and Integration Language). GRAIL é 
implementada como um programa de computador, o módulo de conceitos (Concept Modules) e ferramentas de modelagem associadas. O módulo de conceitos permite que os desenvolvedores de terminologias criem modelos contendo conceitos e relacionamentos e derivem novos conceitos que são composições válidas de outros modelos. GRAIL permite que o sistema utilize os conceitos e relacionamentos para:

- Determinar se uma composição particular é válida;

- Gerar todos os conceitos possíveis baseado em uma composição;

- Automaticamente derivar outros relacionamentos, como classificações hierárquicas, baseados na composição de conceitos [48].

A Listagem 3.1 mostra um exemplo de modelagem de conceitos e relacionamentos para descrever uma observação clínica utilizando a linguagem GRAIL. As palavras que começam com letras maiúsculas são os conceitos e as que começam com minúsculas são os relacionamentos com exceção da palavra which que é o conector.

Listagem 3.1: Exemplo de utilização da linguagem GRAIL

\begin{tabular}{|c|c|c|}
\hline 1 & ( Tumour & which $<$ \\
\hline 2 & & hasTemperature (Temperature which $<$ \\
\hline 3 & & has AbsoluteState hot \\
\hline 4 & & hasTrendInState increasing $>$ ) \\
\hline 5 & & hasTexture (Texture which has AbsoluteState smooth) \\
\hline 6 & & hasMass (Mass which hasQuantity ( Quantity which $<$ \\
\hline 7 & & has Magnitude 100 \\
\hline 8 & & hasUnit gram $>$ )) \\
\hline 9 & $>)$ & \\
\hline
\end{tabular}

Na Listagem 3.1, o modelo define a descrição de um tumor com alta temperatura e com tendência de elevação, com textura lisa e massa de 100 gramas. Apesar da linguagem GRAIL ser especificada para a língua inglesa, há a possibilidade do mapeamento da representação dos conceitos e relacionamentos para outras línguas.

\subsubsection{Sistemas de terminologias orientados a classificação estatística}

Os sistemas orientados a classificação estatística provêm classes onde os casos de interesse devem ser atribuídos. Os vocabulários usados para geração de estatísticas, entre eles o CID, 
têm pouca expressividade e conteúdo, enquanto que aqueles sistemas de conceitos, dentre eles o SNOMED, possuem maior expressidade e conteúdo [40].

\subsubsection{CID}

O Catálogo Internacional de Doenças (CID) foi criado em 1900 pela Organização Mundial da Saúde (OMS) para formatar padrões de "causa mortis" para serem colocados em atestados de óbito. O CID é um catálogo uni-axial, hierárquico e hoje é utilizado para classificar dados de morbi-mortalidade com propósito estatístico e indexar arquivos hospitalares por doença e procedimentos.

A Figura 3.9 mostra parte do CID em sua versão 10, com os códigos e a doença associada.

N28.0 Isquemia e infarto renal
N28.1 Cisto do rim, adquirido
N28.8 Outros transtornos especificados do rim e do ureter
N28.9 Transtorno não especificado do rim e do ureter
N29.0* Sífilis tardia renal (A52.7+)
N29.1*Outros transtornos do rim e do ureter em doenças infecciosas
$\quad$ e parasitárias classificadas em outra parte
N29.8* Outros transtornos do rim e do ureter em outras
$\quad$ doenças classificadas em outra parte
N30.0 Cistite aguda
N30.1 Cistite intersticial (crônica)
N30.2 Outras cistites crônicas
N30.3 Trigonite
N30.4 Cistite por radiação
N30.8 Outras cistites
N30.9 Cistite, não especificada
N31.0 Bexiga neuropática não-inibida não classificada em outra parte
N31.1 Bexiga neuropática reflexa não classificada em outra parte
N31.2 Bexiga neuropática flácida não classificada em outra parte
N31.8 Outra disfunção neuromuscular da bexiga
N31.9 Disfunção neuromuscular não especificada da bexiga

Figura 3.9: Códigos e doenças associadas do CID 10.

Como o CID foi criado com o propósito de notificação e geração de estatísticas de "causa mortis" possui pouca expressividade para descrições clínicas e relatórios de diagnóstico. O CID foi criado antes mesmo da invenção do computador para ser gravado em papel, não sendo adequado para armazenamento em formato digital. Além disso, ele combina previamente os conceitos levando a uma explosão combinatória dificultando o resgate da informação, como mostrado na Tabela 3.4, onde as possibilidades de combinação de conceitos associados a queimadura podem levar a 76.800 combinações diferentes de classificações [39]. 


\begin{tabular}{|c|c|c|c|c|c|c|}
\hline & tipo & local & espessura & extensão & tempo & infecção \\
\hline possibilidades & $\begin{array}{c}2 \\
\text { (química e } \\
\text { térmica) }\end{array}$ & 200 & $\begin{array}{c}4 \\
\text { (3 tipos+ } \\
\text { não especificado) }\end{array}$ & $\begin{array}{c}4 \\
(3 \text { tipos+) } \\
\text { não especificado) }\end{array}$ & $\begin{array}{c}4 \\
\text { (3 níveis de tempo+ } \\
\text { não especificado) }\end{array}$ & $\begin{array}{c}3 \\
\text { (sim, não, } \\
\text { não especificado) }\end{array}$ \\
\hline combinações & 2 & 400 & 1.600 & 6.400 & 25.600 & 76.800 \\
\hline
\end{tabular}

Tabela 3.4: Explosão combinatória das possíveis combinações da descrição de queimaduras. FONTE: Rector [39].

\subsection{Considerações finais}

Os sistemas de terminologias padronizados são vários, sendo que cada um tem foco de atuação diferente com relação ao outro, apesar de possuírem áreas de atuação em comum, o CID 10, por exemplo, está mais voltado para a geração de estatística, .

Na tentativa de integração com ambientes computacionais, este sistemas tendem a adotar um rigidez maior na representação das relações entre os conceitos, o que as vezes pode tornar difícil a sua aplicação. O GALEN, por exemplo, possui um modelo formal bem definido, como descrito na Seção 3.3.2.4. Isto facilita a aplicação de algoritmos e regras para a extração automatizada da relação entre os conceitos, melhorando a eficiência das buscas. Porém, há uma dificuldade muito grande em planejar uma interface de entrada dos dados obedecendo estas regras sem que haja um desconforto por parte do profissional de saúde que se vê restrito em termos de expressão das observações clínicas.

Ainda há muita pesquisa a ser realizada para integração de uma estrutura de dados para a área de saúde e os sistemas, de modo, que haja uma utilização mais expressiva dos recursos computacionais e que o profissional de saúde se sinta confortável com a interface planejada para a inserção dos dados.

Porém atualmente a utilização de sistemas de terminologias para armazenamento dos conceitos já fornece benefícios em relação às soluções add hoc. Dentre eles, a redução da ambigüidade e redundância dos termos armazenados, facilitando a interoperabilidade entre sistemas distintos devido à padronização da relação das palavras com seus conceitos. 


\section{Arquitetura e implementação}

Neste Capítulo será descrita, na Seção 4.1, a arquitetura proposta neste trabalho com enfoque na facilitação da interoperabilidade técnica e semântica, enquanto que a Seção 4.2 descreve a implementação de referência da arquitetura proposta. Os Capítulos 2 e 3 formaram a base teórica necessária para o entendimento da implementação de referência.

\subsection{Arquitetura}

A Figura 4.1 mostra a arquitetura proposta para um sistema de informação em saúde com o objetivo de proporcionar alta interoperabilidade técnica e semântica. A arquitetura é composta pelos seguintes módulos:

- Identificação;

- Observações Clínicas;

- Terminologia;

- Segurança;

- Middleware;

- Cliente.

O módulo de Identificação lida somente com dados que estão relacionados à identificação de pessoas e não com dados específicos de um domínio, como por exemplo, dados clínicos ou financeiros. Ele deve permitir que uma ampla gama de atributos possa ser armazenada, com suporte a extensibilidade, para adaptar-se a atributos específicos que não estejam definidos no momento da especificação do módulo.

O módulo de Terminologia deve oferecer acesso aos termos (conceitos) de um determinado domínio e de domínios relacionados com o objetivo de fornecer interoperabilidade semântica 


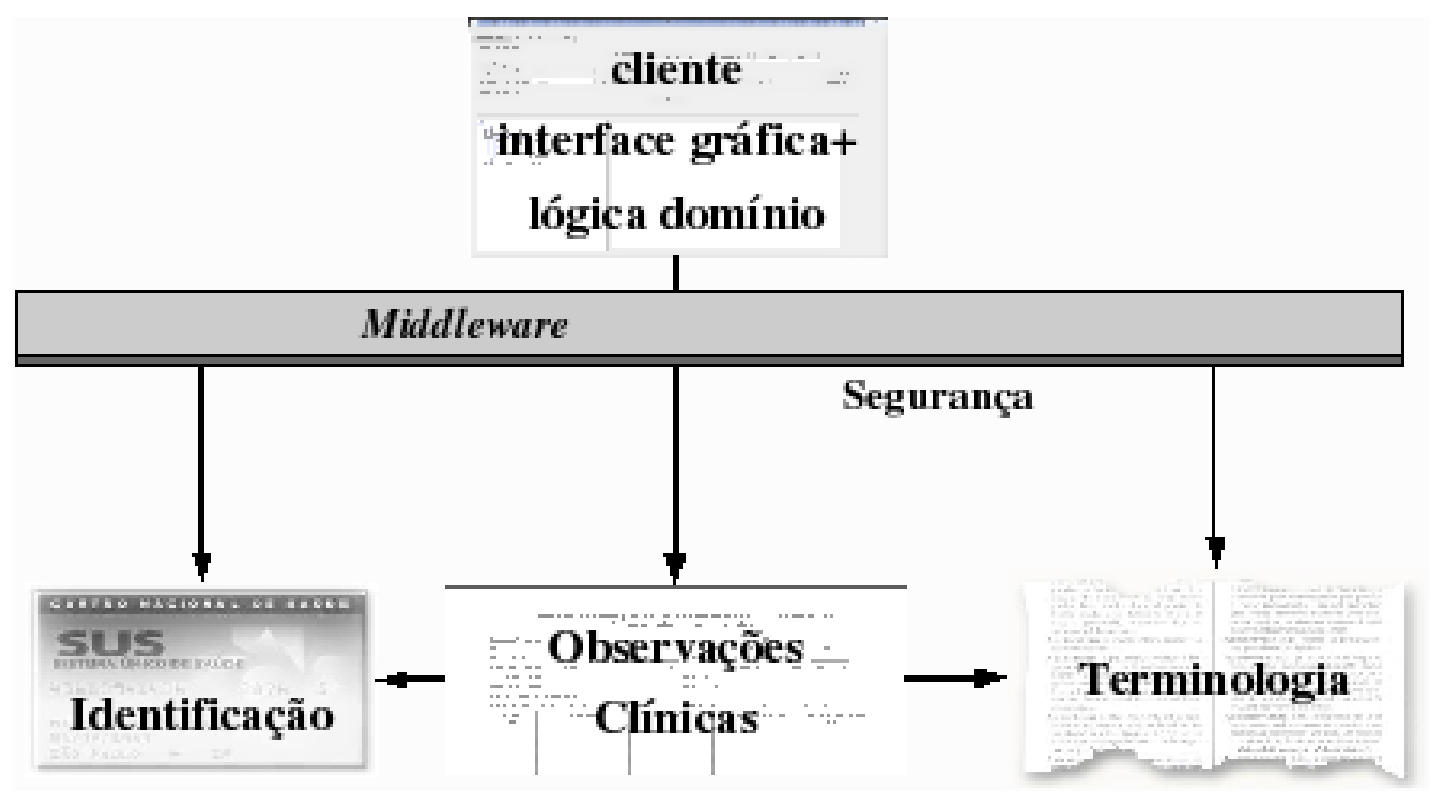

Figura 4.1: Arquitetura do sistema.

com a padronização dos termos e seus relacionamentos. Este modulo deve dar suporte aos sistemas de terminologias existentes, sejam eles utilizados para fins estatísticos ou orientados a conceito, bem como permitir o gerenciamento de conceitos atômicos, compostos e modelos formais de relacionamentos entre os conceitos. O módulo de Terminologia fornece a padronização dos termos com os quais as observações ficarão associadas. Quanto maior a utilização deste módulo para representação da informação, maior será a interoperabilidade semântica, pois qualquer componente que requisita as observações, pode utilizar o módulo de Terminologia para obter informação do significado do conteúdo das observações.

O módulo de Observações Clínicas deve fornecer acesso às informações relacionadas estritamente à área de saúde tais como: exames clínicos, impressões do profissional de saúde, imagens, dentre outras. Ele fica acoplado ao módulo de Identificação para associação da identidade dos pacientes às observações.

O Middleware deve garantir a interoperabilidade técnica, ficando entre os módulos e a camada de rede, garantindo a execução dos serviços requisitados com qualidade e segurança. Detalhes relacionados aos domínios horizontais, como protocolo de rede utilizado, desempacotamento e transmissão de dados e técnica de requisição e execução de operações remotas devem estar ocultos aos desenvolvedores dos módulos. Eles devem se preocupar somente com a lógica do domínio e detalhes de segurança e qualidade de serviço (QoS - Quality of Service).

A camada de Segurança deve fornecer os serviços de autenticação, autorização, criptografia e armazenamento de eventos importantes para futura auditoria. Este serviços fornecem restrições no acesso às informações clínicas, garantindo um nível de segurança necessário de- 
vido às características destas informações.

O Cliente utiliza o Middleware para acessar as informações armazenadas nos módulo de Identificação e Observações Clínicas para visualizar as informações requisitadas e o módulo de Terminologia para entender o seu significado. O Cliente deve ter a autorização para acessar as informações gerenciadas por estes módulos. O Cliente também pode acessar informações armazenadas em Sistemas Legados desde tenham sido implementados adaptadores que realizam a comunicação entre o Middleware e estes sistemas.

\subsection{Implementação}

A Figura 4.2 mostra os componentes utilizados para a implementação da arquitetura proposta.

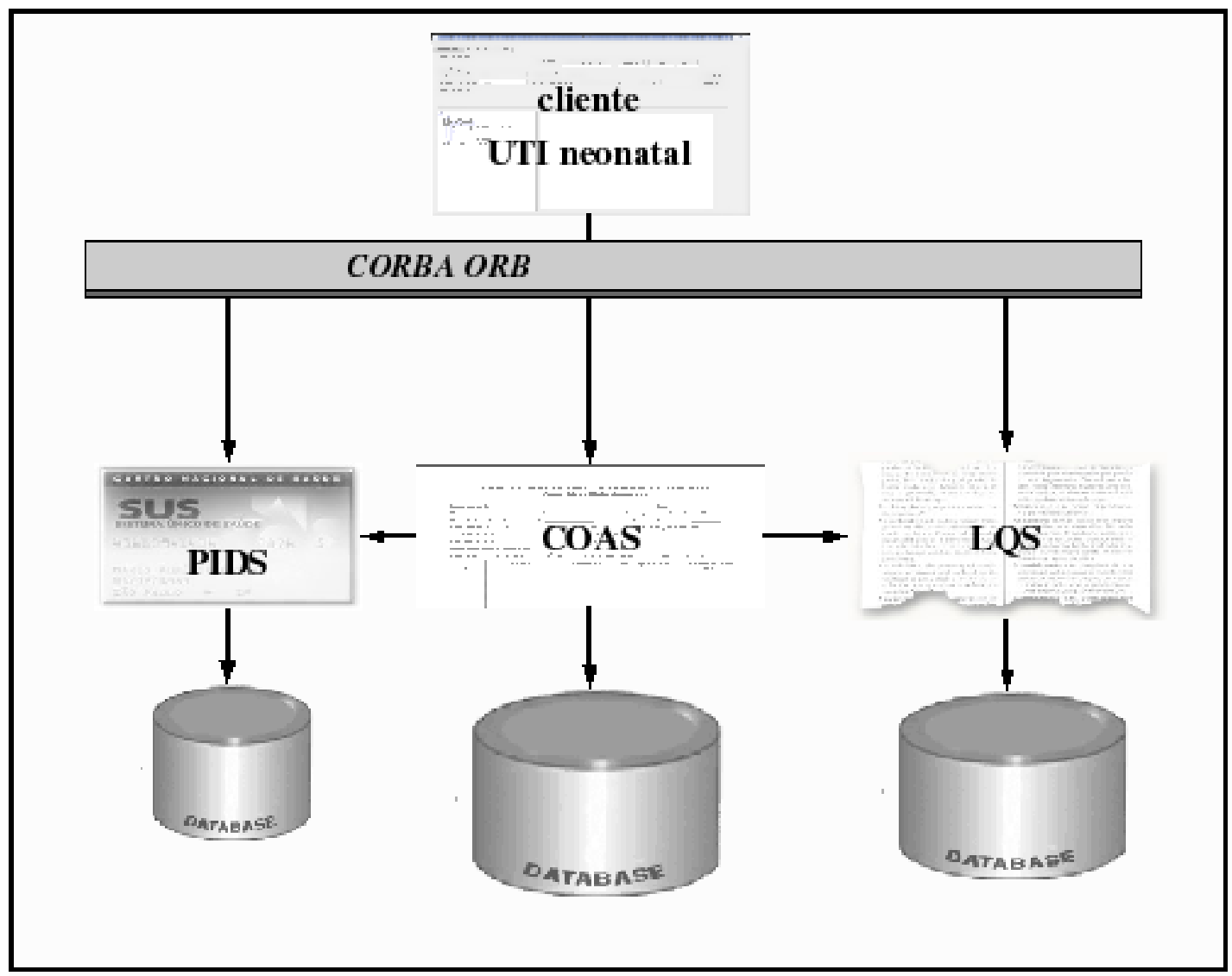

Figura 4.2: Componentes da implementação da arquitetura proposta.

A camada de segurança e a especificação de controle de acesso não foram implementadas pelo fato do foco da tese estar em reforçar o conceito de interoperabilidade. Apesar do aspecto segurança ser importante, o escopo da tese teve que estar limitado para que sua execução fosse 
possível. O serviço de acesso às imagens clínicas (CIAS) também não foi implementado, pois as imagens foram armazenadas no COAS.

Todos os serviços utilizam um sistema gerenciador de banco de dados para recuperação e armazenamento das informações. Para o teste do acesso ao banco de dados foram utilizados os sistemas gerenciadores MySQL4 1 e PostgreSQL7 2 .

Cada componente da arquitetura foi agrupado em um módulo específico mostrado no diagrama de pacotes da Figura 4.3. O pacote neucis implementa a interface gráfica e lógica do domínio de uma UTI Neonatal. Os pacotes pids, coas e lqs implementam as especificações PIDS, COAS e LQS, respectivamente. Todos os pacotes foram implementados usando a linguagem de programação Java e utilizando padrões de projeto permitidos pela linguagem [49] para propiciar a reutilização e formar um vocabulário comum de comunicação da estrutura do código. Eles podem ser utilizados de maneira separada, respeitando os relacionamentos de dependência. O usuário pode, por exemplo, utilizar a interface gráfica de identificação de pacientes, com os pacotes pids e tools, se acaso não desejar utilizar os sistema para armazenar as observações clínicas (COAS).

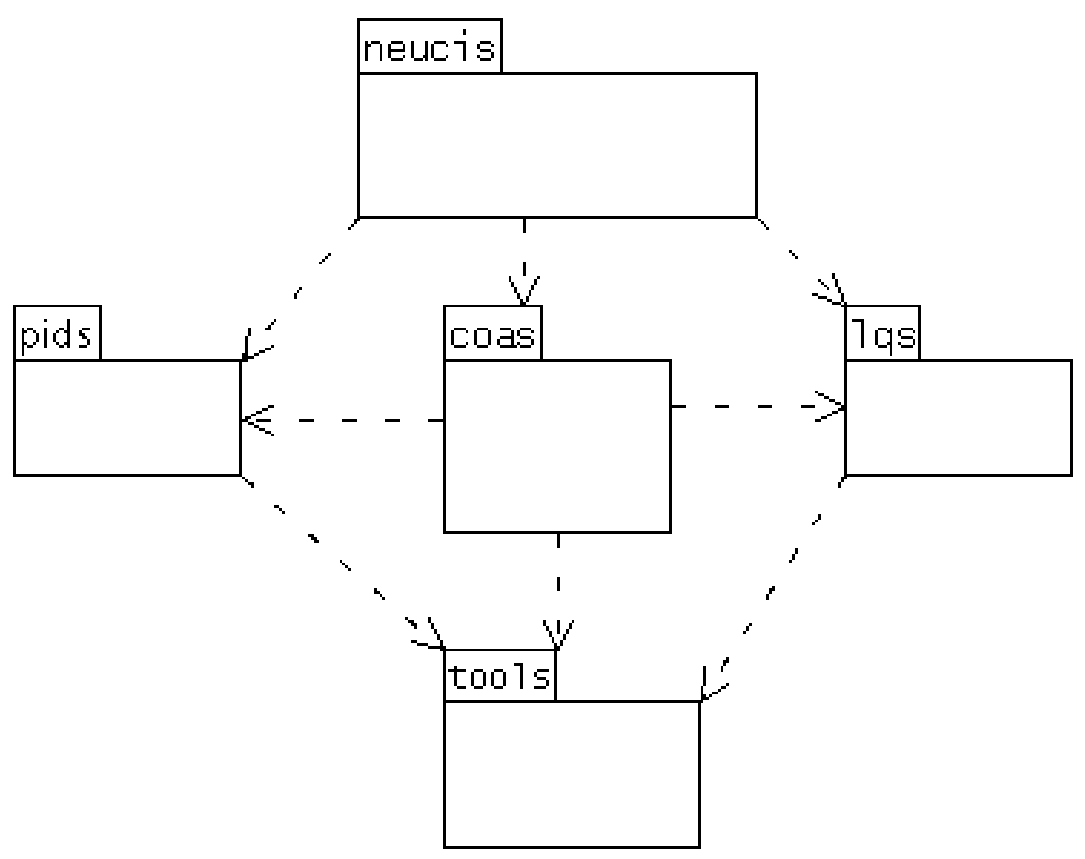

Figura 4.3: Diagrama de pacotes do sistema

\footnotetext{
${ }^{1}$ http://www.mysql.com

${ }^{2} \mathrm{http} / / / \mathrm{www} \cdot$ postgresql.org
} 


\subsubsection{Middleware}

Para fazer o papel do Middleware foi utilizada a arquitetura CORBA, por possuir um modelo de objetos bem definido (OMA - Seção 2.1.1), possibilitar o mapeamento de seus tipos para diversas linguagens de programação e possuir diversas implementações eficientes e estáveis de ORBs para diversas linguagens e plataformas, bem como diversas implementações dos serviços CORBA. Com estas características, a interoperabilidade técnica é facilitada, abrangendo uma grande variedade de hardware e software que podem ser utilizados para integração. Os diversos componentes de serviços já implementados fazem com que o desenvolvedor se preocupe somente com o domínio da aplicação.

Para testar a comunicação com o middleware foram utilizados os ORBs provenientes das distribuições Orbacust $4^{3}$ e OpenORB ${ }^{4}$ v. 1.3, compatíveis com as especificações CORBA 2.5 e 2.4.2, respectivamente. A princípio, qualquer ORB implementado obedecendo a especificação CORBA pode ser utilizado como middleware dos serviços implementados, necessitando apenas de mudanças dos parâmetros de configuração descritos na Seção 4.2.3.1.

\subsubsection{Serviços de domínio}

Os skeletons necessários para a implementação das interfaces dos serviços PIDS, COAS e LQS foram gerados a partir da compilação das IDLs obtidas em [19].

A Listagem 4.1 mostra um fragmento de IDL da especificação a partir da qual são gerados os skeletons para a implementação da interface. A interface ProfileAccess herda a interface IdentificationComponent. A operação get_traits_known () recebe como argumento o tipo PersonId, que representa a identificação da pessoa a ser procurada, e retorna um conjunto (TraitNameSeq - linha 3) contendo os atributo disponíveis para aquela identificação. Os atributos podem ser o nome, endereço, data de nascimento ou quaisquer identificadores especificados no PIDS. Se o identificador for inválido, uma exceção deverá ser lançada (InvalidId linha 4).

\footnotetext{
${ }^{3}$ http://www.orbacus.com

${ }^{4}$ http://openorb.sourceforge.net
} 
Listagem 4.1: Fragmento da definição da interface Profi leAcces s obtido a partir da especificação do PIDS.

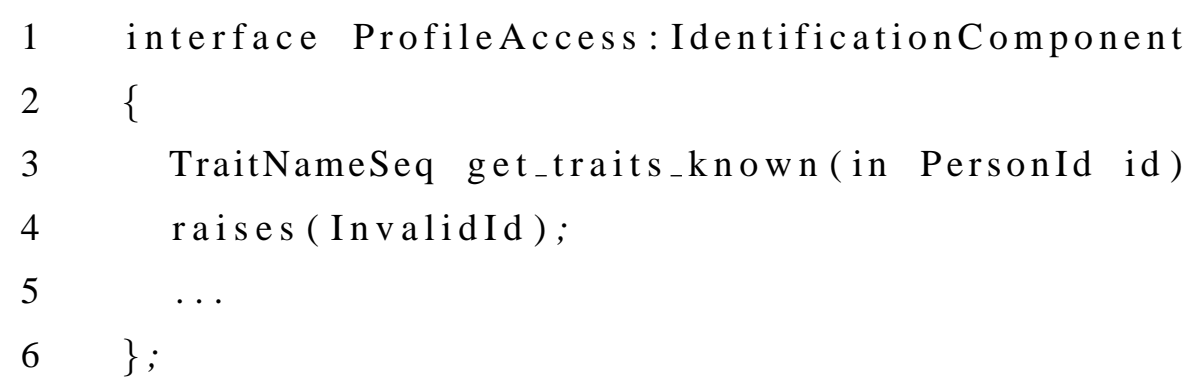

A Listagem 4.2 mostra como realizar a implementação da interface ProfileAccess após a compilação da IDL. A implementação (ProfileAccess Impl) deve estender a classe ProfileAccesSPOA que é gerada a partir da IDL e atua como uma ponte entre a implementação e o adaptador de objetos (POA - Seção 2.1.4). O atributo parent (linha 2) é a forma de forçar a herança de IdentificationComponent. O tipo TraitNameSeq foi mapeado para um vetor de String (linha 6) que é retornado pelo método get_traits_known () (linha 4) que, por sua vez, recebe como argumento uma String (mapeada do tipo PersonId). Se o identificador (atributo id - linha 4) for inválido, será lançada uma exceção (InvaliId - linha5).

Listagem 4.2: Fragmento da implementação da interface ProfileAccess utilizando a linguagem Java.

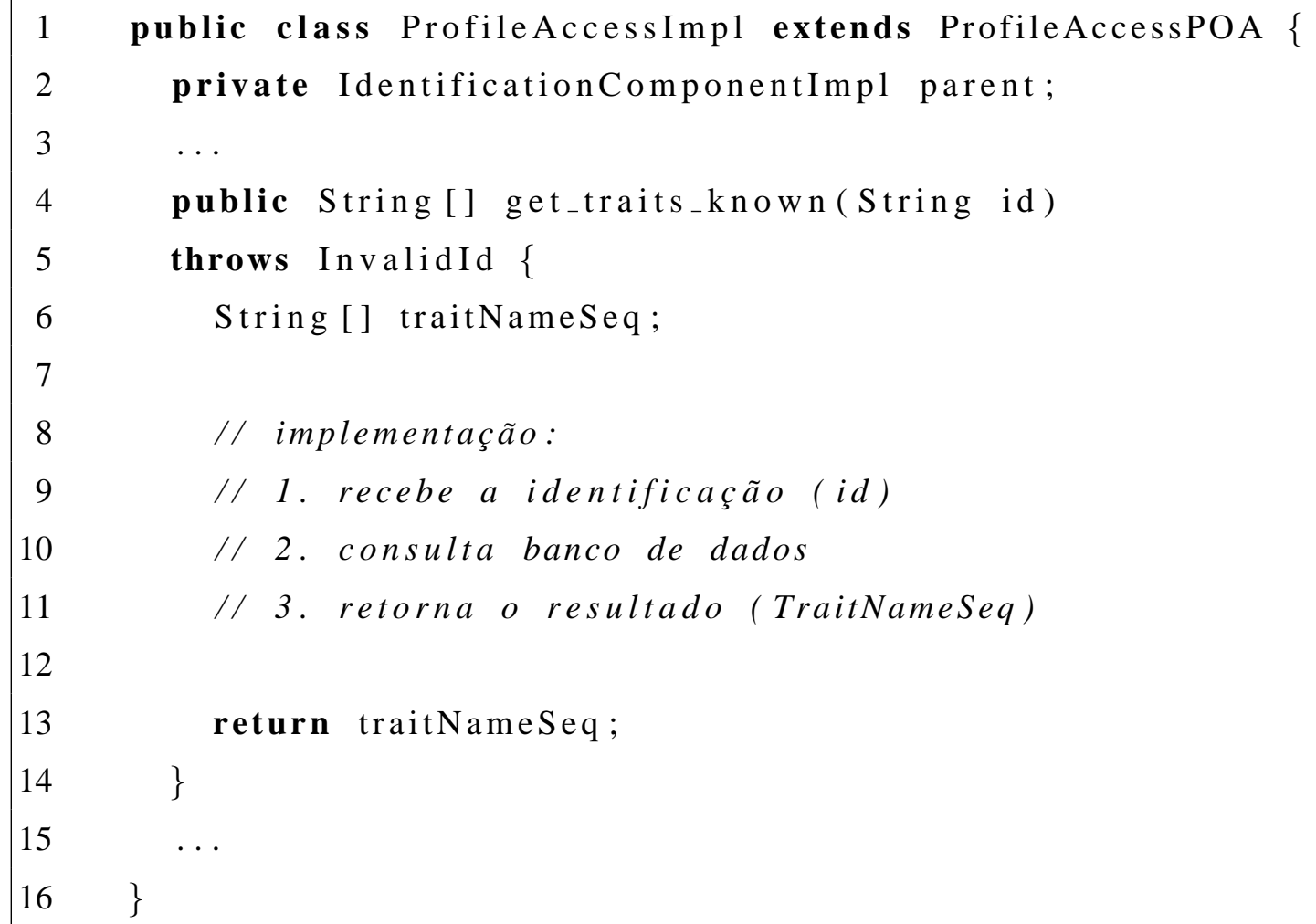


Para invocar o método get_traits_known(), o cliente deve gerar os stubs a partir da compilação da IDL da especificação PIDS, obter uma referência para a interface ProfileAccess, conectar-se ao seu ORB e executar o método.

O objeto que irá fornecer acesso às suas operações deve ser instanciado pelo adaptador de objetos, inscrever uma referência sua no ORB e esta referência deve ser transmitida para o cliente como um arquivo ou, através de uma consulta pelo nome do objeto servidor no serviço de nomes, se houver este serviço.

\subsubsection{Serviço de Identificação de Pacientes}

A Figura 4.4 mostra o diagrama de classes das interfaces implementadas do PIDS contidas no pacote pids. Estas interfaces são descritas a seguir:

- IdentificationComponent: ponto de acesso às interfaces descritas abaixo;

- IdentifyPerson: define funcionalidades para consulta de registros com valores especificados e seus respectivos pesos;

- CandidateIterator: iterador que agrupa o resultado de uma pesquisa, permitindo que parte do resultado fique armazenado no servidor, sendo entregue ao cliente quando requisitado;

- IdMgr: oferece funcionalidades para o gerenciamento de registros;

- ProfileAccess: fornece informações básicas sobre a identidade das pessoas;

- IdentityAccess: fornece acesso individual aos registros;

- Identity: encapsula um registro e seus atributos.

As interfaces funcionais herdam os atributos e operações de IdentificationComponent, sendo que há referência para estas interfaces em IdentificationComponent.

As implementações das interfaces funcionais utilizam uma referência a uma conexão JDBC que utiliza classe utilitária DBManager, descrita na Seção 4.2.3). Usando esta conexão, a manipulação dos dados do paciente é feita utilizando consultas SQL ao banco de dados.

\subsubsection{Serviço de Acesso às Observações Clínicas}

O pacote coas implementa as seguintes interfaces da especificação COAS-HDTF [30] (Figura 4.5): 


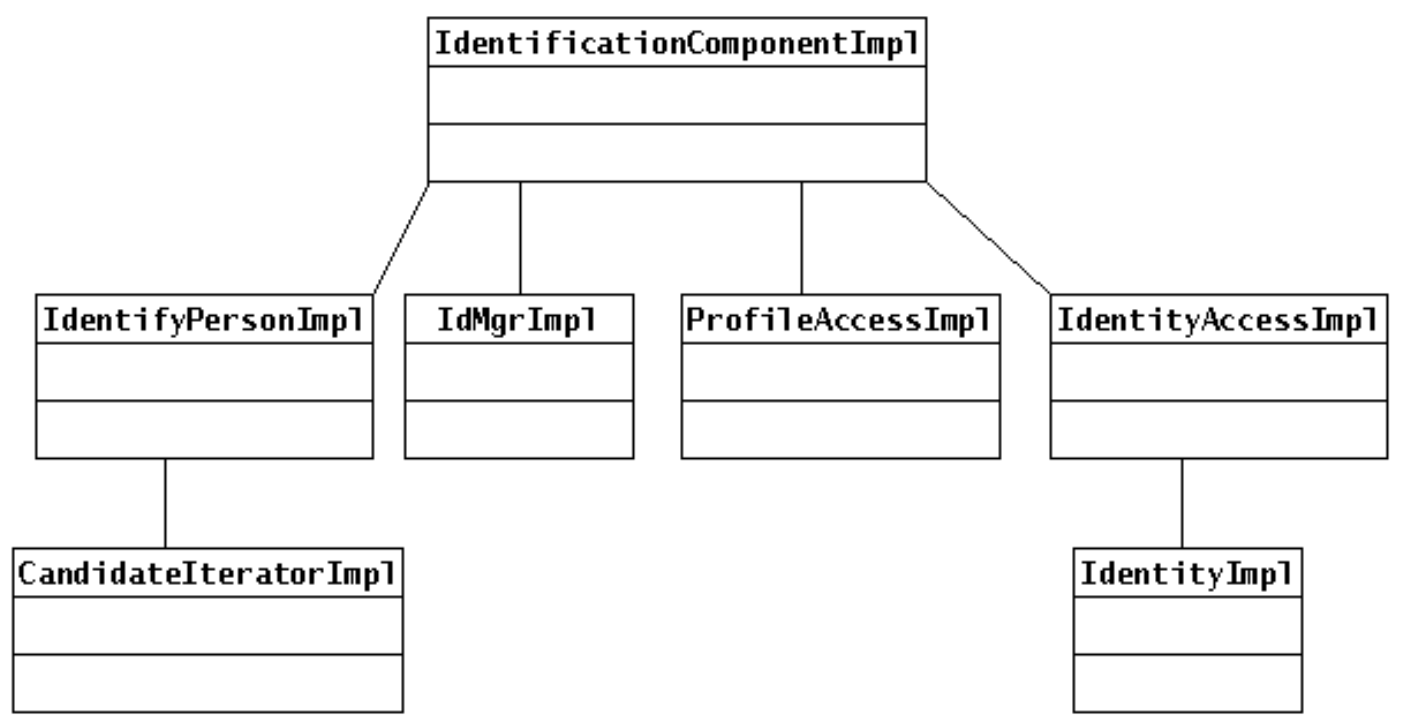

Figura 4.4: Interfaces de gerenciamento implementadas do padrão PIDS.

- AccessComponent: ponto de acesso às interfaces implementadas;

- QueryAccess: interface de consulta que retorna uma estrutura enviada do servidor para o cliente contendo as observações;

- BrowseAccess: interface de consulta que retorna uma referência ao objeto CORBA (ObservationRemote) que representa as observações no servidor;

- ObservationLoader: carrega as observações no servidor.

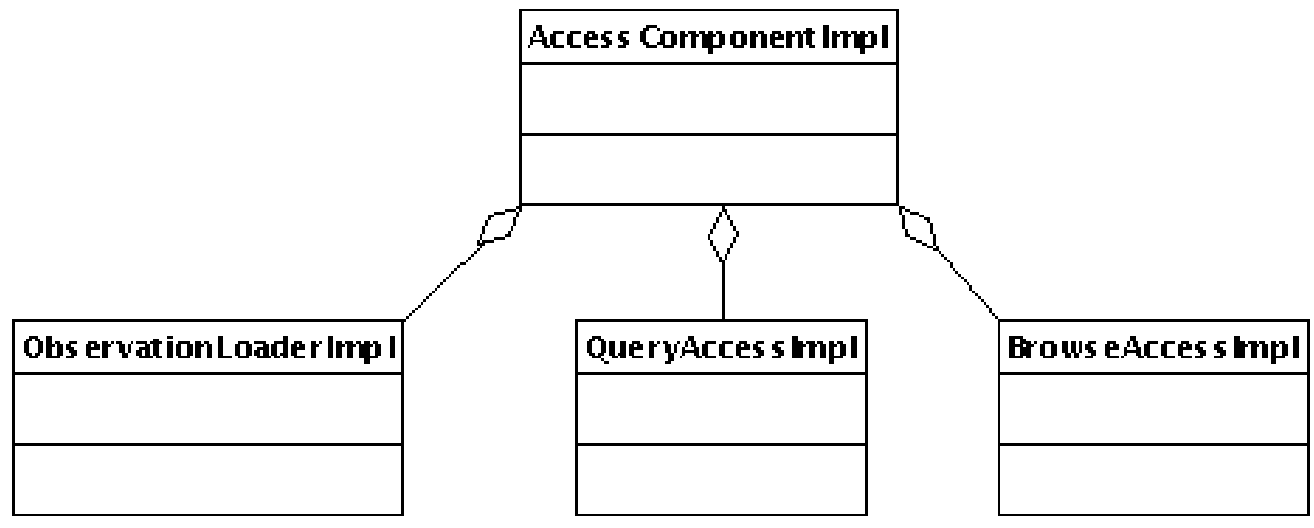

Figura 4.5: Interfaces de acesso implementadas do padrão COAS.

As interfaces que representam as observações remotas, mostradas Figura 4.6, também foram implementadas e são descritas a seguir:

- ObservationRemote: é o tipo que contem uma referência remota as observações; 
- AtomicobservationRemote: contem uma referência remota para observação com um único valor;

- CompositeobservationRemote: contem uma referência remota para observação composta.

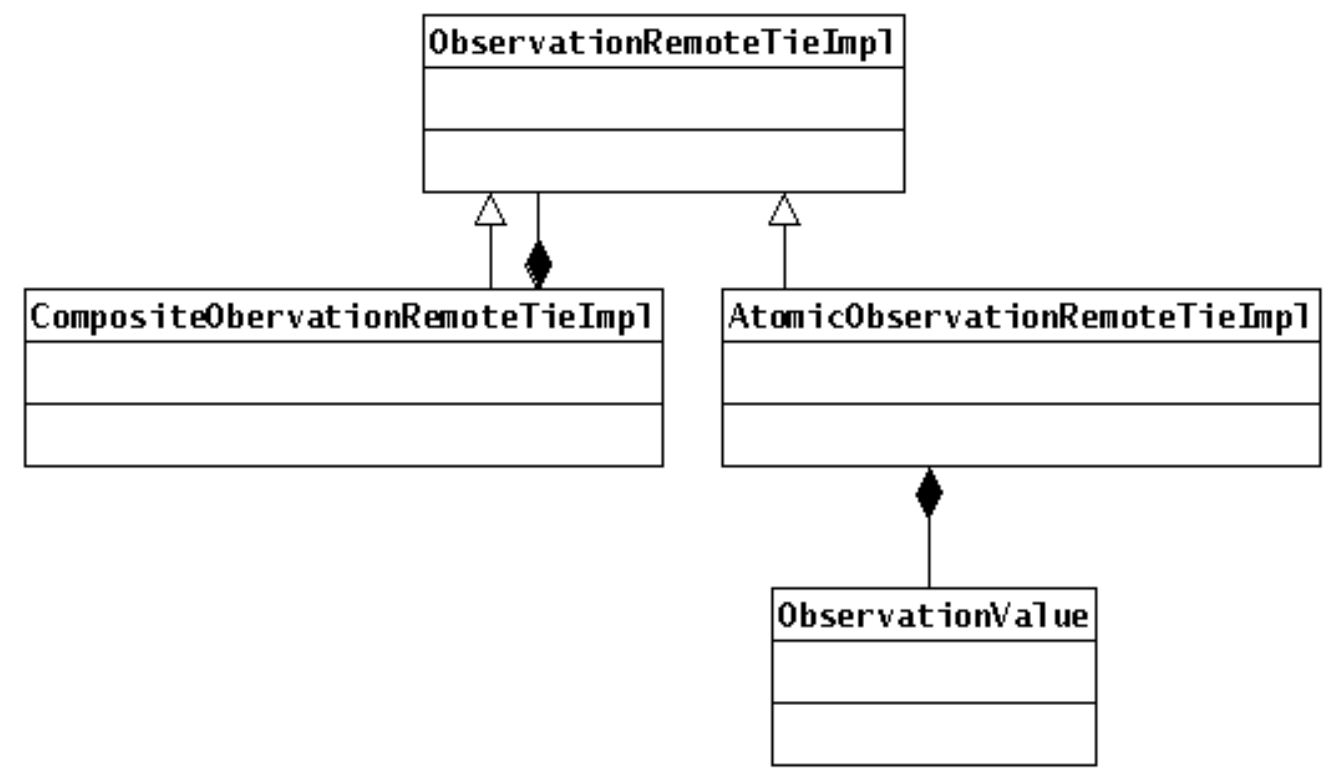

Figura 4.6: Interfaces para acesso remoto às observações.

Os valores das observações clínicas, que foram definidos como tipo ObservationValue são mostrados na Figura 4.7 e permitem armazenar os seguintes tipos de dados:

- Texto (PlainText) - tipo de dados que representa as observações armazenadas como texto livre.

- Elementos codificados (CodedElement) - permite armazenar códigos de algum sistema de codificação e que tenham representação única;

- Multimídia (Multimedia) - é o tipo de dados associado a elementos multimídia, tais como imagem, áudio, texto, vídeo, dentre outros;

- Proporção (Measurement: : Ratio) - tipo de dados que representa proporção;

- Numérico (Measurement : : Numeric) - tipo de dados que representa observações numéricas como, por exemplo, resultados de exames laboratoriais;

- Faixa de valores (Measurement: : Range) - tipo de dados que representa faixa de valores. 


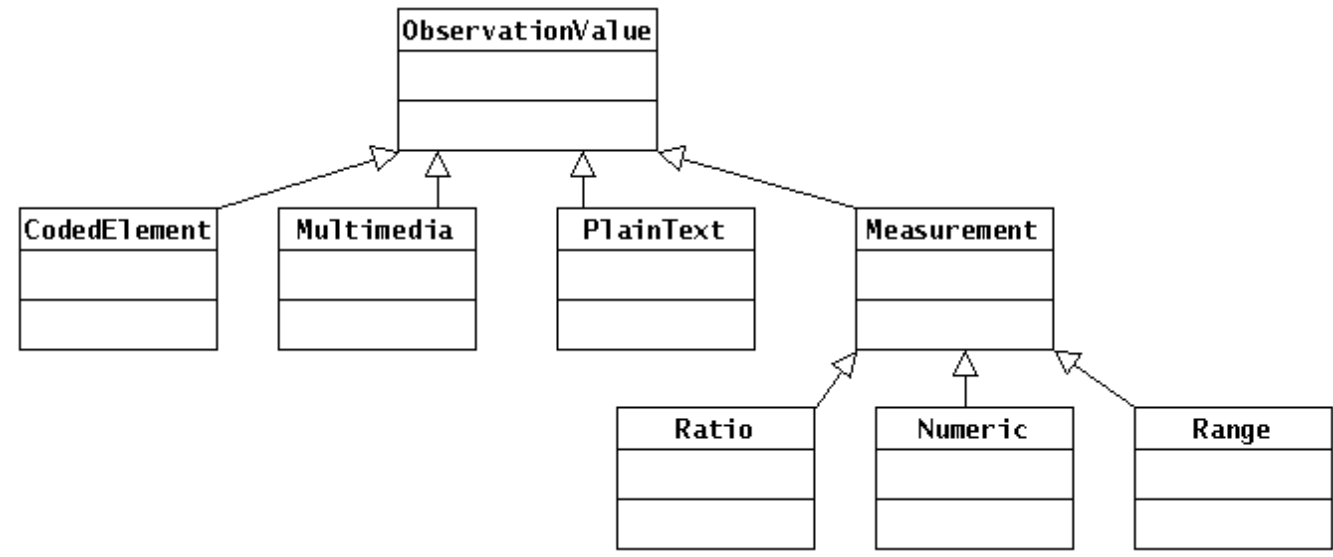

Figura 4.7: Tipo de dados utilizados para representar as observações.

Para acessar as observações clínicas armazenadas no banco de dados as classes de acesso utilizam o mapeador objeto/relacional ObjectBridge $5^{5}$ que utiliza a interface JDBC ${ }^{6}$ (Java Database Connectivity) para comunicar-se com o banco de dados relacional e realizar a persistência dos objetos Java.

\subsubsection{Serviço de Consulta Léxica}

O pacote lqs implementa a interface LexExplorer, da especificação LQS-HDTF, que provê um subconjunto dos serviços de terminologia permitindo o mapeamento dos códigos armazenados para os conceitos.

A Listagem 4.3 mostra um fragmento da IDL da especificação do LQS. Utilizando a operação get_preferred_text () da interface LexExplorer e fornecendo como argumento um código (QualifiedCode - linha 3) e o contexto (UsageContextId - linha 4), a operação retorna o texto associado ou retorna duas exceções, UnknwnCodingScheme e UnknownCode; se o sistema de codificação não existir no sistema e se o código não existir, respectivamente.

Listagem 4.3: Fragmento da definição da interface LexExplorer obtido a partir da especificação do LQS.

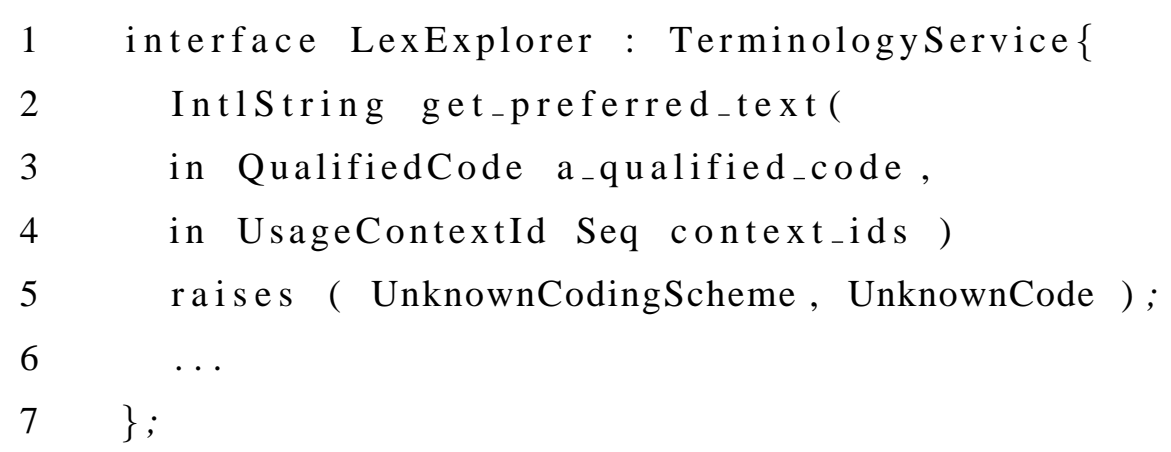

${ }^{5}$ http://db.apache.org/ojb

${ }^{6}$ http://java.sun.com/products/jdbc/ 


\subsubsection{Ferramentas comuns - tools}

A Figura 4.8 mostra o pacote tools que fornece alguns frameworks necessários às implementações das especificações HDTF. Os frameworks fornecem implementações de gerenciamento de banco de dados, gerenciamento de serviços CORBA e algumas utilidades. Os frameworks devem ser configurados de acordo com o ambiente de implantação do sistema, do sistema gerenciador banco de dados e do ORB utilizados.

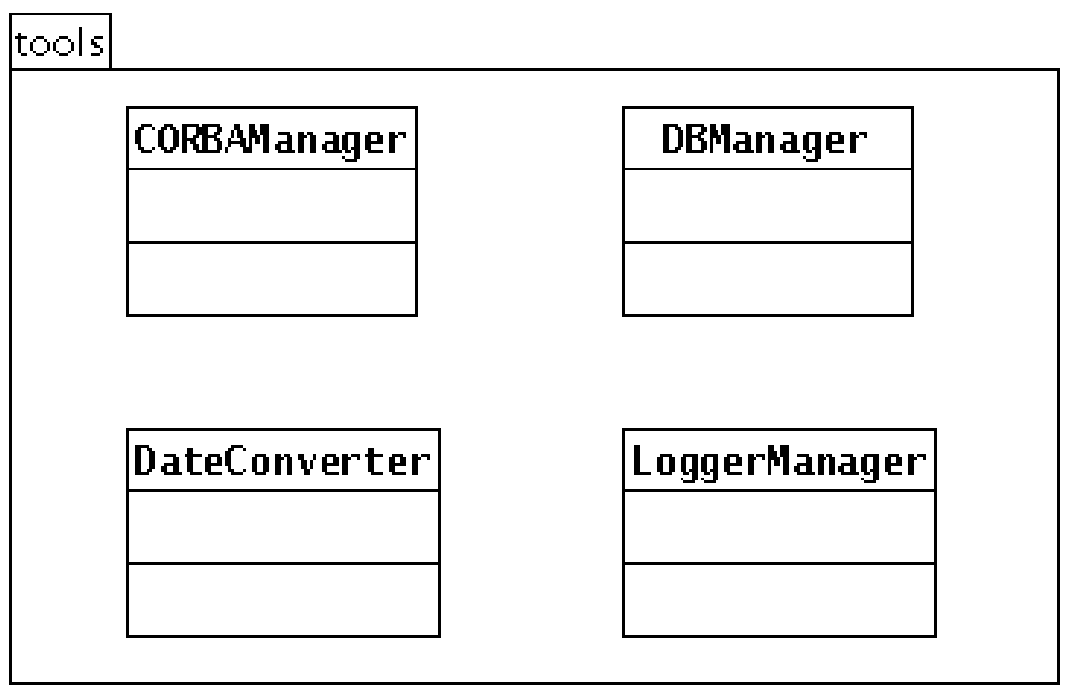

Figura 4.8: Diagrama de classes do pacote tools.

No pacote tools estão os utilitários comuns a todos os módulos e que permitem uniformizar os serviços relacionados a CORBA, ao sistema gerenciador banco de dados e a outros utilitários tais como o que manipula datas.

\subsubsection{CORBA}

O subpacote CORBA contém a classe CORBAManager (Figura 4.9 que fornece um ponto único de acesso utilizando o padrão de projeto Singleton [49, 50]. O padrão Singleton permite que somente uma instância do objeto seja criada, assim qualquer instanciação do objeto por outro receberá uma referência ao mesmo objeto. A classe CORBAManager é responsável pelo gerenciamento dos serviços relacionados ao middleware CORBA. Quando instanciada ela pode inicializar o ORB e retornar uma referência. CORBAManager também pode inicializar e fornecer uma referência ao adaptador de objetos raiz (RootPOA), a partir do qual podem ser criados outros adaptadores (POAs) com políticas modificadas pelo usuário. CORBAManager também possui um método para a criação de objetos do tipo CORBA Any, utilizado para encapsular qualquer tipo CORBA. 


\begin{tabular}{|c|}
\hline \multicolumn{1}{|c|}{\begin{tabular}{c|} 
«Singleton» \\
CORBAManager
\end{tabular}} \\
\hline \\
\hline +getInstance():CORBAManager \\
+get_orb():org.omg.CORBA.ORB \\
+getRootPOA ():org.omg. PortableServer.POA \\
+createAny ():org.omg.CORBA.Any
\end{tabular}

Figura 4.9: Diagrama de classes: CORBAManager.

Um arquivo que é carregado quando CORBAManager é instanciado contêm os seguintes parâmetros de configuração:

- org.omg. CORBA. ORBClass: atributo que contém o nome da classe de implementação do ORB;

- org. omg . CORBA. ORBSinglet onclass: atributo que contém o nome da classe de implementação do Singleton $O R B$ que somente como uma fábrica de TypeCode, que são estruturas de dados utilizadas para carregar descrições de tipos de dados em tempo de execução [17, 15].

\subsubsection{Banco de dados}

O subpacote db contém a classe DBManager, mostrada no diagrama da Figura 4.10 que fornece um ponto único de acesso a conexões de banco de dados para os diferentes módulos.

\begin{tabular}{|c|}
\hline $\begin{array}{c}\text { «Singleton } \\
\text { DBManager }\end{array}$ \\
\hline \\
\hline +getInstance():DBManager \\
+getConnection():java.sq7.Connection
\end{tabular}

Figura 4.10: Diagrama de classes: DBManager.

DBManager é utilizado principalmente pelas implementações PIDS e LQS, que realizam consultas SQL no banco de dados. Os parâmetros a serem passados para o servidor de banco de dados ficam armazenados em um arquivo de configuração.

\subsubsection{Utilitários}

O subpacote util (Figura 4.11) fornece utilitários para conversão de datas do tipo CORBA Timestamp, para o tipo Java Timestamp(DateConverter) e para acesso ao gerenciador de registro de eventos importantes do sistema $(\log s)$ chamado de LoggerManager. O tipo CORBA 
Timestamp é proveniente da especificação do COAS, sendo mapeado para uma cadeia de caracteres na linguagem de Java (String) e tem o seguinte formato:

AAAA-MM-DDThh:mm:ss.dddDZT (Exemplo: 2003-09-26T10:52:33.000+03:00)

onde:

AAAA = 4 dígitos do ano (mínimo-1582, maximo-9999)

$\mathrm{MM}=2$ dígitos do mês

$\mathrm{DD}=2$ dígitos do dia do mês (01 até 31$)$

$\mathrm{T}=$ separador de data e hora

$\mathrm{hh}=2$ dígitos da hora (00 até 23 )

$\mathrm{mm}=2$ dígitos do minuto (00 até 59)

ss $=2$ dígitos do segundo ( 00 até 60; 60 indica um salto positivo de segundo)

ddd = um ou mais dígitos para a fração decimal de um segundo (não há limites no número de dígitos)

DZT = designador da zona de tempo (Z para indicar UTC, hora universal coordenada, ou +hh:mm ou +hh:mm de UTC)

\begin{tabular}{|c|}
\hline \multicolumn{1}{|c|}{ DateConverter } \\
\hline \\
\hline +comert(time:String): java.uti.Date \\
+comert(time:java.uti 1. Date):String \\
\hline
\end{tabular}

\begin{tabular}{|c|}
\hline $\begin{array}{l}<<\text { Singleton }>> \\
\text { Loggerlanager }\end{array}$ \\
\hline $\begin{array}{l}\text { +getInstance( ):LoggerManager } \\
\text { +getLogger(c1assName:String): org. apache. } 1 \text { og4j. Logger }\end{array}$ \\
\hline
\end{tabular}

Figura 4.11: Diagrama de classes: utilitários.

LoggerManager é uma classe implementada utilizando o padrão de projeto Singleton que fornece um ponto único de acesso às suas instâncias. Isto permite que a configuração para todos os objetos que utilizam este gerenciador seja a mesma e que as saídas de log fiquem armazenadas em um único arquivo. Os parâmetros de LoggerManager ficam armazenadas em um arquivo de configuração, sendo que os principais atributos são:

- Local da saída do log;

- Nome e tamanho máximo do arquivo de saída; 
- Formato do log;

- Nível de prioridade para envio de mensagens (DEBUG, INFO, WARN, ERROR, FATAL).

\subsubsection{Cliente}

No pacote neucis está a interface gráfica e lógica de domínio (Cliente), que fornecem acesso aos serviços PIDS, COAS e LQS. A análise e modelagem deste cliente foi feita utilizando os requisitos de uma UTI neonatal.

\subsubsection{Identificação}

A Figura 4.12 mostra a tela do Cliente para a busca do perfil da pessoa (paciente), no caso, um bebê registrado no hospital, cujo perfil pode ser recuperado pelo seu número de registro local, ou pelo número de registro local da mãe ou somente pelo nome da mãe.

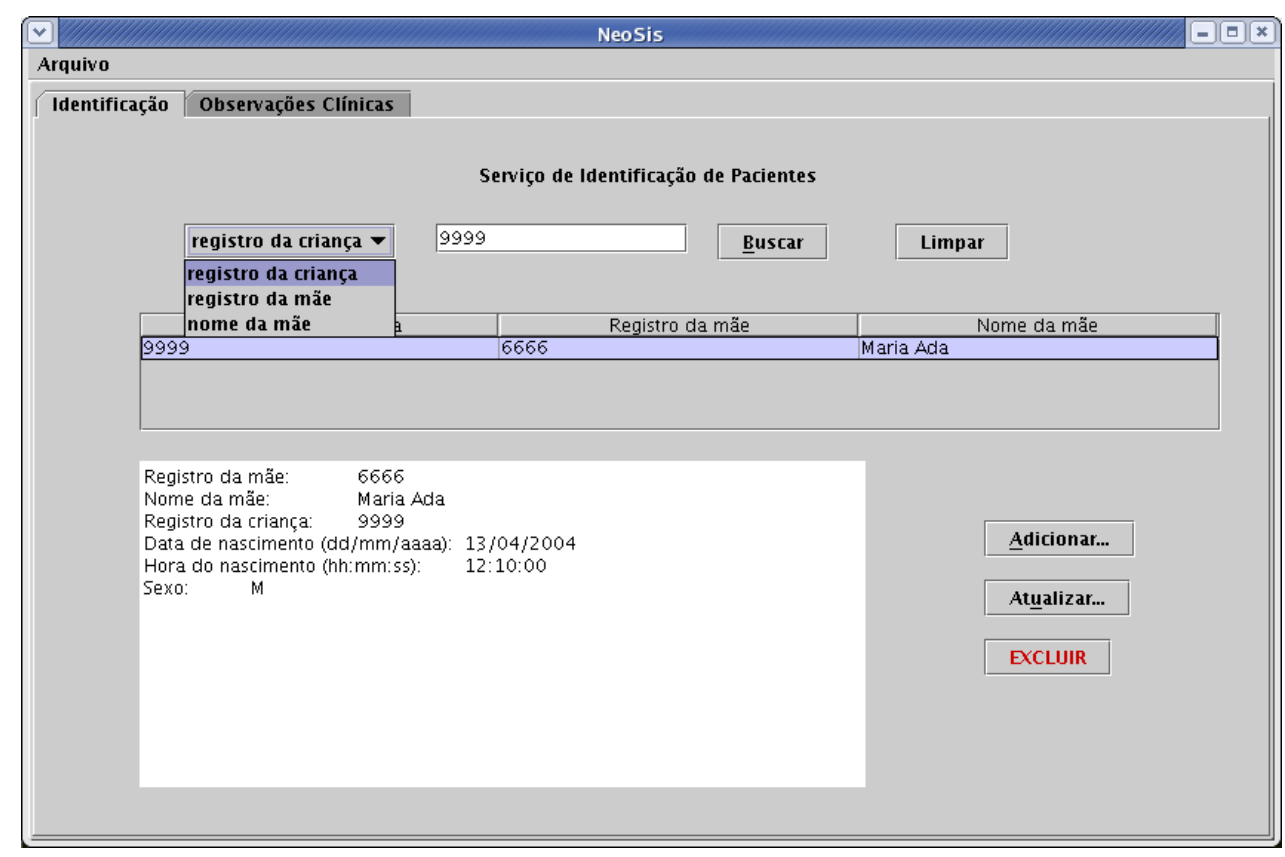

Figura 4.12: Busca no PIDS.

A diagrama da Figura 4.13 mostra como o $\mathrm{Cl}$ iente realiza a requisição de busca no PIDS. Primeiro, o Cliente requisita a referência de ProfileAccess para o objeto IdentificationComponent. Após obter a referência, invoca o método find_candidates em ProfileAccess, fornece como parâmetro atributos que possam ajudar na identificação do perfil procurado. Os atributos no diagrama foram ocultos por motivos de clareza da figura. Recebendo a resposta de ProfileAccess, o Cliente mostra os resultados ou informa que não foi encontrado nenhum perfil com as características requisitadas. 


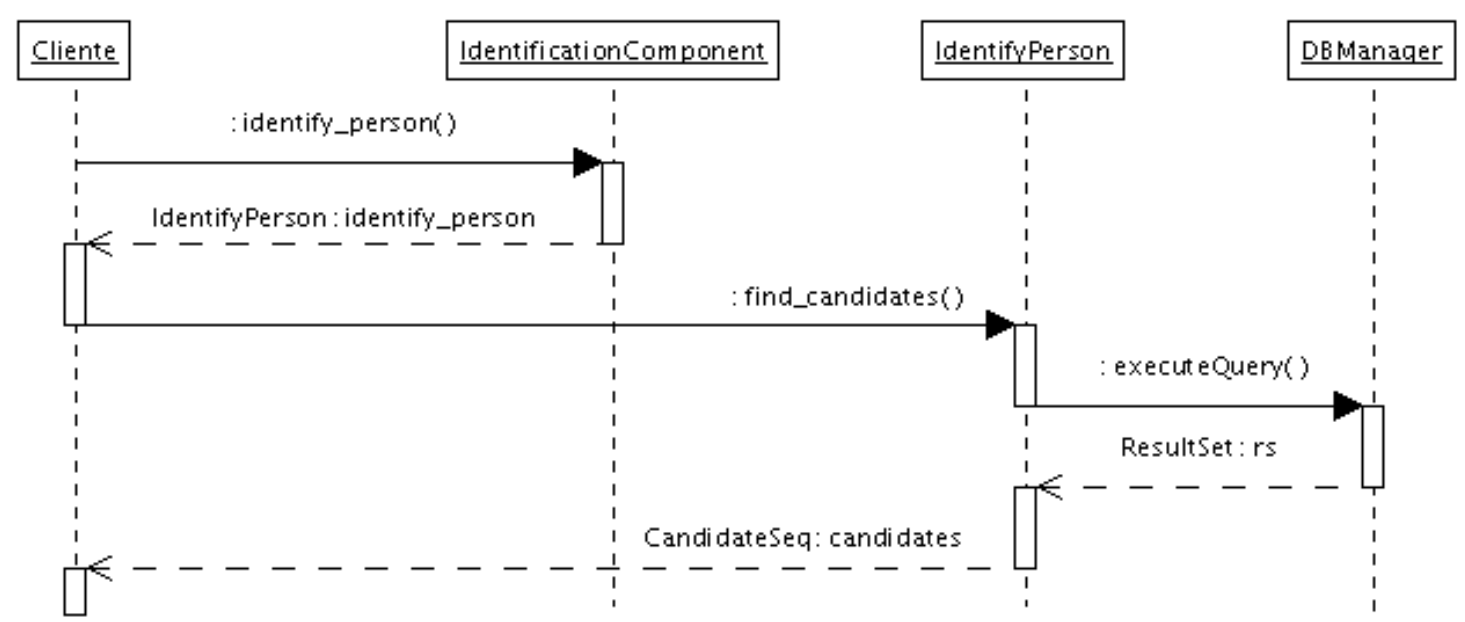

Figura 4.13: Diagrama de sequiência para a busca no PIDS.

Utilizando o Cliente, um perfil também pode ser adicionado. A Figura 4.14 mostra a tela que aparece após o usuário clicar em Adicionar na tela principal de identificação. Será fornecido ao usuário os atributos que podem ser armazenados no PIDS.

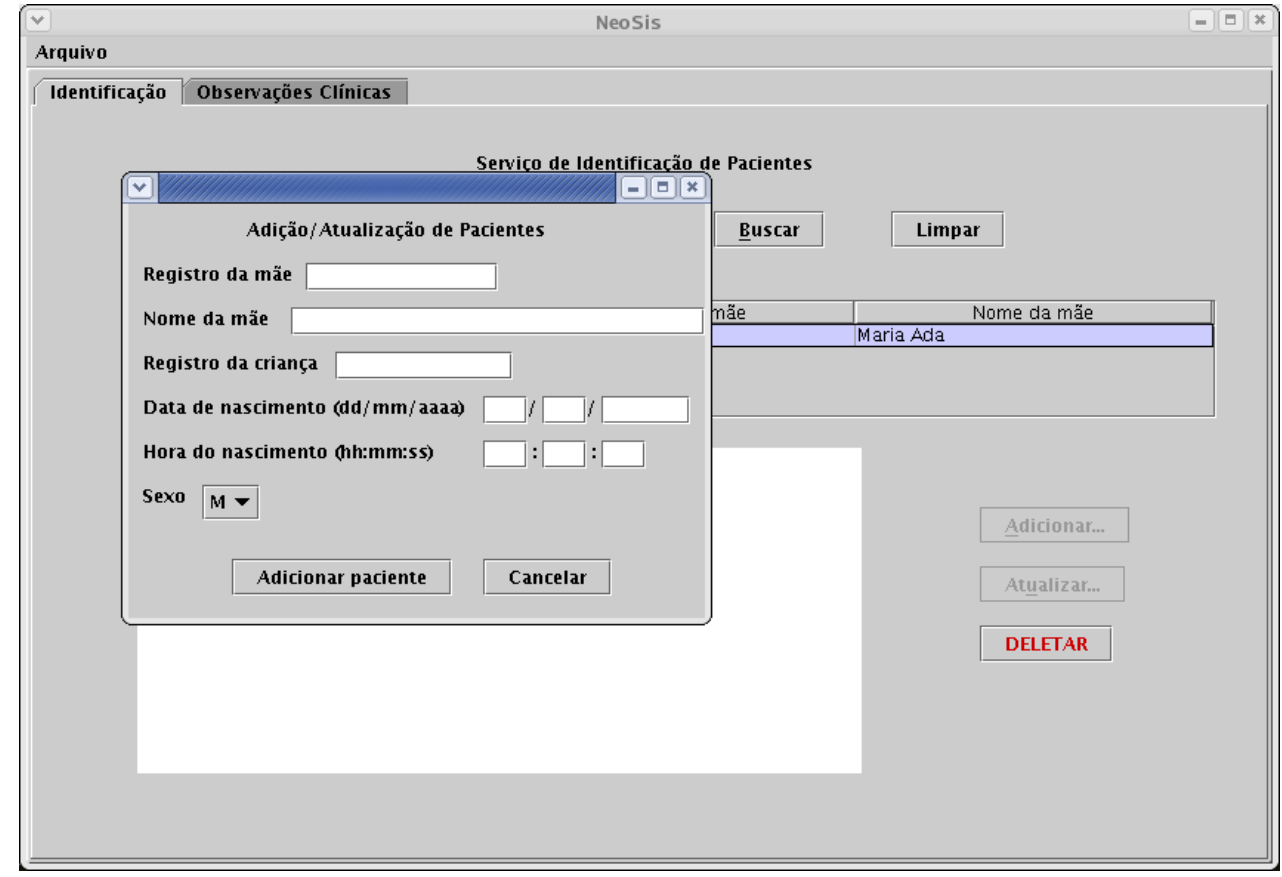

Figura 4.14: Adição de registro feita pelo cliente PIDS .

Para adicionar os dados do bebê, o Cliente requisita uma referência de IdMgr para IdentificationComponent, conforme mostrado pelo diagrama de sequiência (Figura 4.15). Ele invoca o método register_these_ids () fornecendo o tipo TaggedProfile como argumento, que contém o número de registro do bebê, da mãe e os atributos a serem armazenados de ambos. Um aviso de sucesso é lançado se não houver problemas durante a execução das operações 
requisitadas, caso contrário, uma exceção será lançada informando o motivo da impossibilidade de armazenamento.

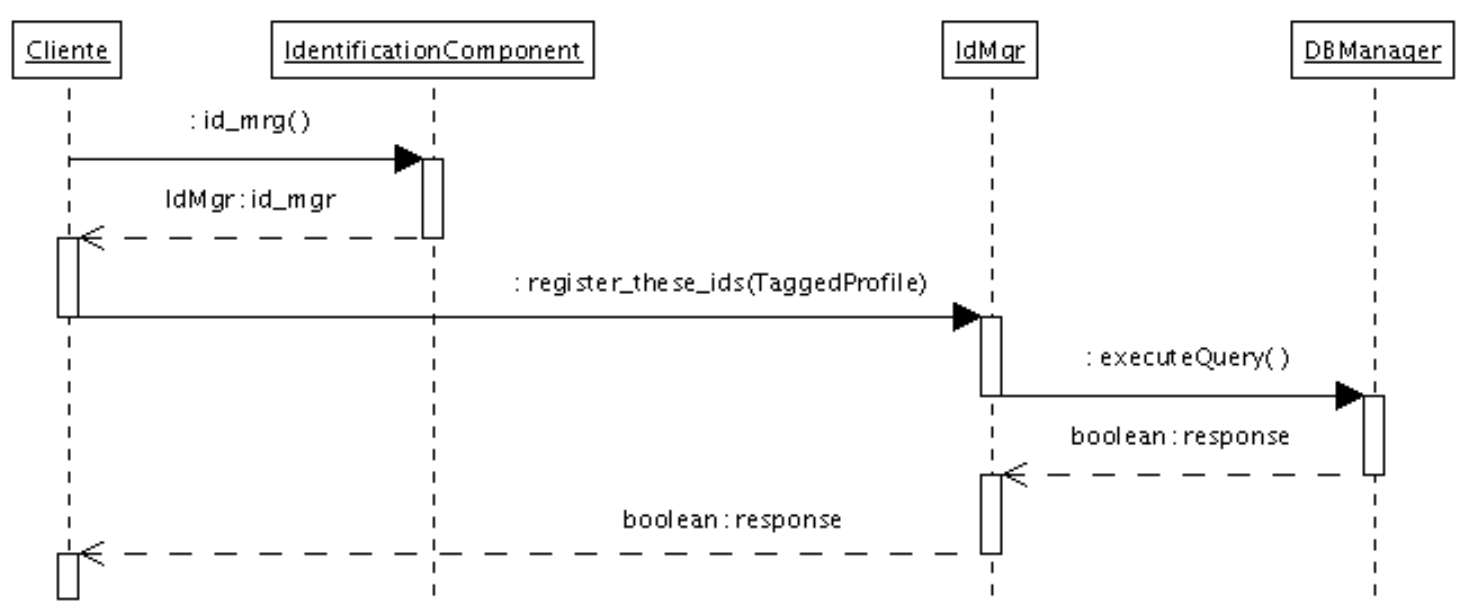

Figura 4.15: Diagrama de sequiência para a busca no PIDS.

Se o usuário necessitar atualizar algum dado, um clique no botão Atualizar abre uma caixa de diálogo com os dados armazenados no PIDS, veja Figura 4.16. Após alterá-los e clicar em Atualizar dados, a alteração é feita no sistema.

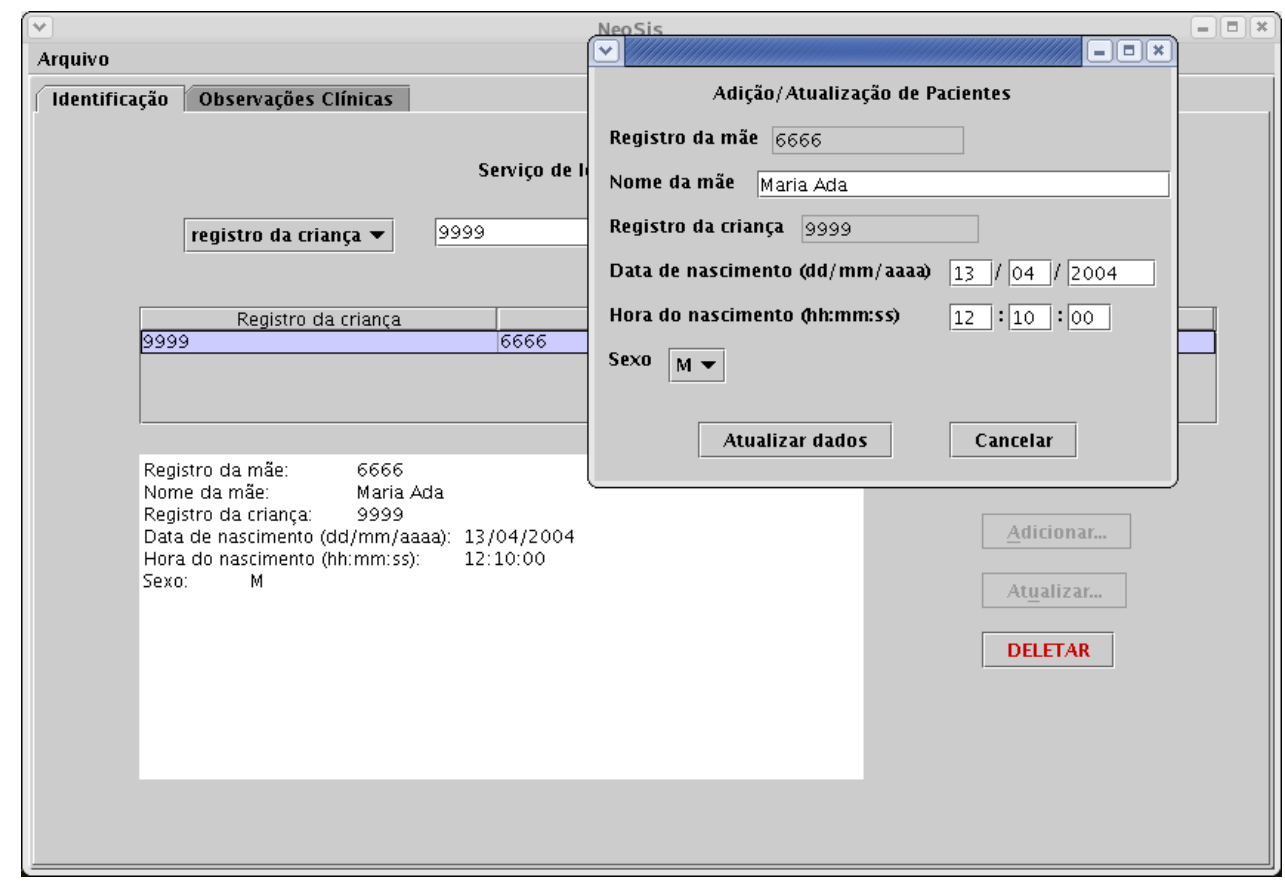

Figura 4.16: Atualização de registro no PIDS feita pelo cliente.

Para atualizar os dados no PIDS, o Cliente invoca o método profile_access () que retorna uma referência para o objeto ProfileAccess. O Cliente utiliza o método update_and_clear_traits() de ProfileAccess fornecendo como argumento os perfis a serem atu- 
alizados. Acompanhe na Figura 4.17. Se nenhuma exceção for lançada, uma mensagem de sucesso é retornada.

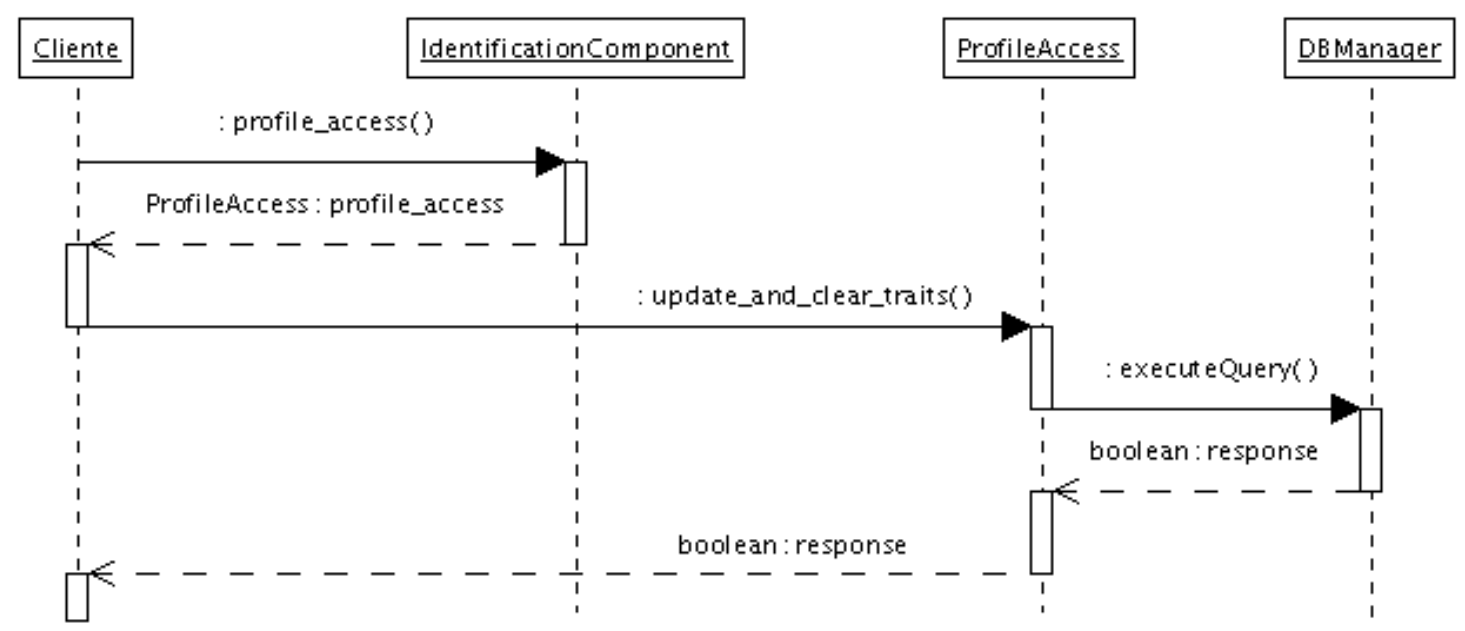

Figura 4.17: Diagrama de sequiência para a busca no PIDS.

Se o botão DELETAR for pressionado, o usuário será questionado sobre a certeza da remoção. Se prosseguir, o registro selecionado será removido do PIDS.

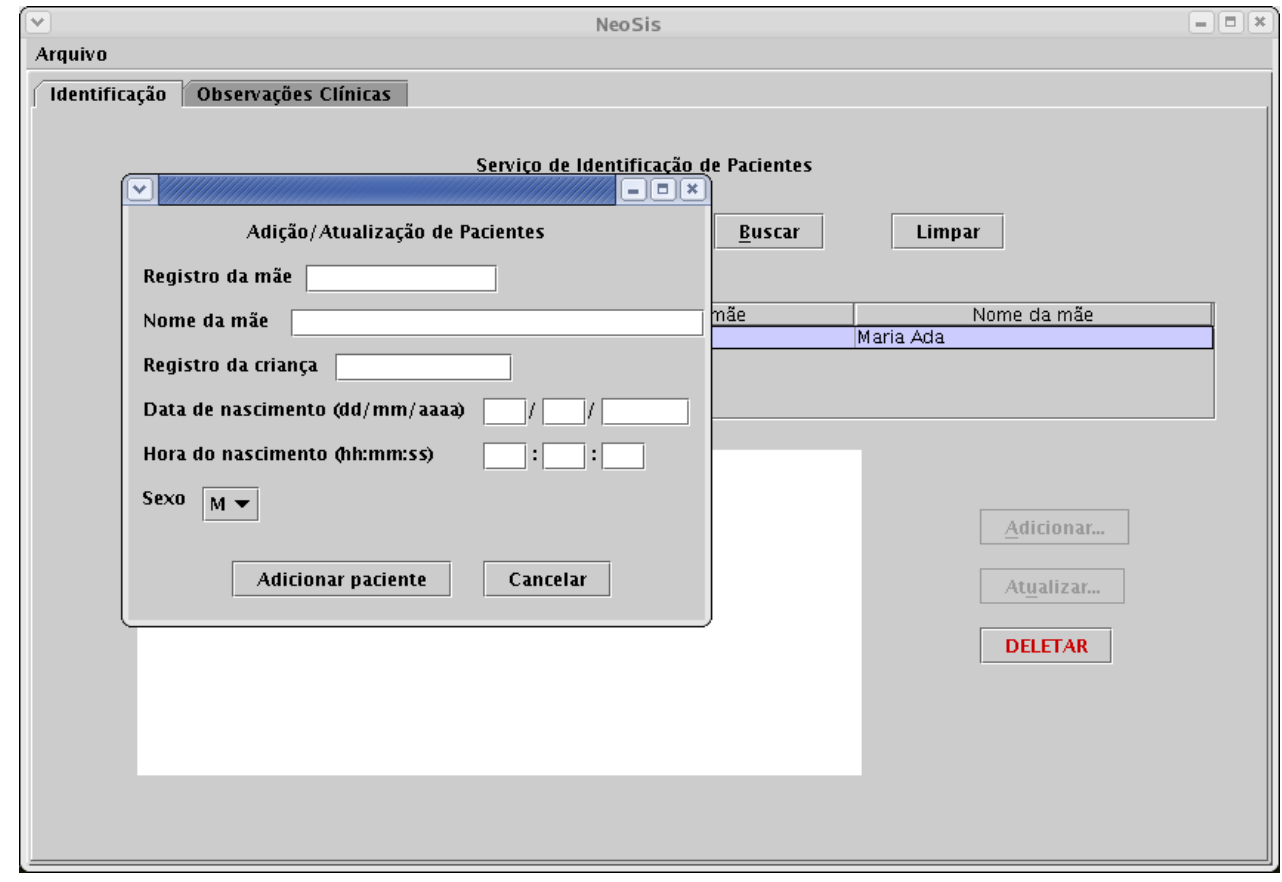

Figura 4.18: Entrada de dados de identificação do paciente.

Como o a interface e lógica do cliente foram projetadas para atender os requisitos de uma UTI neonatal, devem ser armazenados dados dos bebês e de suas mães para que alguns atributos fiquem relacionados. Por exemplo, quando um bebê entra na UTI, ele não possui 
nome ainda, portanto o nome da mãe aparece na tela de resultados quando é feita uma busca por um determinado registro de bebê, apesar dos atributos da mãe estarem separados. Em nossa implementação, um atributo de identificação da mãe, no caso o número de identificação atribuído pelo hospital, é armazenado junto com os dados do bebê. Deste modo, quando uma informação sobre o bebê é requisitada, o sistema verifica a identificação da mãe, requisita seu nome e associa aos dados da criança para gerar seu perfil.

Outro problema de projeto diz respeito a entrada de duas crianças pertencentes à mesma mãe. As crianças são diferenciadas pelo número de identificação atribuído pelo hospital, e nome da mãe aparece na tela de resultados de busca com algum atributo numérico adicionado ao final diferenciando os bebês.

\subsubsection{Observações clínicas}

A Figura 4.19 mostra a interface de gerenciamento das observações clínicas. Podem ser adicionadas as observações iniciais que o profissional fez do paciente, exames, imagens e texto livre, descrevendo as impressões do profissional em um determinado instante. As observações podem ser carregadas de acordo com o perfil selecionado na interface de identificação ou, pelo registro da criança na própria interface.

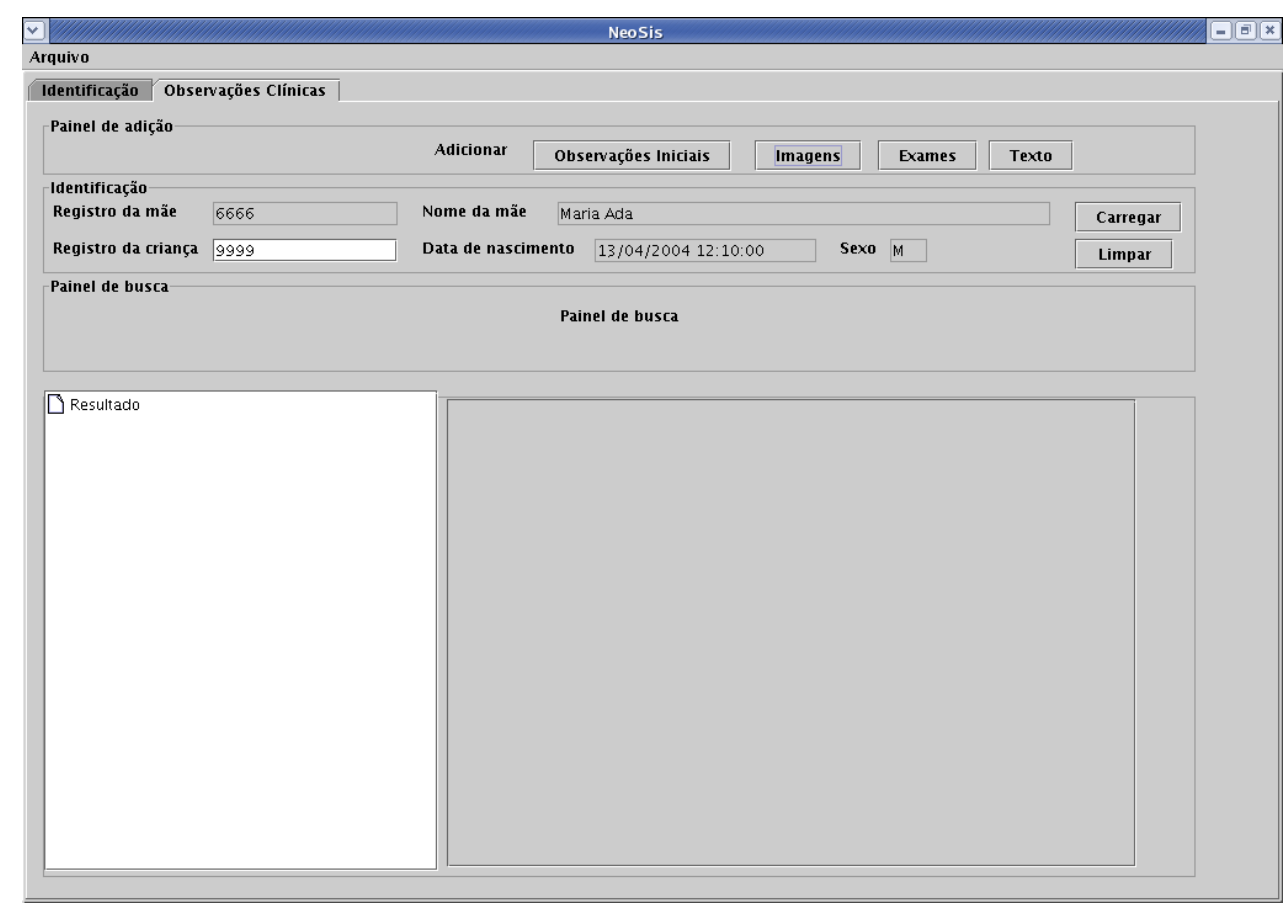

Figura 4.19: Interface principal do cliente COAS.

Ao clicar em Adicionar->0bservações Iniciais aparecerá a interface mostrada na Figura 4.20. As observações iniciais são realizadas no momento em que a criança entra na UTI 
neonatal, com os profissionais realizando algumas medidas e descrevendo algumas impressões iniciais. Os horários de início e término das observações são capturados pelo sistema, sendo que o usuário não tem como alterá-los. Todas as observações ficam associadas a códigos existentes no LQS. Por exemplo, o campo tipo de parto deve possuir um código, sendo que o valor do campo fica associado a um código do CID10. Quando o profissional seleciona como tipo de parto, "vaginal fórceps", o código equivalente ao tipo é armazenado no COAS, neste caso está sendo armazenado o código DNS:hl7.omg.org/I10/O81.0, onde DNS:hl7.omg.org/I10 é a representação do sistema de codificação CID10 e O81.0 é o código que representa o conceito "Parto por fórceps baixo". Para saber qual o texto associado a cada código é necessário realizar uma consulta no LQS.

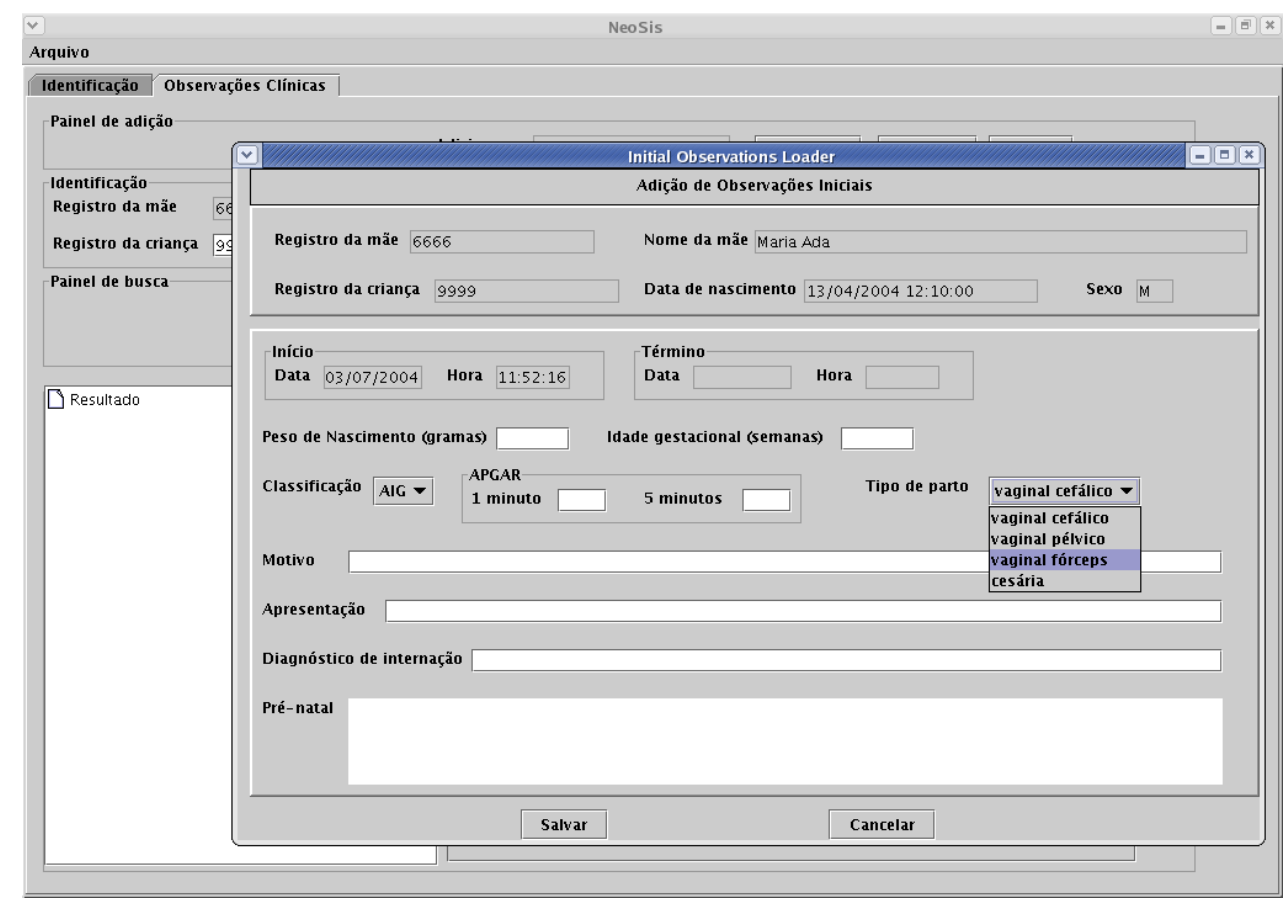

Figura 4.20: Entrada das observações iniciais.

Para adicionar imagens, clicando em Adicionar->Imagens aparece a interface mostrada na Figura 4.21, onde pode ocorrer a seleção de uma ou várias imagens. Um código representando a fonte geradora da imagem (ultra-som, raio X,...) deve ficar associado a estrutura contendo as imagens.

A Figura 4.22 mostra o evento gerado após o clique em Adicionar->Exames. A tela que aparece é utilizada para a entrada de exames clínicos. Sempre deve haver um código associado ao tipo e outro a unidade do valor do exame proveniente do LQS.

Para as observações que exigem maior expressividade e onde há dificuldade de padronizar a sua entrada, há a necessidade de utilização de texto livro. Para o armazenamento de texto 


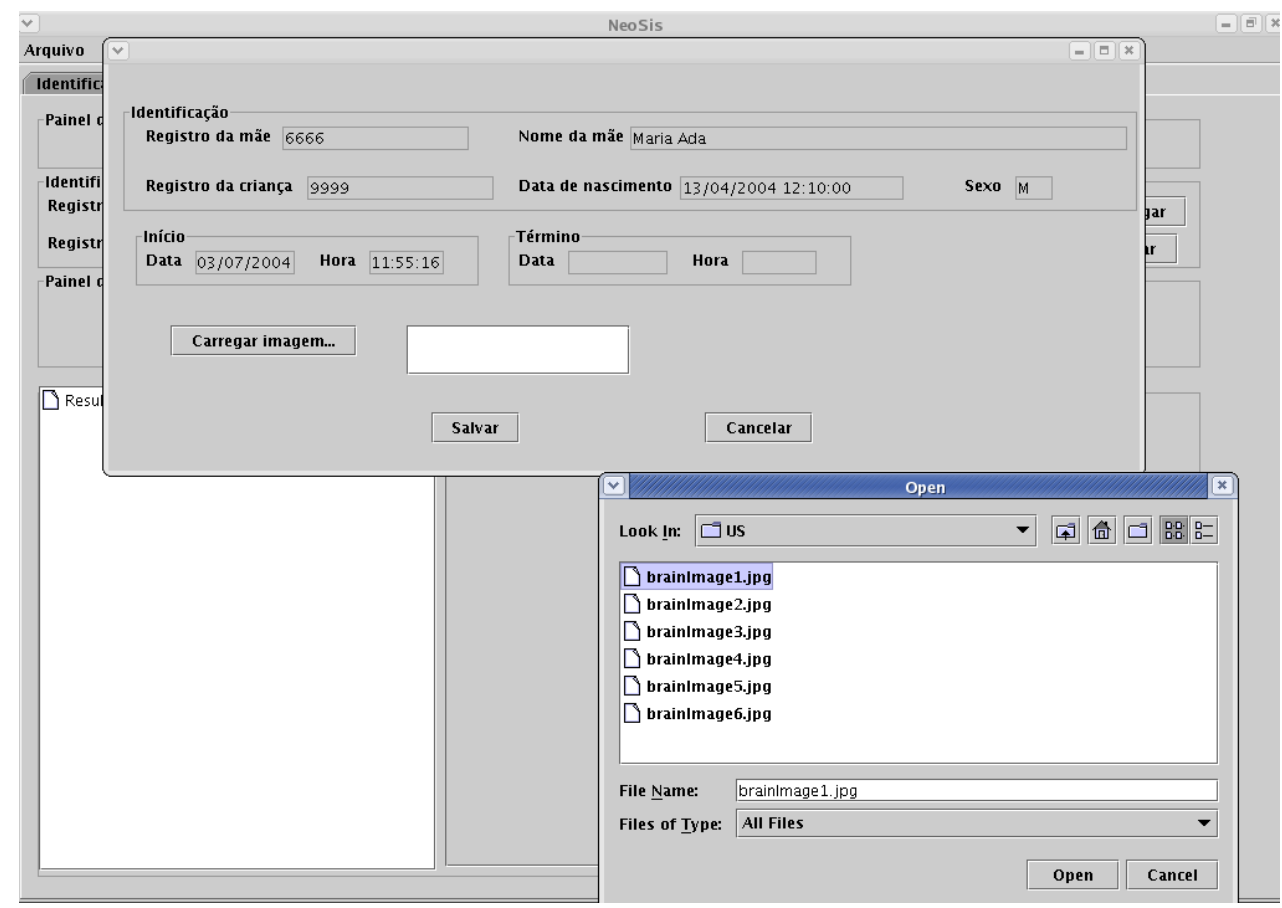

Figura 4.21: Entrada de imagens.

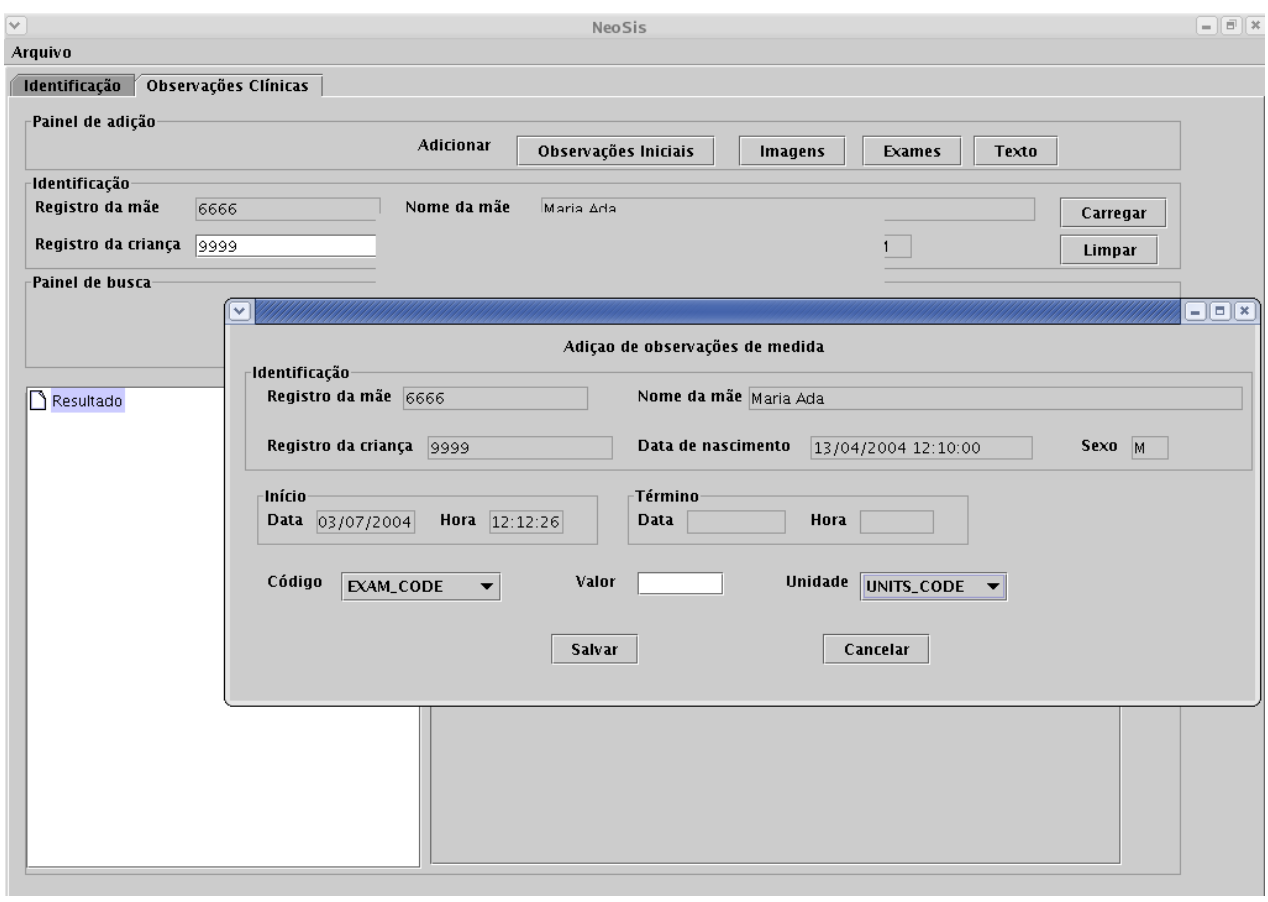

Figura 4.22: Entrada de valores de exames.

livre, clicando em Adicionar->Texto na interface principal (Figura 4.19) aparece a interface mostrada na Figura 4.23, em que o profissional entra com o texto e um código representando o tipo de descrição deve estar associado.

Para armazenar observações iniciais, imagens, exames ou texto, o $\mathrm{Cliente} \mathrm{invoca} \mathrm{o} \mathrm{método}$ get_components () em AccessComponent que retorna o a referência para o objeto Access- 


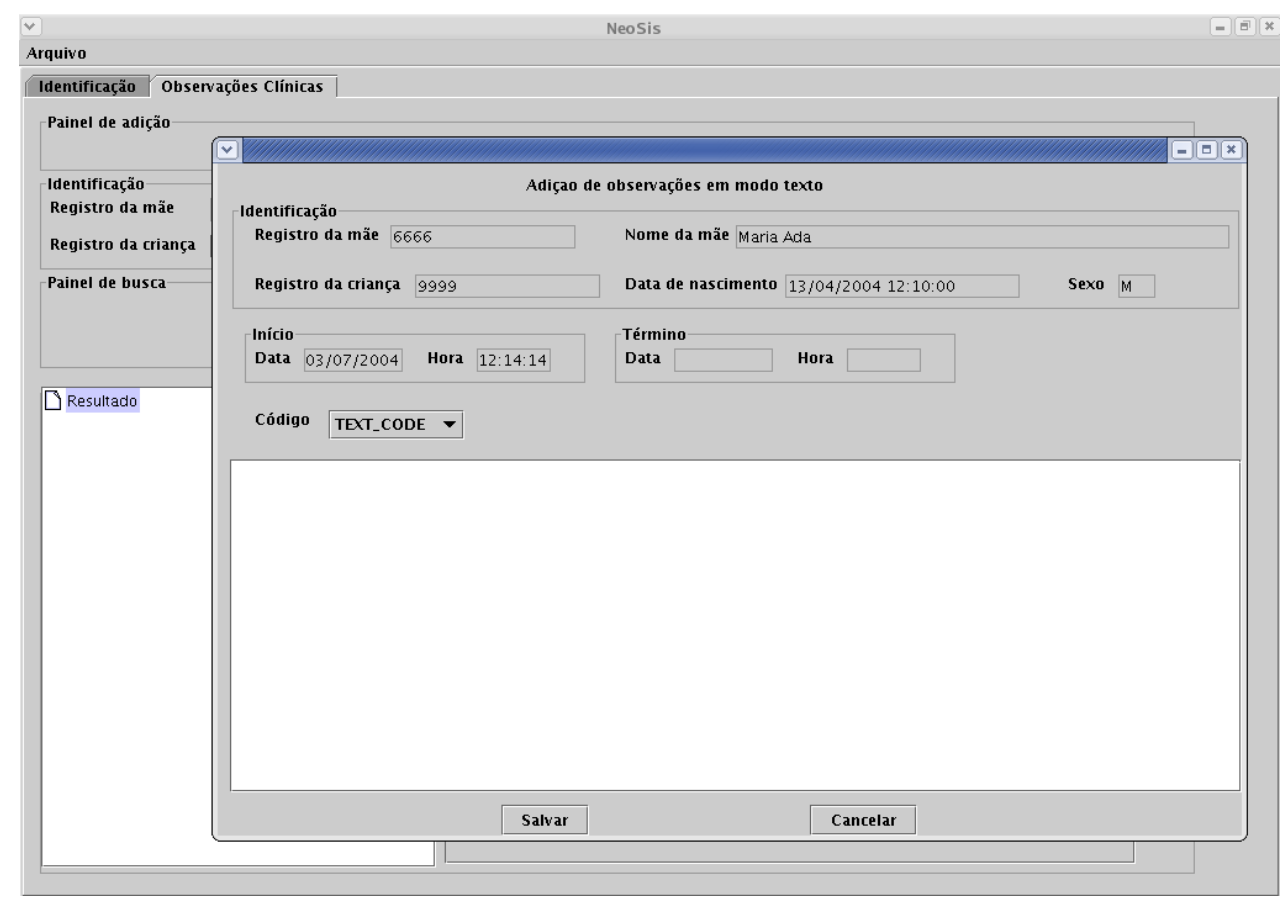

Figura 4.23: Entrada de texto livre.

ComponentData. Este contém as referências para todos os componentes da especificação COAS implementados que fornecem acesso às observações clínicas. Dentre eles, está observationLoader, que fornece o método load_observations (), usado para armazenar as observações enviadas utilizando a estrutura de dados ObservationDatastruct. A Figura 4.24 mostra o diagrama de seqüência da operação de armazenamento das observações, caso ocorra algum problema durante a execução das operações, um booleano false será retornado e o usuário será informado sobre a impossibilidade de armazenamento dos dados entrados.

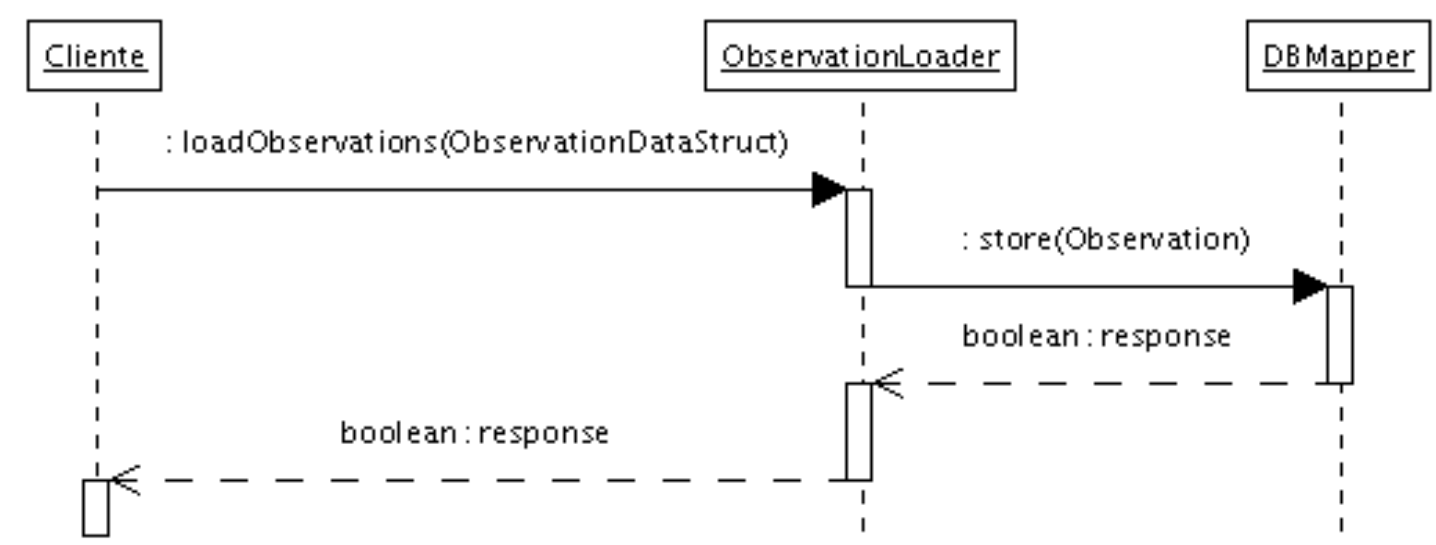

Figura 4.24: Diagrama de seqüência para a adição de observações no COAS.

A Figura 4.25 mostra a interface de consulta com o profissional avaliando as observações 
armazenadas.

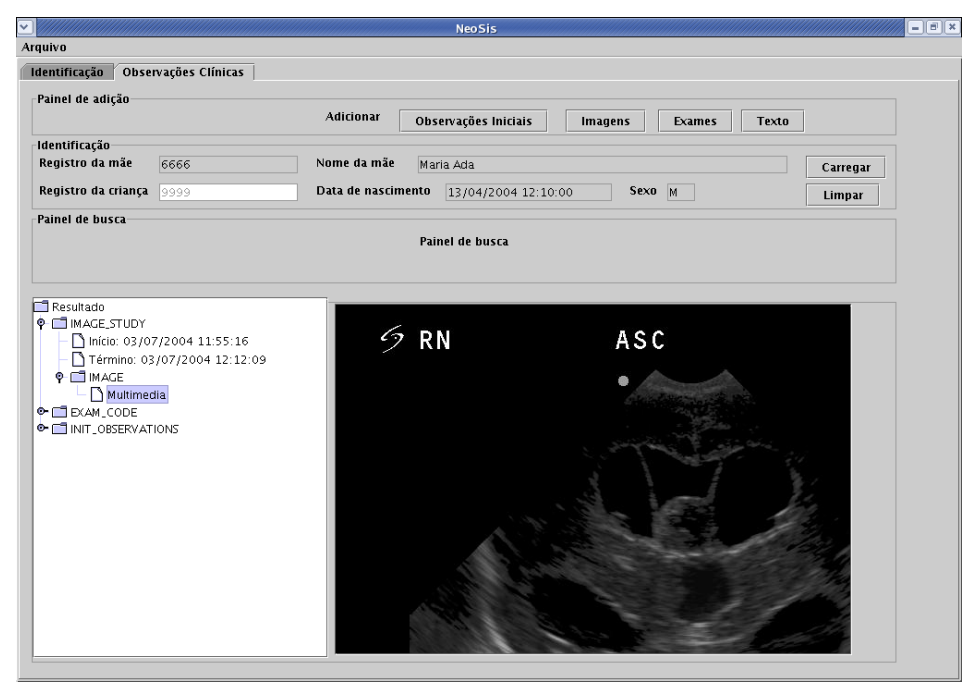

Figura 4.25: Visualização das observações requisitadas.

A Figura 4.26 mostra o diagrama de seqüencia da requisição das observações. O Cliente pede uma referência para QueryAccess invocando o método get_components () em AccessComponent. Depois, ele invoca o método get_observations () em QueryAccess fornecendo como parâmetro, o registro do paciente, que tipo de observações deseja requisitar e o período em que as observações foram realizadas. Um conjunto (vetor) de estruturas de observações ( $\mathrm{Ob}-$ servationDataStruct) é retornado contendo as observações que satisfizeram as condições de busca. Para obter os textos associados aos códigos associados às observações, o Cliente deve consultar o LQS utilizando uma referência para LexExplorer e invocando o método get_preferred_text ( ) fornecendo como argumento o código, onde será retornado o texto associado a ele (Intlstring). 


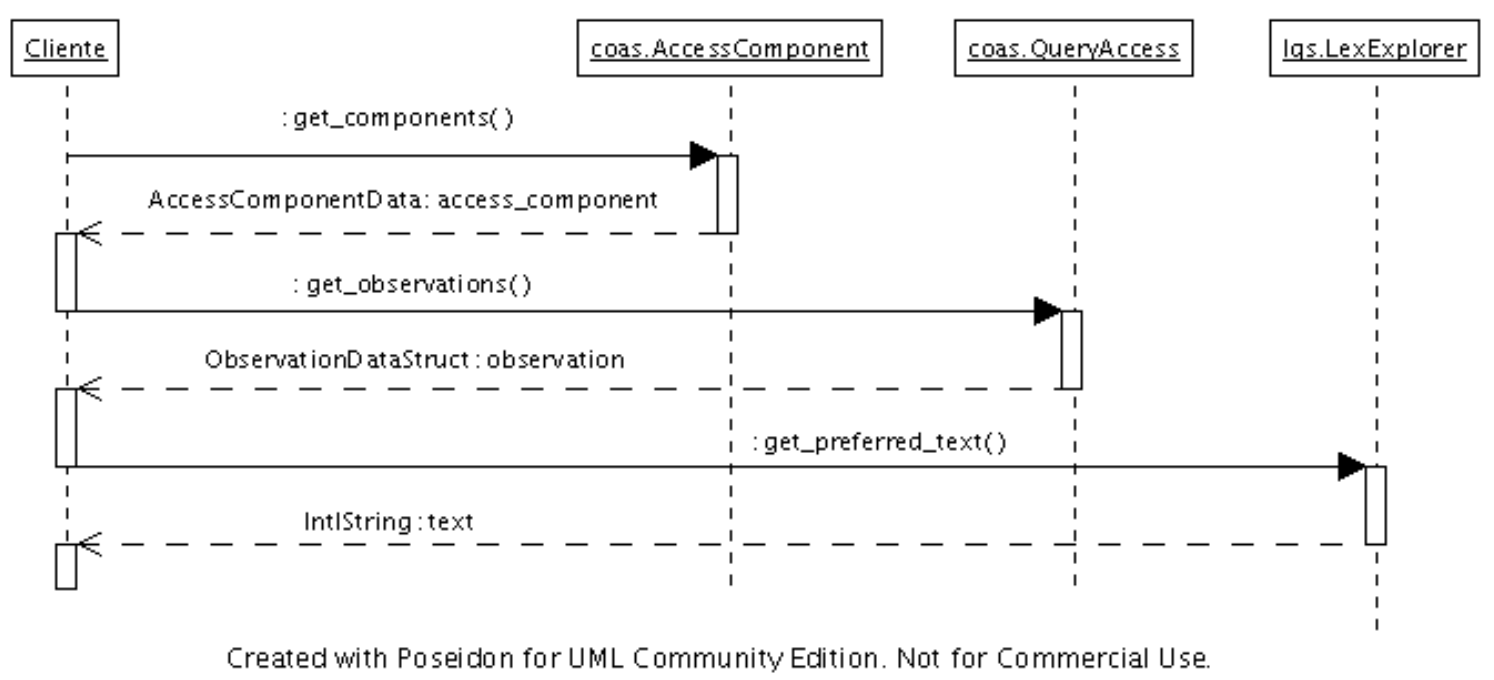

Figura 4.26: Diagrama de seqüencia para a busca de observações no COAS. 


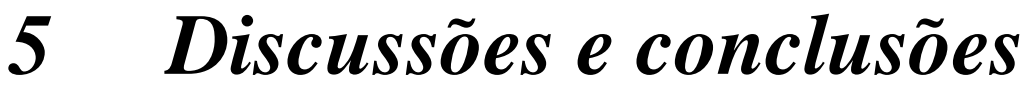

\subsection{Avaliação técnica}

O sistema mostrou-se compatível com os bancos de dados testados (PostgreSQL e MySQL) necessitando apenas algumas modificações no arquivo de configuração do mapeador objetorelacional, devido às diferenças dos tipos de dados entre os bancos. Não houve problemas de comunicação com os middlewares testados (ORBacus e OpenORB), necessitando apenas a troca de alguns parâmetros de configuração do framework de gerenciamento de serviços CORBA para a troca do middleware.

A especificação PIDS lida com um escopo mais definido, possuindo uma variabilidade menor de tipos de dados com uma estrutura mais simples, quando comparada à especificação do COAS. Devido a estas características, a sua implementação foi realizada em tempo menor e na lógica do cliente havia uma complexidade menor, tornando o cliente leve e de fácil manutenção.

A especificação COAS possui uma variabilidade maior de tipos de dados e sua estrutura por ser muito genérica é de difícil implementação. Além disso, contribui para a sua complexidade, as dependências com o PIDS e LQS. Com o PIDS, pelo motivo de cada observação ficar associada ao identificador do paciente obtido em um servidor PIDS e com o LQS, devido ao fato das observações possuírem campos com códigos padronizados obtidos de algum sistema de terminologia, interfaceado por um servidor LQS.

A estrutura de dados genérica do COAS possui a vantagem de possibilitar a sua aplicação em qualquer especialidade clínica, pois engloba um número grande de tipos de dados e dá suporte à extensão de seu modelo de dados. Porém, toda a lógica específica de cada especialidade, que em sistemas convencionais fica localizada na camada do servidor, é transportada para o cliente. Em nosso trabalho, por exemplo, regras de agrupamento das exames, imagens e dados textuais foram todas colocadas na lógica do cliente. O cliente recebe uma estrutura de dados genérica, desempacota seu conteúdo e executa algumas operações baseadas em regras de agrupamento de acordo com a semântica dos dados verificada a partir dos códigos associados. $\mathrm{O}$ 
significado dos códigos é fornecido pelo servidor LQS.

Devido à sua estrutura genérica, a especificação COAS pode atuar como modelo para integração top-down de sistemas de informações. O modelo de dados COAS atuaria como esquema comum de integração e as interfaces como componentes de exportação, adaptando-se aos esquemas locais dos sistemas e extraindo a informação de interesse comum. Há o mapeamento dos dados locais para o modelo COAS, unificando o modelo de informação. Isto facilita ao cliente acessar informações distribuídas aplicando seu modelo de negócios.

Com a modularização da arquitetura, componentes auxiliares para a área da saúde podem ser utilizados em outros domínios. O PIDS, por exemplo, pode ser utilizado em qualquer domínio em que há a necessidade de se armazenar atributos de identificação de pessoas. O LQS pode ser utilizado onde há a necessidade de padronização de conceitos e seus relacionamento de um determinado domínio.

A utilização do serviço de observações clínicas possibilita a padronização dos tipos e estrutura de dados das observações clínicas, bem como a interoperabilidade entre sistemas que possuem autorização de acesso e conheçam o padrão COAS. O serviço de consulta léxica LQS fornece uma especificação de interfaces e estrutura de dados para acesso aos sistemas de terminologia, oferecendo os benefícios da padronização de armazenamento de dados utilizando um sistema de terminologia, possibilitando a interoperabilidade semântica entre sistemas que possuam compatibilidade com os sistemas de terminologias utilizados.

\subsubsection{Benefícios da arquitetura CORBA}

Desde que o OMG foi formado em 1989 e começou a trabalhar sobre a especificação da arquitetura CORBA, a indústria e as universidades têm contribuído para sua evolução. Hoje, CORBA adquiriu uma maturidade que lhe permite ser utilizada em ambientes de produção e críticos. Durante este período de evolução, diversas tecnologias apareceram e caíram em desuso devido às mudanças de paradigma de programação e evoluções tecnológicas. Como exemplo, temos o protocolo RPC (Remote Procedure Call) baseado no modelo procedural de programação e os modelos de componentes COM e DCOM da Microsoft. CORBA, justamente por ser baseado em paradigma de programação amplamente utilizado, e deixar as questões tecnológicas para as implementações, adquiriu um longevidade difícil de ser encontrada em produtos de computação.

A arquitetura CORBA fornece benefícios importantes para o desenvolvimento de aplicativos que trabalham em rede. O fato de CORBA fornecer uma abstração da semântica dos objetos, 
permite que estes sejam reutilizados sem necessidade de saber detalhes de implementação. Esta abstração permite o reuso de funcionalidade horizontais e verticais e evita a implementação redundante de funções.

A infraestrutura CORBA também permite que o ORB gerencie a comunicação com o servidor, podendo enviar as requisições para um pool de objetos, localizados em máquinas diferentes, permitindo o balanceamento de carga.

Umas das vantagens do mapeamento de um modelo único de objetos (OMA - Seção 2.1.1) para as diversas linguagens de programação é a manutenção da integridade conceitual nos projetos de integração que utilizam a arquitetura CORBA. Mesmo que haja diferença do modelo de objetos implementado pelas linguagens de programação, o mapeamento uniformiza estas diferenças com uma camada adicional da arquitetura CORBA. A falta de integridade conceitual foi colocada por Brooks [51] como uma das principais causas de fracasso no desenvolvimento de software.

\subsubsection{Desvantagens da arquitetura CORBA}

Uma das limitações de performance da arquitetura CORBA está no desempacotamento/empacotamento (demarshaling/marshaling) dos tipos de dados para transmiti-lo entre o cliente e o servidor. Dados de tipos simples como long e double são empacotados mais rapidamente do que dados estruturados (struct), tipos definidos pelos usuários e referências a objetos. A taxa de empacotamento depende da rede, hardware, sistema operacional, do compilador e implementação do ORB [15]. Porém, se o cliente e o servidor estiverem sendo executados na mesma máquina, uma técnica de otimização chamada collocation pode ser aplicada para reduzir a taxa de empacotamento durante as requisições [52].

A implementação do sistema também pode se tornar complexa se envolver a participação de diversos serviços durante a inicialização dos objetos no servidor ou durante as requisições dos clientes. O número de camadas adicionais, que fornecem a transparência dos detalhes de transporte de dados, pode dificultar a verificação de erros em tempo de execução.

Como alternativa para a arquitetura CORBA para intermediar a comunicação entre componentes computacionais distribuídos na rede temos os sockets, RPC, DCE (Distributed Computing Environment), Microsoft .Net, Java Enterprise Edition e Web Services. Pelo fato de CORBA ser extensível, ela pode se integrar a estas tecnologias e com a Web, propiciando extensibilidade. 


\subsection{Avaliação semântica}

No cliente desenvolvido neste trabalho, algumas informações puderam ser armazenadas por códigos no COAS. Como exemplo, temos o "tipo de parto" que utilizou códigos provenientes do CID 10 para representar a informação. Outros sistemas de terminologias poderiam ser avaliados para a representação de pesos e medidas, importantes para a representação de exames laboratoriais.

Para verificar quais sistemas de terminologias são utilizados por um servidor COAS para representar a informação, uma consulta ao LQS pode ser realizada. Se foram utilizados o CID10, ICD9-CM e o SNOMED, por exemplo, os códigos retornados serão DNS:hl7.omg.org/I10, DNS:hl7.omg.org/I9C e DNS:hl7.omg.org/SNM3, respectivamente. Uma consulta a respeito dos códigos associados às observações requisitadas pode ser efetuada junto ao LQS para saber qual são os valores associados, recuperando a informação codificada.

A implementação de um servidor de terminologias utilizando os recursos de UMLS e CORBA ajudaria a aumentar a interoperabilidade semântica entre sistemas heterogêneos e distribuídos num ambiente médico. UMLS contribuiria com a padronização dos conceitos e seus relacionamentos de uma forma mais abrangente, possibilitando ampliar o seu escopo de utilização, além de possuir traduções para alguns vocabulários e catálogos médicos. Na versão 2002 possui um tradução para o português do MeSH e CID10. CORBA contribuiria com a especificação das interfaces e estruturas de dados do Serviço de Consulta Léxica (Lexicon Query Service - LQS), viabilizando a comunicação entre sistemas heterogêneos através do conhecimento dos atributos e métodos que devem ser acessados para um comunicação efetiva, além de poder contar com ferramentas já existentes no mercado para a implementação destes serviços.

Com relação à comunicação entre diferentes sistemas que estejam utilizando vocabulários diferentes, UMLS pode fornecer auxílio na busca da integração entre estes sistemas através da ligação entre os conceitos e sua representação nos diferentes vocabulários. Porém, não há um mapeamento direto entre a representação dos conceitos nos vocabulários o que dificultaria esta integração em um nível mais abrangente.

Como UMLS apenas integra as diferentes fontes de vocabulários, não sendo por definição um sistema de terminologia, o benefício que pode ser extraído do UMLS é dependente da qualidade de cada vocabulário integrante. Também não é possível realizar uma classificação automática de combinações de conceitos e geração de linguagem como poderia ser realizado utilizando o GALEN, pois a representação e o relacionamento entre os conceitos no UMLS não 
são baseados em um modelo formal.

Apesar de ser opcional, uma implementação COAS deve estar no nível de conformidade de códigos qualificados (Qualified Code) (seção 2.2.3.3) para garantir interoperabilidade semântica através da comunicação de convenções de termos de outros padrões.

Apesar dos serviços implementados juntamente com o cliente fornecerem uma base para a alta interoperabilidade, ainda há a necessidade de se trabalhar, principalmente na interface com o usuário, caminhando em direção à aplicação de modelos formais na representação entre os relacionamentos dos conceitos. Apesar do módulo LQS dar suporte a este tipo de serviço, atualmente há diversas iniciativas de se estabelecer um modelo formal de relacionamentos de conceitos, dentre eles o GALEN e o SNOMED-CT, porém esta diversidade causa uma dificuldade de uniformização da representação, e por consequiência, cria inconvenientes durante a integração da informação.

\subsection{Integração com os trabalhos do grupo ImagCom}

O grupo ImagCom (Computação de Imagens), ligado ao Departamento de Física e Matemática da Faculdade de Filosofia, Ciências e Letras de Ribeirão Preto da Universidade de São Paulo e coordenado pelo professor Evandro Ruiz, através de suas pesquisas em Informática Médica já produziu alguns trabalhos que poderiam ser integrados com este. O projeto MIDster, por exemplo, especificou e implementou uma arquitetura peer-to-peer para o compartilhamento de informações médicas em uma rede [53, 54], poderia integrar ao trabalho desta tese através do suporte que o MIDster oferece a interfaces CORBA.

Outro projeto do grupo que poderia ser integrado ao sistema implementado é o trabalho de caracterização de tecidos cerebrais em imagens ultra-sonográficas de neonatos através de atributos de textura, que desenvolveu algoritmos de processamento de imagens para realizar a caracterização dos tecidos cerebrais [55]. Este algoritmo poderia ser incorporado ao sistema como um módulo, requisitando as imagens armazenadas da UTI neonatal, para processá-las e mostrar o resultado. Todas estas etapas estariam integradas a interface gráfica do cliente.

\subsection{Trabalhos relacionados}

A seguir são descritos alguns trabalhos encontrados na literatura que estão relacionados com o trabalho desenvolvido nesta tese, mostrando a diferença entre estes e o trabalho da tese. 


\subsubsection{OpenEMed}

OpenEMed ${ }^{1}$, antigamente chamado de TeleMed, é um sistema desenvolvido em conjunto pelo Laboratório Nacional de Los Alamos-EUA e o Centro Judaico Nacional de Imunologia e Medicina Respiratória em Denver-EUA. OpenEMed é um sistema implementado para fornecer ao usuário a visão integrada de um registro virtual de pacientes contendo dados alfanuméricos e imagens. Ele é baseado na especificação CORBA-HDTF para a área médica, implementando os serviços PIDS, COAS e LQS, com um sistema de autenticação e interface para a Web acoplados, além de possuir módulos de persistência para banco de dados relacionais e orientado a objeto [56].

Apesar de ser um sistema amplo, de permitir o acoplamento de diversos bancos de dados e propiciar utilização de interface Web, o OpenEMed é de difícil implantação justamente por causa da complexidade adicionada pela tentativa de ampliar o escopo de aplicação e tecnologias utilizadas. A modularização do sistema é baixa, sendo que se o desenvolvedor quiser utilizar somente a implementação do PIDS, terá dificuldades em separá-la dos outros componentes que vêm em um arquivos único compactado.

$\mathrm{Na}$ implementação do trabalho da tese procurou-se modularizar todos os componentes, sendo que a implementação do PIDS está separada dos outros componentes, e estes só são agrupados a suas dependências, com a separação de cada componente bem definida. Com o objetivo de simplificar e reduzir o número de camadas para gerenciamento da persistência, nosso sistema foi projetado para se acoplar somente a banco de dados relacionais que são os mais utilizados, simplificando o projeto e implantação e, reduzindo a complexidade adicional que poderia degradar o desempenho total do sistema.

Na implementação do COAS, o OpenEMed utiliza tipos definidos pelos desenvolvedores do projeto para empacotar as observações clínicas e facilitar seu gerenciamento. Estes tipos são chamados MedTraits e correspondem registros normalmente encontrados na prática clínica como histórico, relatório, sumário e exames de laboratório do paciente. Apesar destes tipos, que são criados no servidor e entregues ao cliente, facilitar a manipulação dos dados no cliente, eles podem dificultar a interoperabilidade com outros sistemas que desejam extrair as informação do OpemEMed, visto que estes não são tipos padronizados. Em nosso sistema o servidor cria e entrega somente tipos padronizados pela CORBA-HDTF cabendo ao cliente manipular estes tipos de dados. Este procedimento segue recomendações do OMG de não padronizar as aplicações, somente os serviços de domínios.

\footnotetext{
${ }^{1}$ http://openemed.net
} 


\subsubsection{Synapsis}

O objetivo do projeto Synapses ${ }^{2}$ é desenvolver um meio aberto e genérico de compartilhar registros da área de saúde e dados médicos relacionados de um modo simples, consistente e seguro [57]. O ambiente de computação do Synapses consiste de aplicações clientes acessando de uma maneira controlada componentes distribuídos de registros da área de saúde através de um servidor. O servidor está conectado a "sistemas de alimentação" onde estes registros e informações do paciente estão armazenados [58].

A implementação do servidor Synapses usa o padrão CORBA como mecanismo de comunicação. Todos os bancos de dados conectados conectados ao Synapses requerem uma adaptação do seu modelo de dados para o modelo do projeto (SynOM - Synapses Object Model) que fornece um conjunto de blocos de construção e regras de agregação para criar os registros médicos padronizados [59]. Com esta arquitetura, o servidor Synapses transporta para um modelo de dados comum, dados de sistemas heterogêneos distribuídos.

O projeto Synapses não utiliza as especificações CORBA-HDTF para a área da saúde. Qualquer sistema, cliente ou servidor, que deseja se comunicar com o servidor Synapses deve adequar seu modelo de dados ao do servidor. Apesar do projeto Synapses possuir um modelo de dados simples e genérico, esta adaptação requer um esforço adicional no cliente e no servidor para integração dos ambientes.

\subsubsection{GCPR}

O projeto GCPR (Government-wide Computer-based Patient Record) é um projeto em conjunto das agencias federais responsáveis pela área da saúde nos EUA, sendo elas o Departamento de Defesa (Department of Defense), a Administração dos Veteranos (Veteran's Administration) e Serviços de Saúde do Cidadão Indiano (Indian Health Services). Em resposta a uma Diretiva de Pesquisa Presidencial dos EUA motivada pela dificuldade de acesso e compartilhamento de informações médicas durante a Guerra do Golfo em 1997. As agências propuseram a utilização de um modelo de referência para o processamento distribuído aberto baseado na arquitetura CORBA, com a utilização dos serviços PIDS, COAS, LQS e RAD da especificação CORBA-HDTF e de uma camada adicional contendo templates usados para transportar as observações entre os sistemas heterogêneos [14]. Os templates foram convertido de um diagrama de classes para grafos de objetos do tipo ObservationDataStruct, expresso em IDL. Programadores implementaram um template como um grafo direcionado acíclico, onde cada

\footnotetext{
${ }^{2}$ http://www.cs.tcd.ie/synapses/public/
} 
classe, atributo e associação foi implementada como uma estrutura única [31].

Vários modelos foram propostos, durante a especificação do COAS, para transportar as observações, inclusive o modelo de templates do GCPR [60]. Porém o grupo de revisão do COAS decidiu deixar o modelo o mais genérico possível, com a utilização de modelos manipulação das observações no cliente, onde a semântica é definida de acordo com o domínio da aplicação. Em nossa implementação decidimos manter esta recomendação para não especializar o modelo no servidor podendo dificultar a interoperabilidade.

\subsection{Futuros trabalhos}

A implementação da arquitetura proposta nesta tese procurou ser o mais simples possível para evitar que as camadas adicionais do middleware CORBA somassem ao peso da implementação degradando a performance do sistema. Apesar da configuração dos componentes como banco de dados, CORBA e gerenciador de logs não ser muito complexa, ainda há a necessidade de automatizar e facilitar ainda mais a implantação dos serviços. Uma melhoria seria a aplicação do modelo de componentes CORBA (CCM-CORBA Component Model) sobre os serviços (PIDS, COAS e LQS) automatizando e facilitando sua implantação e fornecendo um ambiente para controle de transação entre os objetos e mapeamento objeto-relacional.

Durante a implementação dos serviços notou-se que a modularização por vezes era um pouco prejudicada por alguns aspectos de infraestrutura que não estão relacionados com a lógica de domínio. Como exemplo, temos a geração de $\log s$, necessária para ter um histórico dos eventos que ocorreram no sistema, mas que se mistura com a lógica de domínio aumentando sua complexidade. Poderia ser feito um trabalho sobre a implementação separando estes aspectos, colocando-os em um ponto único de configuração e simplificando a lógica de domínio de objetos específicos dos serviços. Para a realização desta tarefa poderia ser aplicada a programação orientada a aspecto (AOP-Aspect Oriented Programming) que fornece ferramentas para modularizar os aspectos não relacionados à lógica do domínio.

A melhoria dos sistemas de terminologia e da integração destes com sistemas computacionais é uma área que ainda vai exigir muita pesquisa para atender às necessidades de integração da informação provenientes de sistemas heterogêneos. Por melhoria entende-se a compatibilização do conteúdo e da estrutura destes sistemas para que as ferramentas computacionais consigam extrair informações relevantes para os usuários com um custo relativamente baixo. Para se estudar a estrutura destes sistemas existem diversas ferramentas que poderiam ser aplicadas. Uma delas seria Redes Complexas que podem fornecer informações estatísticas 
dos termos fornecendo uma visão geral da estrutura.

Holanda et al. [61] realizaram um estudo utilizando Redes Complexas sobre um tesauro de uso geral para verificar a estatística básica das ligações formadas pelas relações entre os termos do tesauro. Este método poderia ser aplicado ao meta-tesauro do UMLS, com o objetivo de verificar a consistência das relações entre os termos e fornecer melhorias que seriam repassadas em cadeia para os sistemas que o utilizam.

Apesar do servidor LQS dar suporte ao armazenamento de observações clínicas compostas pela união de conceitos atômicos obedecendo algum modelo formal para intermediar a relação entre estes conceitos, o estudo do desenvolvimento de uma interface com o profissional de saúde utilizando este modelo de representação não foi realizado. A investigação de como aplicar uma formalização para a representação da informação clínica é um trabalho que poderia ser desenvolvido e integrado com os sistemas implementados.

Um sistema de autenticação baseado na especificação de segurança CORBA ou mesmo um sistema simples para fornecer autorização de acesso ao sistema somente a usuário cadastrados não foi implementado por fugir do escopo do trabalho que era o foco na interoperabilidade. Outro requisito relacionado à segurança seria a utilização do RAD para verificação e autorização de acesso à informação de acordo com o perfil do usuário.

O CIAS não foi implementado pelo fato da maioria das imagens geradas em um ambiente de saúde poderem ser armazenadas no COAS. O CIAS fornece interfaces mais adequadas para transmissão de imagens, dando suporte para padrões estabelecidos como o , porém é possível acoplar uma implementação CIAS ao COAS do nosso trabalho quando o sistema exigir maior sofisticação no gerenciamento de imagens.

O acoplamento de uma camada de segurança e a interface CIAS para gerenciar de modo mais adequado as imagens mais sofisticadas servem como sugestões para trabalhos futuros. 


\section{Referências}

[1] E. T. Wong, T. A. Pryor, S. M. Huff, P. J. Haug, and H. R. Warner, "Interfacing a standalone diagnostic expert system with a hospital information system," Comput. Biomed. Res., vol. 27, no. 2, pp. 116-129, 1994.

[2] P. Wegner, "Interoperability," ACM Computing Surveys (CSUR), vol. 28, no. 1, pp. 285287, 1996.

[3] F. Manola, "Interoperability issues in large-scale distributed object systems," ACM Computing Surveys (CSUR), vol. 27, no. 2, pp. 268-270, 1995.

[4] T. Benson, "Why general practitioners use computers and hospital doctors do not-Part 2:scalability," BMJ, vol. 325, pp. 1090-1093, 2002.

[5] S. Heiler, "Semantic interoperability," ACM Computing Surveys (CSUR), vol. 27, no. 2, pp. 271-273, 1995.

[6] W. Hasselbring, "Information system integration," Communications of the ACM, vol. 43, no. 6 , pp. 33-38, 2000.

[7] B. Blobel and M. Holena, "Comparing middleware concepts for advanced healthcare system architectures," International Journal of Medical Informatics, vol. 46, pp. 69-85, September 1997.

[8] A. Rector, W. Solomon, W. Nowlan, T. W. Rush, P. E. Zanstra, and W. M. A. Claansen, "A terminology server for medical language and medical information systems," Methods of Information in Medicine, vol. 34, no. 1-2, pp. 147-157, 1995.

[9] A. R. Mori, F. Consorti, and E. Galeazzi, "Standards to support development of terminological systems for healthcare telematics," Methods of Information in Medicine, vol. 37, no. 4-5, pp. 551-563, 1998.

[10] T. Peth, "The future information technology equation," Home Health Care Management \& Practice, vol. 16, no. 4, pp. 302-302, 2004.

[11] D. W. Forslund and D. G. Kilman, Managing healthcare information systems with Webenabled technologies, ch. The impact of the global, extensible electronic health record, pp. 3-13. Idea Group Publishing, 2000.

[12] R. Walker, M. Dieter, W. Panko, and A. Valenta, "What it will take to create new internet initiatives in health care," Journal of Medical Systems, vol. 27, no. 1, pp. 95-103, 2003.

[13] R. V. de Velde, "Framework for a clinical information system," International Journal of Medical Informatics, vol. 57, no. 1, pp. 57-72, 2000. 
[14] C. Egyhazy and R. Mukherji, "Interoperability architecture using RM-ODP," Communications of the ACM, vol. 47, no. 2, pp. 93-97, 2004.

[15] M. Henning and S. Vinoski, Advanced CORBA Programming with C++. Addison-Wesley, 1999.

[16] K. Seetharaman, "The CORBA connection," Communications of the ACM, vol. 41, no. 10, pp. 34-36, 1998.

[17] G. Brose, A. Vogel, and K. Duddy, Java Programming with CORBA: Advanced Techniques for Building Distributed Applications. John Wiley \& Sons, 2001.

[18] R. Orfali and D. Harkey, Client/Server Programming with Java and CORBA. John Wiley \& Sons, 2nd ed., 1998.

[19] "Catalog of OMG CORBAservices Specifications." http://www.omg.org/technology/documents/corbaservice_spec_catalog.htm.

[20] J. Siegel, "OMG overview: CORBA and the OMA in enterprise computing," Communications of the ACM, vol. 41, no. 10, pp. 37-43, 1998.

[21] "Catalog of OMG CORBAfacilities Specifications." http://www.omg.org/technology/documents/corbafacilities_spec_catalog.htm.

[22] S. Vinoski, "CORBA: integrating diverse applications within distributed heterogeneous environments," IEEE Communications Magazine, vol. 14, no. 2, 1997.

[23] Z. Yang and K. Duddy, "CORBA: a platform for distributed object computing," ACM SIGOPS Operating Systems Review, vol. 30, no. 2, pp. 4-31, 1996.

[24] J. Kleindienst, “CORBA and Java compared: Object model,” Tech. Rep. 97/11, Department of Software Engineering, Charles University, Prague, September 1997.

[25] D. C. Schmidt, "Evaluating architectures for multithreaded Object Request Brokers," Communications of the ACM, vol. 41, no. 10, pp. 54-60, 1998.

[26] S. Vinoski, "New features for CORBA 3.0," Communications of the ACM, vol. 41, no. 10, pp. 44-52, 1998.

[27] G. Boers, H. van der Linden, and A. Hasman, "A distributed architecture for medical research," in Proceedings of Medical Informatics Europe; Budapeste, pp. 734-738, 2002.

[28] H. van der Linden, J. L. Talmon, H. Tange, G. Boers, and A. Hasman, "An architecture for virtual electronic health record," in Proceedings of Medical Informatics Europe; Budapeste, pp. 220-225, 2002.

[29] O. M. G. - Object Management Group, "Person Identification Service (PIDS) Specification v. 1.1.” http://www.omg.org/cgi-bin/doc?formal/2001-04-04, April 2001.

[30] O. M. G. - Object Management Group, "Clinical Access Observation Service (COAS) Specification v. 1.0.” http://www.omg.org/cgi-bin/doc?formal/2001-04-06, April 2001. 
[31] C. J. Egyhazy, "On the implementation of standard interface specifications," in CBMS '01: Proceedings of the Fourteenth IEEE Symposium on Computer-Based Medical Systems, p. 237, IEEE Computer Society, 2001.

[32] O. M. G. - Object Management Group, "Lexicon Query Service (LQS) Specification v. 1.0.” http://www.omg.org/cgi-bin/doc?formal/2000-06-31, June 2000.

[33] P. E. Zanstra, A. L. Rector, W. Ceusters, and P. F. de Vries Robbé, "Coding systems and classification in healthcare: the link to the record," International Journal of Medical Informatics, vol. 48, pp. 103-109, 1998.

[34] P. Degoulet, D. Sauquet, M. Jaulent, E. Zapletal, and M. Lavril, "Rationale and design considerations for a semantic mediator in health information systems," Methods of Information in Medicine, vol. 37, no. 4-5, pp. 518-526, 1998.

[35] M. Santos, "Implementação de módulos para a comunicação de imagens médicas em protocolo dicom," Dissertação de Mestrado, Departamento de Física e Matemática da Faculdade de Filosofia, Ciências e Letras da Universidade de São Paulo, 2002.

[36] W. E. Hammond and J. J. Cimino, Medical Informatics, ch. Standards in Medical Informatics, pp. 212-256. Springer-Verlag, second ed., 2000.

[37] T. Benson, "Why industry is not embracing standards," International Journal of Medical Informatics, vol. 48, pp. 133-136, 1998.

[38] J. J. Cimino, "Desiderata for controlled medical vocabularies in the Twenty-First Century," Methods of Information in Medicine, vol. 37, no. 4-5, pp. 394-403, 1998.

[39] A. Rector, "Clinical terminology: why it is so hard?," Methods of Information in Medicine, vol. 38 , no. 239-252, 1999.

[40] J. Ingenerf and W. Giere, "Concept-oriented standardization and statistics-oriented classification: continuing the classification versus nomenclature controversy," Methods of Information in Medicine, vol. 37, pp. 527-539, 1998.

[41] K. A. Spackman, K. E. Campbell, and R. A. Côté, "SNOMED RT: a reference terminology for health care," in Proceedings of AMIA Annual Fall Symposium, pp. 640-644, 1997.

[42] M. Q. Stearns, C. Price, M. Phil, K. A. Spackman, and A. Y. Wang, "SNOMED Clinical Terms: overview of the development proccess and project status," in Proceedings of AMIA Annual Fall Symposium, 2001.

[43] K. A. Spackman and K. E. Campbell, "Compositional concept representation using SNOMED: towards further convergence of clinical terminologies," in Proceedings of AMIA Annual Fall Symposium, pp. 740-744, 1998.

[44] O. Bodenreider, "The Unified Medical Language System (UMLS): integrating biomedical terminology," Nucleic Acids Research, vol. 32, pp. 267-270, 2004.

[45] B. L. Humphreys, D. A. B. Lindberg, H. M. Schoolman, and G. O. Barnett, "The Unified Medical Language System: An informatics research collaboration," Journal of the American Medical Informatics Association, vol. 5, no. 1, pp. 1-11, 1998. 
[46] A. Burgun and O. Bodenreider, "Comparing terms, concepts and semantic classes in WordNet and the Unified Medical Language System," in Proceedings of NAACL'2001 Workshop, WordNet and Other Lexical Resources: Applications, Extensions and Customizations, pp. 77-82, Association for Computational Linguistics, 2001.

[47] A. Rector, W. Solomon, W. Nowlan, T. W. Rush, P. E. Zanstra, and W. M. A. Claansen, "A terminology server for medical language and medical information systems," Methods of Information in Medicine, vol. 34, no. 1-2, pp. 147-157, 1995.

[48] “About GALEN Technology.” http://www.opengalen.org/technology/technology.html.

[49] S. Stelting and O. Maassen, Applied JAVA Patterns. Sun Microsystems Press, 2002.

[50] E. Gamma, R. Helm, R. Johnson, and J. Vlissides, Padrões de Projeto: Soluções Reutilizáveis de Software Orientado a Objetos. Editora Bookman, 2000.

[51] F. P. Brooks, The Mythical Man-Month: Essays on Software Engineering. AddisonWesley Professional, 20th anniversary edition ed., 1995.

[52] D. C. Schmidt, N. Wang, and S. Vinoski, "Collocation optimizations for CORBA," C++ Report, vol. 11, October 1999.

[53] I. T. Pisa, P. R. L. Lopes, A. J. Holanda, D. F. Pires, and E. E. S. Ruiz, "MIDster: Sistema distribuído de imagens médicas baseado em modelos peer-to-peer (P2P) e serviços web," in Anais do IX Congresso Brasileiro de Informática em Saúde, 2004.

[54] I. T. Pisa, MIDster - Uma arquitetura de compartilhamento de imagens médicas baseada em modelos peer-to-peer (P2P) e serviços web. Tese de Doutorado, Departamento de Física e Matemática da Faculdade de Filosofia, Ciências e Letras da Universidade de São Paulo, 2003.

[55] J. E. E. Oliveira, P. S. Perez, L. A. Bailão, and E. E. S. Ruiz, "Caracterização de tecidos cerebrais em imagens ultra-sonográficas de neonatos através de atributos de textura," in Anais do IX Congresso Brasileiro de Informática em Saúde, 2004.

[56] D. G. Kilman and D. W. Forslund, "An international collaboratory based on virtual patient records," Communications of the ACM, vol. 40, no. 8, pp. 110-117, 1997.

[57] J. Grimson, W. Grimson, D. Berry, G. Stephens, E. Felton, D. Kalra, P. Toussaint, and O. W. Weier, "A CORBA-based integration of distributed electronic healthcare records using the synapses approach," IEEE Transactions Information Technology in Biomedicine, vol. 2, no. 3, pp. 124-138, 1998.

[58] W. Grimson, D. Berry, J. Grimson, G. Stephens, E. Felton, P. Given, and R. O'Moore, "Federated healthcare record server-the Synapses paradigm.," International Journal of Medical Informatics, vol. 52, no. 1-3, pp. 3-27, 1998.

[59] J. Grimson, G. Stephens, B. Jung, W. Grimson, D. Berry, and S. Pardon, "Sharing healthcare records over the internet," IEEE Internet Computing, vol. 5, no. 3, pp. 49-58, 2001.

[60] “Corbamed meeting minutes." http://www.omg.org/docs/corbamed/00-03-18.pdf, March 2000. 
[61] A. J. Holanda, I. T. Pisa, O. Kinouchi, A. S. Martinez, and E. E. S. Ruiz, "Thesaurus as a complex network," Physica A, vol. 344, no. 3-4, pp. 530-536, 2004. 